Comparação entre os Principais

Protocolos para Combinação de

Chaves Criptográficas Quânticas

Luis Antonio Brasil Kowada

DISSERTAÇÃO APRESENTADA

$\mathrm{AO}$

INSTITUTO DE MATEMÁTICA E ESTATÍSTICA

DA

UNIVERSIDADE DE SÃO PAULO

PARA

OBTENÇÃO DO GRAU DE MESTRE

EM

MATEMÁTICA APLICADA

Área de Concentração: Ciência da Computação

Orientador: Prof. Dr. Routo Terada

Durante a elaboração deste trabalho o autor recebeu apoio financeiro do CNPq

-São Paulo, maio de 1999- 


\title{
Comparação entre os Principais \\ * Protocolos para Combinação de \\ Chaves Criptográficas Quânticas
}

\author{
Este exemplar corresponde à redação \\ final da dissertação devidamente corrigida \\ e defendida por Luis Antonio Brasil Kowada \\ e aprovada pela comissão julgadora.
}

São Paulo, 31 de maio de 1999.

Banca examinadora:

- Prof. Dr. Routo Terada (orientador) - IME-USP

- Prof. Dr. Ricardo Dahab - IC-Unicamp

- Prof. Dr. Cristina Gomes - IME-USP 
A Deus, que conhece todos segredos do mundo. 


\section{Agradecimentos}

Ao professor Routo Terada, pela paciência, compreensão e incentivo com que me orientou e pelo esforço dedicado para produzirmos este trabalho.

À professora Cristina, pelo trabalho que teve em realizar a revisão deste trabalho.

Ao colega Roberto Monteiro por colocar em disposição todo seu conhecimento sobre o assunto, sem o qual não seria possível a realização deste trabalho.

Aos meus professores e companheiros que estiveram sempre dispostos a ajudar no que fosse necessário.

Aos meus pais e irmãos que sempre me apoiaram e nunca mediram esforços para que eu pudesse atingir meus objetivos. 


\begin{abstract}
In this work, we show the main protocols for secret cryptographic key distribution applying the Quantum Mechanics' principles. With these, we can detect an eavesdropper's presence who tries to read the transmission channel. This is not possible with the traditional protocols.
\end{abstract}

A comparative analysis is made of theoretical viewpoint and by simulation results of these protocols. 


\section{Resumo}

Neste trabalho, pretende-se mostrar e comparar os principais protocolos de distribuição de chaves criptográficas secretas baseados nos princípios de Mecânica Quântica. Tais protocolos detectam a presença de intrusos pelo simples fato de tentarem ler o canal de transmissão, o que não é possível nos protocolos convencionais.

A comparação é feita de um ponto de vista teórico e com base nos resultados de simulações destes protocolos. 


\section{Sumário}

1 Introdução $\quad 7$

1.1 Conceitos básicos . . . . . . . . . . . . . . . 7

1.1.1 Importância da combinação de chaves na Criptografia $\ldots \ldots \ldots \ldots$. . . 7

1.2 Divisão deste documento . . . . . . . . . . . . . . . . . 10

2 Princípios de Mecânica Quântica $\quad 11$

2.1 Quantização da energia . . . . . . . . . . . . . . . . . 11

2.2 Polarização . . . . . . . . . . . . . . . . . . . . . . 12

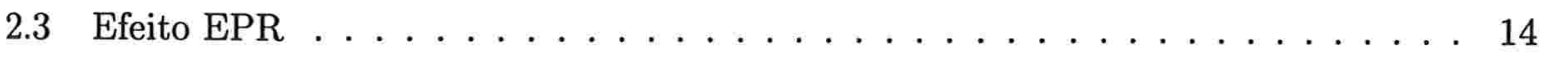

2.4 Desigualdade de Bell . . . . . . . . . . . . . . . . 15

3 Protocolo de Bases Conjugadas $\quad 18$

3.1 Protocolos Quânticos para Combinação de Chaves Criptográficas . . . . . . . . . 18

3.2 Histórico . . . . . . . . . . . . . . . . . . . . 19

3.3 Descrição geral . . . . . . . . . . . . . . . . . . . 20 
3.3.1 Transmissão de uma seqüência de bits aleatórios . . . . . . . . . . . 21

3.3 .2 Reconciliação . . . . . . . . . . . . . . . . . . 23

3.3.3 Deteç̧ão de intruso e correção de erros . . . . . . . . . . . . . . . . . 24

3.3.4 Amplificação da Privacidade . . . . . . . . . . . . . . . . 27

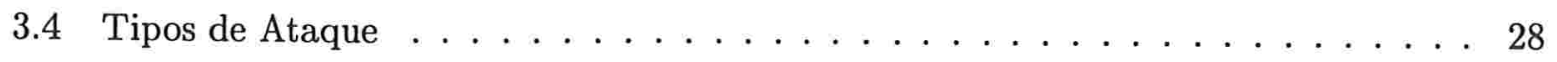

3.4 .1 Interceptação e Reenvio $(\mathrm{I} / \mathrm{R}) \ldots \ldots \ldots \ldots \ldots \ldots \ldots$

3.4 .2 Divisão de feixe . . . . . . . . . . . . . . . . 29

3.4 .3 Ataque de Breidbart . . . . . . . . . . . . . . . . . 29

3.4 .4 Alteração causada pelo intruso . . . . . . . . . . . . . . . . 30

4 Protocolo de Estados Não Ortogonais $\quad 34$

4.1 Descrição Geral . . . . . . . . . . . . . . . . . . . . . . . . . 34

4.1.1 Transmissão de uma seqüência de bits aleatórios . . . . . . . . . . 35

4.1 .2 Reconciliação . . . . . . . . . . . . . . . . . 37

4.1.3 Deteç̧ão de intruso e correção de erros $\ldots \ldots \ldots$. . . . . . . . . . 39

4.1.4 Amplificação da Privacidade . . . . . . . . . . . . . . . . 39

5 Protocolo EPR $\quad 40$

5.1 Descrição geral . . . . . . . . . . . . . . . . . . . 41

5.2 Deteç̧ão de intruso . . . . . . . . . . . . . . . . . . 42 
6.1 Geração de números aleatórios . . . . . . . . . . . . . . . . . 44

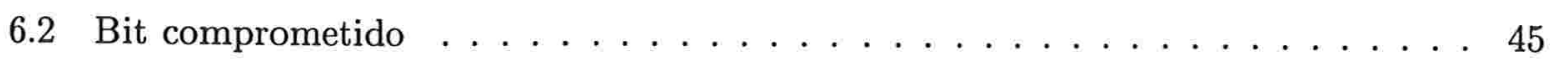

7.1 Comparação teórica . . . . . . . . . . . . . . . . . . 47

7.1.1 Definição dos parâmetros de comparação $\ldots \ldots$. . . . . . . . . . . 47

7.1 .2 Complexidade . . . . . . . . . . . . . . . 48

7.1 .3 Resistência a ataques $\ldots \ldots \ldots \ldots \ldots \ldots \ldots$

7.2 Comparação baseada no resultado da simulação . . . . . . . . . . . . . . . 52

7.2 .1 Características das simulações . . . . . . . . . . . . . . . 52

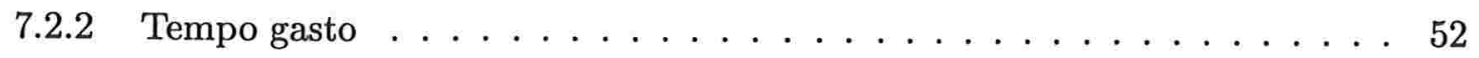

7.2.3 Resistência a ataques - porcentagem de sucesso na detecção de intruso . . 54

7.2 .4 Alteração causada pelo intruso . . . . . . . . . . . . . . 57

7.2 .5 Quantidade de informação do intruso . . . . . . . . . . . . . . 58

7.2.6 Tamanho da Chave Criptográfica Gerada . . . . . . . . . . . . . . 60

7.2.7 Exemplos de Chaves Combinadas . . . . . . . . . . . . . . . 61

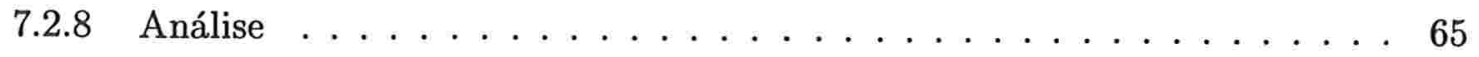


C.1 Descrição das Classes Implementadas . . . . . . . . . . . . . . . . . . . 75

C.1.1 sequencia . . . . . . . . . . . . . 76

C.1.2 BasesConjugadas . . . . . . . . . . . . . . . . 77

C.1.3 EstadosNaoOrtogonais . . . . . . . . . . . . . . . . 78

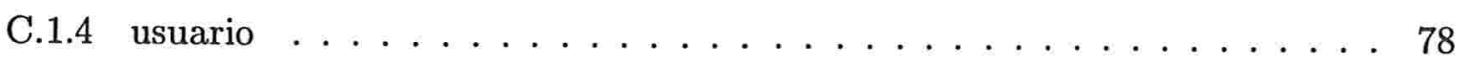

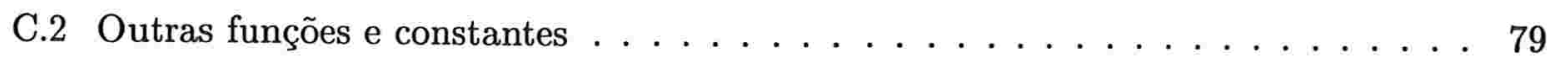

C.2.1 Funções . . . . . . . . . . . . . . . . . . . . . 79

C.2.2 Constante usadas na autenticação $\ldots \ldots \ldots \ldots$. . . . . . . . 79

C.2.3 Constantes para definir valores . . . . . . . . . . . . 80

C.2.4 Constantes para definir tipos de ataque . . . . . . . . . . . . 80

C.3 Descrição dos principais métodos e funções $\ldots \ldots \ldots$. . . . . . . . . 80

C.3.1 função Principal $(\operatorname{main}) \ldots \ldots \ldots \ldots \ldots$. . . . . . . . . 80

C.3.2 função Execução do Protocolo BB84 (execBB84) . . . . . . . . . . . . 81 
C.3.3 função Execução do Protocolo B92 (execB92) . . . . . . . . . . . . . . . . 84

D Listagem do programa de simulação dos protocolos

Índice Remissívo 


\section{Capítulo 1}

\section{Introdução}

\subsection{Conceitos básicos}

\subsubsection{Importância da combinação de chaves na Criptografia}

Cada vez há uma maior quantidade de informações trocadas entre as pessoas e a distâncias cada vez maiores. Muitas vezes é necessário enviar informações muito importantes e que não podem ser conhecidas por outros. Um problema que surge com isso é a confidencialidade, isto é, como tornar possível a comunicação, sem que outros não autorizados tenham acesso ao seu conteúdo?

Uma das formas mais eficientes utilizadas para garantir a confidencialidade é a criptografia. Esta técnica consiste em converter a mensagem (texto claro ou texto legível) em algo ilegível (texto cifrado ou texto criptografado ou ainda texto codificado), de forma que mesmo que um intruso (isto é, pessoa não autorizada) tenha acesso a mensagem cifrada, ele não consegue extrair dela nenhuma informação útil. Este processo também é chamado de ciframento. O processo reverso é conhecido como deciframento. Antigamente, todos os métodos de criptografia, também chamados de sistemas criptográficos, funções cripto-

gráficas ou cripto-sistemas eram baseados na combinação prévia de uma chave comum (em 
geral, seqüência de caracteres) entre as partes comunicantes, que seria necessária para cifrar ou decifrar uma mensagem. Partindo do pressuposto que apenas os usuários legítimos tinham acesso à chave, nenhuma outra pessoa conseguiria decifrar a mensagem.

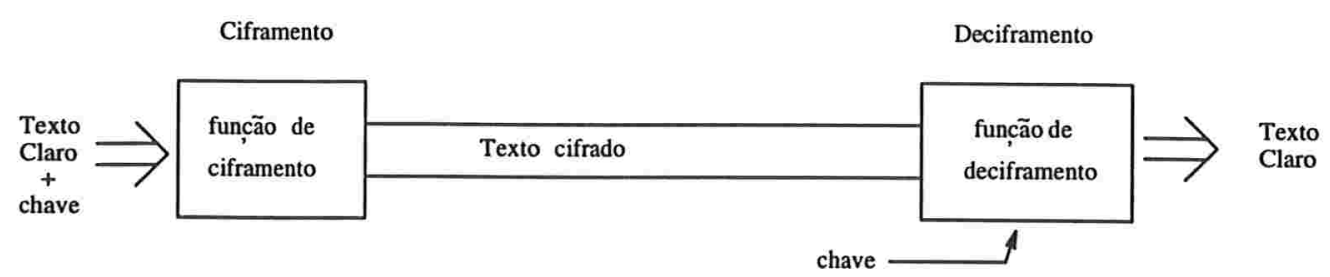

Figura 1.1: Funcionamento de um cripto-sistema

Neste tipo de algoritmo há um problema: como combinar a chave quando os usuários não se encontram pessoalmente e nem possuem um canal seguro de comunicação para esta finalidade?

Em 1976, Diffie e Hellman escreveram um artigo [DH76] dizendo que acreditavam ser possível criar um sistema criptográfico em que a chave de ciframento fosse diferente da chave de deciframento. Como as chaves de ciframento e de deciframento são distintas, pode-se ter uma comunicação relativamente segura sem que haja nenhuma informação prévia secreta comum aos usuários. Caso um usuário, por exemplo Bob, deseje que todas as mensagens destinadas a ele não sejam lidas por ninguém além dele, ele pode usar um algoritmo de chave pública da seguinte forma: Bob gera um par de chaves, retendo uma chave (chave privada) e divulgando a outra chave (chave pública). A chave pública, neste caso, serve para cifrar as mensagens enviadas por qualquer um a Bob, e a chave privada é a única que consegue decifrar estas mensagens.

Dois anos depois, já surgiria um criptosistema que funciona desta forma, o RSA, cujo nome é derivado das iniciais dos seus criadores Rivest, Shamir e Adleman. Tal sistema é utilizado até hoje. Ele é baseado na dificuldade de se fatorar números grandes em primos [RSA78].

Depois surgiram vários outros sistemas com esta propriedade de possuir chaves diferentes para cifrar e decifrar [Sti95, Cap. 4]. Esta classe de sistemas ficou conhecida como algoritmos de chave pública ( $P K C$ - Public Key Criptography). 
Além dos sistemas PKC que existem serem lentos [Sti95, Cap. 8], um outro inconveniente mais grave é nunca poderem prover uma segurança incondicional, isto é, não se pode garantir que seja impossível deduzir o valor de uma chave ou do texto claro a partir de outras informações. Por exemplo, a partir de uma das chaves, pode se descobrir a outra. Isto se deve ao fato das duas chaves estarem necessariamente relacionadas [Sti95, Cap. 4].

Em 1949, Shannon [Sha49] provou formalmente que certos sistemas podem ter segurança incondicional (segredo perfeito), desde que se use uma chave não conhecida por intrusos do tamanho da mensagem e esta chave seja utilizada apenas uma única vez e seja aleatória. Um dos algoritmos que possui esta propriedade é o One Time Pad, criado por Vernan em 1917 [Ver26]. Ele consiste em aplicar a operação "XOR" a cada bit da mensagem original (texto claro) $P$ com cada bit da chave $K$ a fim de gerar o texto criptografado $C$. O comprimento de $P$ deve ser o mesmo de $K$ e de $C$. Para decifrar a mensagem, basta aplicar o "XOR" de cada bit de $K$ sobre cada bit de $C$.

Logo, se for possível, para cada mensagem que se deseja enviar, combinar uma chave criptográfica do tamanho da mensagem de forma que apenas as pessoas autorizadas tenham acesso a esta chave, então se pode garantir que a mensagem será transmitida em segurança. A criptografia quântica chega muito próximo deste objetivo pois a chance de um intruso ser detectado durante a combinação da chave é muito próxima de 100\%, tarefa impossível à criptografia convencional [BBE92].

Neste trabalho é mostrado como funcionam os protocolos de troca de chaves na criptografia quântica.

\subsection{Divisão deste documento}

No Capítulo 2 são definidos e explicados os principais conceitos de física necessários para a compreensão dos algoritmos criptográficos quânticos. 
No Capítulo 3 é descrito o funcionamento do primeiro e mais conhecido sistema quântico para distribuição de chaves criptográficas, o protocolo de Bases Conjugadas (BB84).

No Capítulo 4 é descrito o protocolo de Estados Não Ortogonais cujas etapas são comparadas com as etapas do protocolo anterior.

No Capítulo 5 são descritas as linhas gerais do protocolo EPR.

No Capítulo 6 podem ser vistas outras aplicações para os princípios de Mecânica Quântica na criptografia.

No Capítulo 7 é feita uma comparação dos dois protocolos analisados, BB84 e B92, tanto teoricamente quanto de acordo com o resultado da simulação.

Os apêndices A e B apresentam tabelas com as possíveis combinações de estados entre as partes comunicantes, inclusive considerando a presença de um intruso.

No Apêndice C estão descritas as características do programa elaborado para fazer as simulações dos protocolos de Bases Conjugadas (BB84) e de Estados Não Ortogonais (B92).

No final do documento tem-se um índice remissivo para facilitar a localização das principais definições e explicações básicas. 


\section{Capítulo 2}

\section{Princípios de Mecânica Quântica}

Tratar-se-á aqui apenas da parte da física que possa ter alguma utilidade direta para a criptografia quântica, e de forma mais aplicada possível.

\subsection{Quantização da energia}

Experimentos realizados sobre a luz mostram que a energia óptica sempre é múltipla da constante de Planck, $h=6,63 \cdot 10^{-27} \mathrm{ergs} / \mathrm{seg}$, e da freqüência da onda luminosa, isto é,

$$
E=k \cdot h \cdot \nu
$$

onde $k$ é uma constante qualquer e $\nu$ é a freqüência. Isto é, a energia não pode assumir qualquer valor.

Além disso, foram observados vários fenômenos luminosos que são explicados somente se a luz for também matéria, isto é, se ela for formada por um conjunto de partículas, como no caso do efeito fotoelétrico, em que um feixe de luz desloca elétrons de uma placa de metal, o que só é possível se a onda luminosa for composta de partículas [ER85, Cap. 2]. Juntando estes dois fatos, tem-se que o pacote mínimo de energia, $h . \nu$, deveria ser uma partícula que foi denominada de fóton. Esta partícula elementar da luz possui uma propriedade peculiar: sua 
massa é igual a. zero, além de ser indivisível.

\subsection{Polarização}

Em um determinado instante, uma onda luminosa consiste de dois campos mutualmente perpendiculares $\mathbb{E}$ (elétrico) e $\mathbb{B}$ (magnético) em cada ponto do espaço. A direção de polarização é definida como a direção de $\mathbb{E}$. O plano de polarização é definido como o plano que contém tanto $\mathbb{E}$ quanto a direção de propagação do feixo. Logo, a direção de $\mathbb{B}$ é perpendicular ao plano de polarização. Se a onda possui apenas um plano de polarização em toda a sua extensão, ela é dita polarizada. Caso possua diferentes planos de polarização distribuídos aleatoriamente, então ela é não polarizada [Ore79, Cap. 23].

A maioria das fontes luminosas emite luz não polarizada. Mas toda onda eletromagnética pode ser polarizada com a utilização de polarizadores. Estes polarizadores, também chamados de filtros polarizadores, deixam passar os fótons com uma determinada direção de polarização e absorvem os que possuem direção ortogonal através de um conjunto de campos eletromagnéticos induzidos na mesma direção ou através de uma malha de moléculas alinhadas. Em alguns filtros polarizadores, os fótons que seriam absorvidos são refletidos [BBE92], como é o caso do cristal de carbonato de cálcio $\left(\mathrm{CaCo}_{3}\right)$, também chamado de calcita.

A intensidade da energia de um feixe de luz que atravessa o polarizador é dada pela expressão abaixo:

$$
I_{s}=I_{e} \cdot \cos ^{2} \alpha
$$

onde $I_{e}$ é a intensidade da luz total que incide no polarizador e $\alpha$ é a diferença angular entre o eixo de polarização e o feixe de luz incidente no mesmo.

Foi dito anteriormente que um fóton isolado não pode ser dividido, por isso para transmissão de um fóton, a intensidade de saída não pode ser menor do que a de entrada, a não ser que seja nula pelo fato de o fóton ter sido barrado pelo polarizador. A coerência com a. equação acima é mantida pelo fato de alguns fótons passarem mesmo tendo a mesma diferença 
angular $\alpha$ de outros fótons que não passaram, possuindo o plano de polarização igual ao do filtro. E a chance de isto ocorrer é

$$
P=\cos ^{2} \alpha
$$

Esta expressão é conhecida como Postulado de Redução de Von Newman.

Logo, um fóton na direção perpendicular em relação ao polarizador não passará e um fóton com diferença de $\frac{\pi}{4}$ tem $50 \%$ de chance de passar. A explicação para isto vem do fato de que os estados de um sistema físico pertencem a um espaço vetorial, portanto, podem ser superpostos linearmente. Cada propriedade (posição, movimentos, e outros) do sistema é representado por um operador cujos autovetores formam uma base ortonormal para o espaço de Hilbert [PT95].

Pode-se fazer uma transmissão de informações usando polarização. Basta que as partes comunicantes definam uma base, isto é, dois eixos perpendiculares de polarização e convencionem um eixo para ser 0 e o outro para ser 1. Por exemplo, o eixo horizontal é 0 e o eixo vertical é 1. Querendo se transmitir um 0 basta que o emissor rotacione o filtro, deixando o na posição horizontal, e envie um fóton. Combinando com o emissor um intervalo constante entre as partículas, o receptor pode deixar um outro polarizador numa das duas posições da base, por exemplo no eixo vertical e se o fóton passar é porque foi enviado um 1, caso contrário foi enviado um 0 . O meio entre os polarizadores é chamado de canal quântico.

Um fato muito importante derivado da afirmação anterior é que um fóton lido e retido pelo segundo polarizador perde sua polarização original. Pois se não passou, significa que ele pode ter possuido qualquer inclinação que seja diferente da segunda polarização. E se ele passou, a única conclusão que pode se tirar disto é que não foi polarizado com o eixo perpendicular ao que se está medindo. 


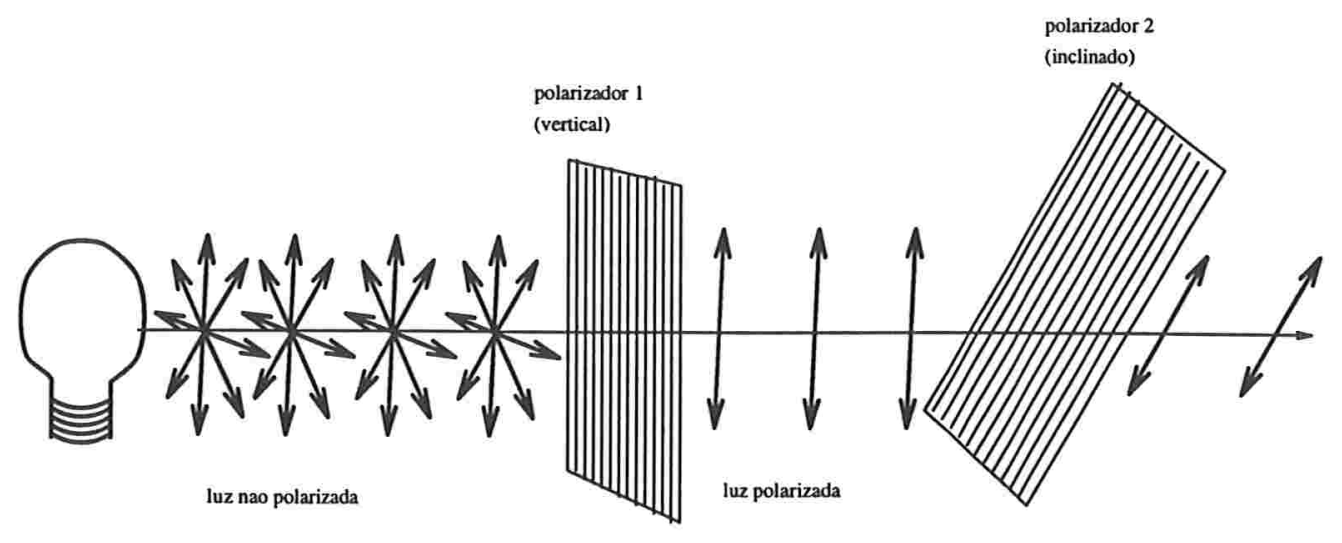

Figura 2.1: Transmissão de fótons utilizando polarizadores

\subsection{Efeito EPR}

Em 1935, Einstein junto com dois colegas, Podolsky e Rosen, publicou um artigo em que afirmava a seguinte tese: "Ou a Mecânica Quântica não explica certos fenômenos ou duas quantidades físicas não podem ser simultaneamente reais." [EPR35]. Para demonstrar isto, os autores citavam um fenômeno que ficou conhecido posteriormente como efeito EPR.

Através de choques entre elétrons e pósitrons geram-se dois fótons. Os pósitrons são partículas com propriedades idênticas as do elétron, com a exceção de que possuem carga positiva. $\mathrm{O}$ momento resultante do choque é nulo. Um fóton nunca pode ter momento angular zero, pois neste caso ele precisaria ter uma simetria esférica o que é impossível para uma onda transversal [BCP82]. Por isso, os fótons gerados possuem momentos angulares opostos um em relação ao outro e movendo-se em direções contrárias, obedecendo ao princípio de conservação de energia. Estes fótons são chamados de fótons gêmeos ou par EPR. Outra forma de geração destes fótons é através do decaimento do píon neutro.

Pelo Princípio da Incerteza de Heisenberg, a Mecânica Quântica afirma que ao se medir a posição de uma particula com uma determinada precisão, se perde informação sobre seu momento angular, e vice-versa. Logo, não é possível calcular o momento de um dos fótons do par EPR e a posição do outro fóton. Isto foi comprovado experimentalmente. Mas então fica a dúvida: como a medição em uma partícula pode afetar as propriedades de outra partícula 
bem distante?

Para responder a esta questão, Einstein sugeriu a existência de variáveis escondidas (hidden variables). Estas variáveis, que até o presente momento não foram detectadas, seriam as responsáveis pela ligação das partículas gêmeas e passariam a informação de um fóton para o outro.

\subsection{Desigualdade de Bell}

Em 1964, Bell da Organização Européia para Pesquisa Nuclear (CERN) propôs um mecanismo para testar a existência das variáveis escondidas propostas por Einstein para explicar o fenômeno EPR [CHSH69]. O teste consiste em verificar se uma determinada inequação é satisfeita; caso não seja, então tais variáveis não resolvem o paradoxo EPR.

Esta inequação, chamada de Desigualdade de Bell, relaciona três propriedades não comutáveis de ambas partículas, como por exemplo o spin em três direções distintas, através de uma correlação clássica que seria dada pelas variáveis escondidas.

Considerando que estas propriedades (direções a, b e c) podem tomar dois valores possíveis: positivo (+) e negativo (-), pode-se afirmar que os resultados lidos em uma direção de cada partícula de um par EPR são opostos, pois elas estão anti-correlacionadas para manter o momento total do sistema nulo como foi explicado na seção anterior. Logo, se na primeira partícula for lido o valor $\mathrm{a}^{+}$, a segunda partícula terá o valor $\mathrm{a}^{-}$e vice-versa.

Separando em grupos as partículas com as mesmas propriedades tem-se:

Todos os grupos da tabela acima são não-negativos, isto é, não é possível se ter uma quantidade negativa de pares. Por isso, pode-se afirmar que:

$$
N 3+N 4 \leq N 3+N 4+N 2+N 7
$$




\begin{tabular}{c|c|c} 
População & Partícula 1 & Partícula 2 \\
\hline N1 & $a^{+} b^{+} c^{+}$ & $a^{-} b^{-} c^{-}$ \\
N2 & $a^{+} b^{+} c^{-}$ & $a^{-} b^{-} c^{+}$ \\
N3 & $a^{+} b^{-} c^{+}$ & $a^{-} b^{+} c^{-}$ \\
N4 & $a^{+} b^{-} c^{-}$ & $a^{-} b^{+} c^{+}$ \\
N5 & $a^{-} b^{+} c^{+}$ & $a^{+} b^{-} c^{-}$ \\
N6 & $a^{-} b^{+} c^{-}$ & $a^{+} b^{-} c^{+}$ \\
N7 & $a^{-} b^{-} c^{+}$ & $a^{+} b^{+} c^{-}$ \\
N8 & $a^{-} b^{-} c^{-}$ & $a^{+} b^{+} c^{+}$
\end{tabular}

já que $N 2+N 7 \geq 0$. Reagrupando os termos obtem-se:

$$
N 3+N 4 \leq(N 3+N 7)+(N 2+N 4)
$$

Chamando de $N\left(x^{ \pm}, y^{ \pm}\right)$a quantidade de pares em que a partícula 1 possui as propriedades $x^{ \pm}$e $y^{ \pm}$, a inequação anterior passa a ser:

$$
N\left(a^{+} b^{-}\right) \leq N\left(b^{-} c^{+}\right)+N\left(a^{+} c^{-}\right)
$$

Ou seja, o grupo de pares que possui $\mathrm{a}^{-} \mathrm{b}^{+}$na primeira partícula $(\mathrm{N} 3+\mathrm{N} 4)$ é menor ou igual ao grupo de pares com $\mathrm{b}^{+} \mathrm{c}^{-}$na partícula 1 acrescido da quantidade de pares onde a partícula 1 possui $\mathrm{a}^{-} \mathrm{c}^{+}(\mathrm{N} 2+\mathrm{N} 4)$.

Definindo como $n\left[x^{ \pm}, y^{\mp}\right]$ o número de medições em que se encontra $x^{ \pm}$na partícula 1 e $y^{\mp}$ na partícula 2, tem-se que $n\left[x^{ \pm}, y^{\mp}\right]$ deve ser proporcional a $N\left(x^{ \pm}, y^{ \pm}\right)$sobre o número total de pares. Por isso, a expressão torna-se:

$$
n\left[a^{+}, b^{+}\right] \leq n\left[a^{+}, c^{+}\right]+n\left[c^{+}, b^{+}\right]
$$

Esta é a desigualdade de Bell.

Pela teoria quântica, em algumas condições, a desigualdade de Bell é violada para o par EPRe consequentemente a hipótese de variáveis escondidas não resolve o problema. 
Pelo que foi dito neste capítulo, pode se verificar se esta desigualdade é válida, lendo os valores da primeira partícula nas direções $a$ e $c$ e na segunda partícula os valores nas direções $b$ e $c$. 


\section{Capítulo 3}

\section{Protocolo de Bases Conjugadas}

\subsection{Protocolos Quânticos para Combinação de Chaves Cripto- gráficas}

Os principais protocolos quânticos para a combinação de chaves criptográficas (QKDQuantum Key Distribution) desenvolvidos até o momento visam a combinação de uma chave aleatória secreta entre os usuários legítimos. Estes protocolos não servem para a transmissão da mensagem, pois parte da mesma pode se perder ou ser modificada no caminho, devido à própria natureza do protocolo.

A comunicação é feita através de partículas elementares polarizadas, mais comumente fótons, mas podem ser usados também elétrons com seus spins.

O protocolo de Bases Conjugadas foi o primeiro protocolo quântico que surgiu e também o primeiro a ser implementado [PT95], tendo sido feito pela dupla Bennett e Brassard em 1984, e por isso ficou conhecido como BB84 [BB84]. Mas a idéia de utilizar os princípios de Mecânica Quântica na criptografia é muito mais antiga. Na década de 70, Stephen J. Wiesner da Universidade da Columbia escreveu um artigo chamado "Conjugate Coding", no qual diz que a Mecânica Quântica pode ser usada para duas atividades impossíveis para a Mecânica clássica. 
Uma delas é produzir notas de dinheiro cuja falsificação é fisicamente impossível. A outra é criar um esquema para enviar por um canal quântico duas mensagens clássicas combinadas, tal que o receptor poderia reconstruir apenas uma das mensagens, mas não ambas, pois lendo uma destrói a outra [Wie83]. Wiesner não conseguiu publicar este artigo até 1983.

Depois disto surgiram outros dois protocolos também relevantes: um chamado EPR pois está fundamentado no efeito EPR, explicado no capítulo anterior, por Arthur Ekert em 1991 [Eke91] e outro, chamado de Protocolo de Estados Não Ortogonais, mais conhecido por B92 [Ben92].

Até o momento não se conseguiu implementar o protocolo EPR devido à dificuldade de manipulação e armazenamento de fótons [BBE92] [PT95] e por se fundamentar em fenômenos não totalmente comprovados como por exemplo a violação da desigualdade de Bell [d'E79].

Já foram realizados vários experimentos com os protocolos BB84 e B92, mostrando a real possibilidade de se utilizar tais protocolos num futuro próximo.

Com pequenas variações, os protocolos quânticos podem ser usados para outras aplicações como: geração de números realmente aleatórios, envio de bit oculto mas com valor comprometido e outros. Algumas aplicações são descritas no Capítulo 6. A força destes criptosistemas está no fato de que um intruso não consegue interceptar a mensagem enviada pelo remetente e reenviá-la de forma intacta ao destinatário, o que é sempre possível em criptosistemas tradicionais.

\subsection{Histórico}

Em outubro de 1979, durante o $20^{\text {th }}$ IEEE Symposium on the Foundations of Computer Science, Bennett, que conhecia as idéias de Wiesner, e Brassard decidiram estudar um sistema de criptografia de chave pública baseado na Mecânica Quântica. Usando tal sistema os usuários sem nenhuma informação pré-combinada poderiam se comunicar secretamente. A descrição do 
sistema foi desenvolvida e publicada entre 1982 e 1984, mas faltavam alguns detalhes para que pudesse ser implementado na prática. Depois de algumas modificações, uma implementação foi completada em 1989 pelo Centro de Pesquisa Thomas J. Watson da IBM. Os maiores problemas eram a existência de ruídos e a dificuldade de se controlar fótons individualmente. Estes problemas foram resolvidos com o aumento de informação trocada entre os usuários e o uso de feixes de luz com intensidade muito baixa [BBB92]. Neste experimento foram transmitidas seqüências de feixes de luz polarizados a uma distância de $30 \mathrm{~cm}$ com sucesso. Mais recentemente foram feitas experiências que atingiram $30 \mathrm{~km}$ de distância com uma taxa de erro de $40 \%$ e $10 \mathrm{~km}$ de distância com erro de $1,5 \%$ e a uma taxa de 20KBits/seg [PT95]. Apesar de ser o primeiro sistema, ainda se mostra muito eficaz. Inclusive pelo menos dois outros experimentos foram realizados: em Genebra, com mais de $1 \mathrm{~km}$ de distância entre as partes comunicantes [MBG93] e pela British Telecom juntamente com a Defense Research Agency usando modulação de fase com mais de $10 \mathrm{~km}$ de distância entre os usuários [TRT93].

\subsection{Descrição geral}

Considerando que o remetente se chama Alice e o destinatário Bob, abaixo pode-se ver de um modo geral a seqüência de passos do protocolo BB84:

1. Transmissão de uma seqüência de bits aleatórios

(a) Geração de bases(Linear ou Diagonal) tanto da Alice quanto do Bob;

(b) Geração de uma seqüência aleatória de bits pela Alice;

(c) Envio da seqüência de bits de acordo com as bases da Alice;

(d) Bob lê a seqüência usando suas bases.

2. Reconciliação

(a) Bob publica as suas bases;

(b) Alice indica publicamente quais as bases que coincidiram entre ambos. 
3. Detecção de intruso e correção de erros

(a) Bob envia uma sub-parte da informação em que as bases coincidiram;

(b) Alice verifica se a taxa de erro está dentro do esperado.

4. Amplificação da Privacidade

(a) Alice escolhe uma função de espalhamento e envia os parâmetros para Bob;

(b) Bob recebe estes parâmetros, e ambos amplicam a função sobre suas seqüências.

\subsubsection{Transmissão de uma seqüência de bits aleatórios}

A polarização de um fóton pode ser representada matematicamente por um vetor unitário de um espaço de Hilbert bidimensional. Ou seja, cada fóton transmitido pode ser definido utilizando uma base deste espaço vetorial. Também é necessário escolher uma base para ler a informação. Por causa disso, tanto Alice quanto Bob devem gerar seqüências de bits aleatórios para servir de bases de leitura/escrita da mensagem.

Nenhum dos dois conhece as bases do outro. O tamanho das seqüências de bases deve ser no mínimo igual ao tamanho da mensagem a ser transmitida, pois cada bit da mensagem será codificado/decodificado por uma base. Além da seqüência de bases, Alice deve gerar outra seqüência de bits aleatória que servirá de mensagem. A seqüência de bases da Alice indica o tipo de polarização que a partícula irá sofrer. Pode ser linear ( $\rightarrow)$ ou diagonal ( $(\mathbb{X})$. A base linear faz com que a partícula seja polarizada com $0^{\circ}(\leftrightarrow)$ ou $90^{\circ}(\uparrow)$ se o conteúdo da mensagem for 0 ou 1 respectivamente. E a base diagonal polarizará a partícula com $45^{\circ}(\swarrow)$ ou $135^{\circ}(\nwarrow)$ com a mensagem 0 ou 1 respectivamente. Esta polarização é feita no plano perpendicular ao eixo de transmissão. Algumas versões do BB84, ao invés de usar a base diagonal, usam uma polarização circular $(\bigcirc)$ : circular para direita $(\circlearrowright)$ e circular para esquerda $(\circlearrowleft)$, chamando a base linear de base retilínea. Para facilitar a compreensão, não se falará mais de base circular. Serão usadas daqui por diante, portanto, as bases linear e diagonal. No apêndice (Tabela A.1) pode-se ver as possíveis combinações de valores obtidos por Bob para um bit enviado pela Alice. 
A Tabela 3.1 mostra um exemplo da atuação do emissor na $1^{a}$ fase do protocolo BB84.

\begin{tabular}{|l|cccccccccccccccc|}
\hline Posição dos bits & 1 & 2 & 3 & 4 & 5 & 6 & 7 & 8 & 9 & 10 & 11 & 12 & 13 & 14 & 15 & 16 \\
\hline Escolha das bases da Alice & $\oplus$ & $\nwarrow$ & $\oplus$ & $\nwarrow$ & $\oplus$ & $\oplus$ & $\oplus$ & $\oplus$ & $\nwarrow$ & $\nwarrow$ & $\nwarrow$ & $\oplus$ & $\nwarrow$ & $\oplus$ & $\nwarrow$ & $\nwarrow$ \\
Escolha da mensagem & 0 & 1 & 0 & 1 & 0 & 0 & 1 & 0 & 0 & 1 & 1 & 1 & 0 & 1 & 0 & 1 \\
Polarização das partículas & $\leftrightarrow$ & $\searrow$ & $\leftrightarrow$ & $\searrow$ & $\leftrightarrow$ & $\leftrightarrow$ & $\uparrow$ & $\leftrightarrow$ & $\nearrow$ & $\searrow$ & $\searrow$ & $\uparrow$ & $\nearrow$ & $\downarrow$ & $\nearrow$ & $\searrow$ \\
\hline
\end{tabular}

Tabela 3.1: Um exemplo da atuação de Alice na fase de envio da mensagem

Após Alice ter enviado as partículas polarizadas, Bob, com as suas bases, tenta ler a mensagem. Mas como ambos geraram as bases aleatoriamente, para alguns elementos da mensagem, Bob escolhe a base linear enquanto que a Alice polarizou-os com a base diagonal, e vice-versa. Se as bases estiverem defasadas em $45^{\circ}$, como ocorrem com as bases linear e diagonal, então a chance da leitura estar correta é $\cos ^{2}\left(45^{\circ}\right)=1 / 2$. Neste caso, não há como o Bob saber se o valor que leu está correto ou não sem alguma outra informação da Alice. Por isto, se as bases não coincidem, os respectivos elementos da mensagem são ignorados, mesmo que Alice e Bob possuam o mesmo valor. No exemplo da Tabela 3.2 isto acontece com os bits $1,4,7,9,10,12,14,15$ e 16. Quando as bases do Bob e da Alice coincidirem, Bob conseguirá ler o valor correto, salvo os erros de transmissão, caso não haja intruso.

\begin{tabular}{|c|c|c|c|c|c|c|c|c|c|c|c|c|c|c|c|c|}
\hline Posição dos bits & 1 & 2 & 3 & 4 & 5 & 6 & 7 & 8 & 9 & 10 & 11 & 12 & 13 & 14 & 15 & 16 \\
\hline Escolha das bases da Alice & $\phi$ & $\mathbb{Z}$ & $\oplus$ & $\mathbb{Z}$ & $\oplus$ & $\oplus$ & $\oplus$ & $\oplus$ & 2 & $\mathfrak{X}$ & $\mathbb{X}$ & 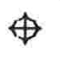 & 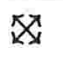 & $\oplus$ & $\mathbb{X}$ & $\mathbb{Z}$ \\
\hline Escolha da mensagem da Alice & 0 & 1 & 0 & 1 & 0 & 0 & 1 & 0 & 0 & 1 & 1 & 1 & 0 & 1 & 0 & 1 \\
\hline Polarização das partículas & $\leftrightarrow$ & $\nwarrow$ & $\leftrightarrow$ & $\nwarrow$ & $\leftrightarrow$ & $\leftrightarrow$ & $\downarrow$ & $\leftrightarrow$ & $\swarrow$ & $\nwarrow$ & $\nwarrow$ & $\uparrow$ & $\swarrow$ & 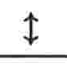 & $\swarrow$ & $\nwarrow$ \\
\hline Escolha das bases do Bob & $\mathbb{Z}$ & $\mathbb{Z}$ & $\oplus$ & 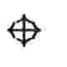 & $\oplus$ & 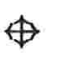 & 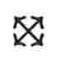 & $\uparrow$ & $\oplus$ & 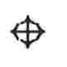 & $\mathbb{X}$ & $\mathbb{X}$ & 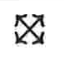 & $\mathbb{Z}$ & $\oplus$ & $\oplus$ \\
\hline Mensagem recebida pelo Bob & 0 & 1 & 0 & 1 & 0 & 0 & 0 & 0 & 1 & 0 & 1 & 0 & 0 & 1 & 1 & 0 \\
\hline
\end{tabular}

Tabela 3.2: Bob recebe a mensagem da Alice 


\subsubsection{Reconciliação}

Bob recebeu a mensagem, mas ainda não sabe quais bits estão corretos e quais não estão. E a Alice também desconhece como Bob recebeu sua mensagem. Portanto, é necessário que Alice conheça a seqüência de bases do Bob e depois diga para o Bob quais bases dele estão corretas. Tanto Alice quanto Bob precisam ter a certeza de que a seqüência de bases trocada nesta fase é do outro e não de um intruso (chamado aqui de Eva). Logo, esta fase precisa de uma autenticação boa, caso contrário, Alice pode estar trocando uma chave com Eva e não com Bob. A divulgação da seqüência de bases não acarreta em perigo ao protocolo pois não revela nenhuma informação sobre a mensagem. Uma autenticação eficiente é a publicação num meio público, como por exemplo um jornal de grande tiragem, desta forma, dificilmente Eva conseguirá se passar por Alice ou por Bob.

Em relação ao exemplo considerado na Tabela 3.3, depois da reconciliação Alice e Bob sabem que os bits $2,3,5,6,8,11$ e 13 são comuns a ambos se não houve nenhuma tentativa de lê-los ao longo do caminho.

\begin{tabular}{|c|c|c|c|c|c|c|c|c|c|c|c|c|c|c|c|c|}
\hline Posição dos bits & 1 & 2 & 3 & 4 & 5 & 6 & 7 & 8 & 9 & 10 & 11 & 12 & 13 & 14 & 15 & 16 \\
\hline Escolha das bases da Alice & $\oplus$ & $\mathbb{Z}$ & $\oplus$ & $\mathbb{Z}$ & $\oplus$ & $\oplus$ & $\oplus$ & $\oplus$ & $\mathbb{X}$ & 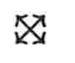 & $\mathbb{Z}$ & $\oplus$ & $\mathbb{Z}$ & $\uparrow$ & 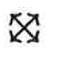 & $\mathbb{Z}$ \\
\hline Escolha da mensagem da Alice & 0 & 1 & 0 & 1 & 0 & 0 & 1 & 0 & 0 & 1 & 1 & 1 & 0 & 1 & 0 & 1 \\
\hline Polarização das partículas & $\leftrightarrow$ & $\nwarrow$ & $\leftrightarrow$ & $\searrow$ & $\leftrightarrow$ & $\leftrightarrow$ & $\downarrow$ & $\leftrightarrow$ & $\nearrow$ & $\nwarrow$ & $\nwarrow$ & $\downarrow$ & $\swarrow$ & $\uparrow$ & $\swarrow$ & $\nwarrow$ \\
\hline Escolha das bases do Bob & 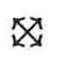 & 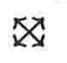 & $\oplus$ & $\oplus$ & 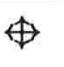 & $\mapsto$ & $\mathbb{X}$ & $\oplus$ & $\oplus$ & $\$$ & $ख$ & $\mathbb{Z}$ & 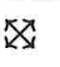 & 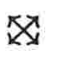 & $\oplus$ & $\oplus$ \\
\hline Mensagem recebida pelo Bob & 0 & 1 & 0 & 1 & 0 & 0 & 0 & 0 & 1 & 0 & 1 & 0 & 0 & 1 & 1 & 0 \\
\hline Bases que estão corretas & & $\sqrt{ }$ & $\sqrt{ }$ & & $\sqrt{ }$ & $\sqrt{ }$ & & $\sqrt{ }$ & & & $\sqrt{ }$ & & $\sqrt{ }$ & & & \\
\hline Informação comum & & 1 & 0 & & 0 & 0 & & 0 & & & 1 & & 0 & & & \\
\hline
\end{tabular}

Tabela 3.3: Informação comum à Alice e ao Bob

\section{A presença de um intruso}

Caso o intruso (Eva) tenha interceptado a mensagem antes da mesma chegar ao Bob, Eva não consegue enviar a mensagem igual à que Alice mandou, pois Eva não conhece até o 
momento as bases de Alice. Ela saberá as bases corretas apenas depois de Bob ler a mensagem. Como Eva alterou a mensagem, agora, mesmo que Alice e Bob tenham escolhido a mesma base, pode ser que não possuam o mesmo conhecimento sobre o referido elemento. Descontando os erros de transmissão, a garantia de Bob ter recebido o elemento enviado pela Alice ocorrerá somente se a base dos três (Alice, Bob e Eva) for comum. Caso contrário, o resultado é imprevisível. Na tabela 3.3.2 se vê por exemplo que o bit 8 e o bit 11 são diferentes entre o Bob e a Alice apesar de terem utilizado as mesmas bases.

\begin{tabular}{|c|c|c|c|c|c|c|c|c|c|c|c|c|c|c|c|c|}
\hline Posição dos bits & 1 & 2 & 3 & 4 & 5 & 6 & 7 & 8 & 9 & 10 & 11 & 12 & 13 & 14 & 15 & 16 \\
\hline Escolha das bases da Alice & $\oplus$ & $\mathbb{Z}$ & $\mapsto$ & $\mathbb{Z}$ & $\oplus$ & $\oplus$ & $\oplus$ & $\oplus$ & $\mathbb{Z}$ & $\mathbb{Z}$ & $\mathbb{Z}$ & $\oplus$ & $\mathbb{Z}$ & $\oplus$ & $\mathbb{Z}$ & 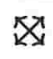 \\
\hline Escolha da mensagem da Alice & 0 & 1 & 0 & 1 & 0 & 0 & 1 & 0 & 0 & 1 & 1 & 1 & 0 & 1 & 0 & 1 \\
\hline Polarização das partículas & $\leftrightarrow$ & $\nwarrow$ & $\leftrightarrow$ & $\nwarrow$ & $\leftrightarrow$ & $\leftrightarrow$ & $\uparrow$ & $\leftrightarrow$ & $\swarrow$ & $\nwarrow$ & $\nwarrow$ & $\downarrow$ & $\swarrow$ & $\uparrow$ & $\nearrow$ & $\nwarrow$ \\
\hline Escolha das bases de Eva & $\mathbb{2}$ & Z & $\oplus$ & $Z$ & $\oplus$ & $\oplus$ & $\oplus$ & $\mathbb{Z}$ & $\oplus$ & $\$$ & $\oplus$ & 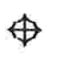 & $Z$ & $\oplus$ & Z & 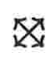 \\
\hline Mensagem recebida pela Eva & 1 & 1 & 0 & 1 & 0 & 0 & 1 & 0 & 1 & 0 & 1 & 1 & 0 & 1 & 0 & 1 \\
\hline Escolha das bases do Bob & $\mathbb{Z}$ & $\mathbb{Z}$ & $\$$ & $\oplus$ & $\oplus$ & $\oplus$ & $\mathbb{Z}$ & $\oplus$ & $\oplus$ & $\oplus$ & $\mathbb{Z}$ & 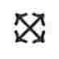 & 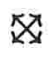 & 飞 & $\$$ & $\uparrow$ \\
\hline Mensagem recebida pelo Bob & 1 & 1 & 0 & 1 & 0 & 0 & 0 & 1 & 1 & 0 & 0 & 1 & 0 & 1 & 1 & 0 \\
\hline Bases que estão corretas & & $\sqrt{ }$ & $\sqrt{ }$ & & $\sqrt{ }$ & $\sqrt{ }$ & & & & & & & $\sqrt{ }$ & & & \\
\hline Informação comum & & 1 & 0 & & 0 & 0 & & & & & & & 0 & & & \\
\hline
\end{tabular}

Tabela 3.4: Eva entra na comunicação

\subsubsection{Detecção de intruso e correção de erros}

Depois de publicadas as bases corretas para a leitura da mensagem, se não houve intruso, a parte da mensagem referente às bases de Alice e Bob que coincidiram é comum a ambos, e, além disto, é secreta. Se houve algum intruso (Eva) no meio do caminho, então mesmo para aqueles elementos para os quais Alice e Bob possuem bases comuns não há garantia de que a mensagem chegou corretamente, isto é, Eva, com grande chance, alterou a mensagem mesmo sem querer. Isto tudo, é claro, desconsiderando os erros de transmissão.

Os erros de transmissão podem vir a ocorrer, mas costumam ser baixos (por volta de $3 \%$ ) [BBB92]. Normalmente são causados por ruídos no canal ou devido ao desalinhamento 
entre os polarizadores [BBB92].

Para os interloucutores identificarem as possíveis diferenças entre suas seqüências, causadas tanto pela presença de intruso quanto pelos erros de transmissão, é necessário que um deles dê ao outro alguma informação sobre a sua seqüência para verificarem se coincidem. Isso pode ser feito através da publicação implícita de parte dos bits através de um código de correção de erros, como por exemplo envio de bits de paridade. Como este procedimento também revela informação para o intruso, é necessário que alguns bits sejam descartados. No caso de se usar bits de paridade, para cada teste feito, um bit deve ser descartado.

Para identificar e corrigir os erros não se deve utilizar os códigos de correção de erros clássicos, pois eles assumem que poucos erros são mais desejáveis que muitos e além disso, estes erros não seriam causados por um intruso, como acontece no protocolo em questão, onde é esperado que o intruso modifique o maior número de bits para ser detectado [BBR88].

Uma forma de verificar a existência de erros é escolher uma função aleatória $f$ : $\{0,1\}^{N} \rightarrow\{0,1\}^{K}$ onde $N$ é o tamanho de uma seqüência e $K$ é um parâmetro de segurança. Verifica-se então se a função aplicada à seqüência $\mathrm{X}$ de um comunicante é igual ao resultado da função aplicada à seqüência $\mathrm{Y}$ do outro. Neste caso, há uma forte evidência de que $\mathrm{X}=\mathrm{Y}$ com erro provável de $2^{-K}$, independentemente do comprimento da seqüência e de quanto diferem, pois cada bit testado multiplica a chance de erro por $2^{-1}$. O problema é o custo de espaço, e consequentemente de tempo, pois há $2^{k \cdot 2^{k}}$ funções possíveis e por isso, seriam necessários $K \cdot 2^{K}$ bits para selecionar uma das funções. Uma forma eficiente de resolver isso é utilizando uma classe universal de funções de espalhamento (hash). Com ela, mantém-se a chance de deteç̧ão de intruso em $2^{-K}$ e diminui-se o custo de espaço, pois para selecionar a função basta definir o valor dos parâmetros da mesma. Há outros procedimentos que poderiam ser utilizados como alternativa às funções de espalhamento, como por exemplo, coleções polirandômicas [GGM84], mas as funções de espalhamento são mais eficazes pois são facilmente computáveis e oferecem segurança sobre poder computacional ilimitado [BBR88].

Não se deve utilizar sempre a mesma função $f$, pois se o intruso conhece $f$, ele consegue 
minimizar os efeitos do seu ataque.

Se o número de erros for pequeno, há alguns procedimentos que podem corrigi-los.

Não é relevante definir qual dos usuários deve escolher a função a ser usada, mas é importante que esta função seja escolhida depois da primeira fase do protocolo, para que Eva não leia o canal quântico de forma a minimizar o efeito na função de espalhamento.

Supondo que seja o Bob quem escolhe a função de espalhamento $f$, antes de mais nada ele deve fazer algumas permutações na seqüência para retirar de Eva a possível informação das posições dos erros. Depois então, ele deve calcular sobre cada um dos blocos da seqüência e enviar o resultado para Alice por um canal autêntico, além de enviar, é claro, os parâmetros de $f$ e da permutação.

Alice faz a permutação também e em seguida aplica $f$ sobre os blocos da sua seqüência, conferindo o resultado com o resultado enviado por Bob. Caso o resultado não seja o mesmo, ela sabe que pelo menos um bit é diferente para aquele bloco.

Na Tabela 3.5 pode ser visto o resultado da aplicação de uma função após uma permutação sobre o exemplo que está sendo considerado.

\begin{tabular}{|c|c|}
\hline$\pi$ & $(2 \rightarrow 3),(3 \rightarrow 6),(5 \rightarrow 1),(6 \rightarrow 4),(8 \rightarrow 2),(11 \rightarrow 7),(13 \rightarrow 5)$ \\
\hline Seq. Bob & $(0,1,1,0,0,0,0)=48$ \\
Seq. Alice & $(0,0,1,0,0,0,1)=17$ \\
\hline$f(x)$ & $a x^{2}+b x+c \bmod m$ \\
parâmetros da f & $a=7, b=3, c=4, m=11$ \\
f(Seq Bob) & $7 \cdot(48)^{2}+3 \cdot 48+4 \bmod 11=7$ \\
$\mathrm{f}$ (Seq Alice) & $7 \cdot(17)^{2}+3 \cdot 17+4 \bmod 11=3$ \\
\hline
\end{tabular}

Tabela 3.5: Resultado da função de espalhamento

Como o resultado de $f$ da Alice foi diferente do Bob no exemplo dado, então há diferença 
entre as suas seqüências. Quando a quantidade de erros estimados por bloco for pequeno, podese aplicar um procedimento chamado de bit twiddling que consiste em alterar um bit da seqüência e aplicar novamente a função [BBR88]. Caso se deseje verificar se mais bits estão discordantes, este procedimento pode ter um custo computacional alto, pois para verificar se $\mathrm{k}$ bits foram alterados num bloco de tamanho $\mathrm{m}$, podem ser necessárias $\Theta\left(m^{k}\right)$ comparações.

A solução é usar blocos pequenos (com aproximadamente 1 erro), mas lembrando que quanto menor o bloco, mais bits serão descartados, considerando que a quantidade de bits testados por bloco é constante. A chance de $f(x)$ ser igual a $f(y)$ para $x \neq y$ é aproximadamente $m^{-1}$, onde $m$ é o tamanho do bloco.

\subsubsection{Amplificação da Privacidade}

Mesmo que sejam encontrados poucos erros na fase anterior, ainda assim não se deve descartar a possibilidade de haver um intruso, pois ele pode ter lido alguns bits e ter deixado passar outros com o propósito de diminuir a sua influência no canal. E neste caso, o intruso terá alguma informação sobre a futura chave.

Existem procedimentos chamados de amplificação da privacidade que servem para tirar esta informação do intruso. A amplificação da privacidade é um procedimento no qual Alice e Bob combinam publicamente uma função de compressão que devolve uma chave secreta a partir de uma seqüência comum a ambos não completamente secreta [BBCM95]. Utiliza-se comumente para isso uma função de espalhamento.

Supondo que o intruso pode possuir $m$ bits da seqüência comum entre Alice e Bob, então aplica-se uma função $f: n \rightarrow n-m$, obtendo uma nova seqüência de comprimento $n^{\prime}=n-m$ completamente secreta [BBCM95]. 


\subsection{Tipos de Ataque}

Há alguns procedimentos que um intruso pode realizar que diminuem a chance de que ele seja detectado, ou que ajudem-no a obter mais informação sobre a chave criptográfica.

Aqui, parte-se da hipótese que o intruso consegue efetuar o ataque "man-in-the-middle" no canal quântico, onde o intruso escuta a mensagem enviada e retransmite-a.

É assumido que o intruso possui poder computacional ilimitado, mas compatível com a Mecânica Quântica.

\subsubsection{Interceptação e Reenvio (I/R)}

Este tipo de ataque consiste na leitura do canal quântico por parte do intruso antes da mensagem chegar ao seu destino. A leitura é feita através de uma seqüência de bases aleatórias, onde os tipos de bases são os mesmos utilizados por Alice e pelo Bob, por exemplo, as bases linear e diagonal.

Como em algumas posições a base do intruso não coincide com a escolhida pelo emissor, a mensagem pode ser recebida incorretamente. Considerando que aproximadamente metade das bases da Eva e da Alice serão coincidentes e sabendo que no caso em que tais bases forem diferentes a chance do bit recebido ser correto é próxima de 50\%, tem-se que Eva terá cerca de $25 \%$ dos bits incorretos.

Não é possível ao intruso ler o canal quântico e ao mesmo tempo deixar passar a mensagem para Bob [BBB92], por isso Eva deve reenviar os fótons de acordo com a mensagem que recebeu, isto é, com aproximadamente $25 \%$ de erro.

Esta abordagem foi a utilizada nos exemplos deste capítulo, mas em vez de Eva tentar ler todos os fótons, ela pode ler apenas alguns e deixar passar outros, pois ela altera próximo de $25 \%$ do que leu e não de toda a mensagem. Por exemplo, se ela lê apenas a metade dos fótons 
ela altera cerca de $12,5 \%$ do total. Por isso, encontrar $X$ erros pode significar que intruso possui por volta de $4 \cdot X$ bits lidos.

\subsubsection{Divisão de feixe}

Com a tecnologia atual, não se consegue transmitir um fóton por pulso de luz [BBB92]. Para se produzir um pulso coerente, ele deve ser formado por uma superposição de estados quânticos com 0, 1, 2 ou mais fótons. Por isso, sem querer Alice pode estar enviando uma informação em mais de um fóton, e se por acaso o intruso conseguir ler apenas um dos fótons, ele pode deixar passar o outro sem que haja perda desta informação.

Para evitar este tipo de ataque, o que se costuma fazer é usar intensidade muito baixa para transmitir os fótons (por volta de $\mu=0,12$ fótons por pulso). Se Eva desviar uma fração $f$ da intensidade original, a chance dela conseguir ler corretamente o fóton é de $f \mu$, mas a intensidade do feixe que chega até Bob passa a ser $1-f$ da intensidade original [BBB92].

\subsubsection{Ataque de Breidbart}

Já foi demonstrado que se o intruso usar as bases convencionais: linear e diagonal, a alteração que ele causa no sistema é de aproximadamente $25 \%$, e possui $75 \%$ da informação. Mas existe uma forma dele obter mais informação durante a sua leitura.

Suponha-se que as bases usadas na comunicação entre os usuários sejam a linear e a diagonal, com a seguinte codificação:

linear: $\quad 0 \leftrightarrow 0^{\circ} \quad 1 \leftrightarrow 90^{\circ}$

diagonal: $0 \leftrightarrow 45^{\circ} \quad 1 \leftrightarrow 135^{\circ}$

Se o intruso usar uma base intermediária: $\left(0 \leftrightarrow 22,5^{\circ} ; 1 \leftrightarrow 112,5^{\circ}\right)$, a chance de ele 
ler um bit correto será:

$$
P=\cos ^{2}\left(22,5^{\circ}\right) \approx 0,85
$$

pois a diferença angular entre seu polarizador e a polarização do fóton será de $22,5^{\circ}$ independentemente se foi usada a base linear ou a diagonal.

A proporção entre os bits diferentes para mesmas posições (distância de Hamming) e o tamanho da seqüência de dados de Alice e de Eva continua a ser de $25 \%$. A proporção para os dados de Eva e de Bob também é de 25\%, por causa do seguinte raciocínio: Seja $b$ o bit enviado pela Alice, Eva tem $85 \%$ de chance de ler este bit corretamente, e há $85 \% \cdot 85 \%=$ $72,25 \%$ de chance de repassar este bit corretamente para Bob, pois a diferença angular entre os polarizadores de Eva e de Bob também é de 22,5 $5^{\circ}$ Mas Eva pode receber o valor de $b$ invertido e quando Bob ler este bit, ele pode inverter novamente o seu valor com chance $15 \% \cdot 15 \%=2,25 \%$ e receber também o valor correto. Por isso que Bob continua a receber o bit correto com $72,25 \%+2,25 \%=75 \%$ de chance.

Em compensação, no ataque de I/R, após a fase de reconciliação, Eva sabia com certeza o valor de aproximadamente metade dos bits que seriam usados na fase seguinte, e com este ataque ela não tem certeza sobre nenhum valor. Ou seja, utilizando o ataque de I/R, Eva sabe exatamente quais dos seus bits estão corretos enquanto que pelo ataque de Breidbart ela não sabe quais são esses bits.

\subsubsection{Alteração causada pelo intruso}

Seja $n$ o tamanho da mensagem, então as seqüências de bases da Alice baseA e do Bob base $B$, além da de um possível intruso base $E$, terão também tamanho $n$. Como cada elemento da seqüência de bases pode assumir somente um de dois valores, o índice de coincidência entre quaisquer dois de base $A$, baseB e baseE é de $50 \%$. Desconsiderando os erros de transmissão (que costumam ser baixos), se não houver intruso, haverá aproximadamente $\frac{n}{2}$ bits da mensagem comuns a Alice e ao Bob. Se Eva interceptar a mensagem, então ela altera $25 \%$ destes bits, devido ao fato de haver aproximadamente $50 \%$ de diferença entre a seqüência de bases da Alice 
com ela e de que apenas metade da diferença altera a informação. Logo, em vez de haver por volta de $\frac{n}{2}$ bits comuns, haverá $\frac{3 n}{8}$. Logo, na etapa de detecção de intruso e correção de erros, se for trocado 1 bit para verificação, a chance de Eva ser detectada é de $25 \%$. Se $k$ bits forem trocados, a chance de Eva passar despercebida é de $\left(\frac{3}{4}\right)^{k}$, e o tamanho da chave final será de $\frac{n}{2}-k$ bits.

\section{Alteração causada pelo intruso havendo ruído}

A análise pode ser feita para um bit pois eles são independentes entre si, isto acontece porque cada fóton é polarizado ou lido com uma base própria e a alteração num determinado fóton não altera os outros.

Considerando que o canal quântico possui um ruído uniforme gerando uma taxa de erro X, então:

Se não houver intruso, $\mathrm{X} \%$ dos bits serão invertidos. Se hover intruso, então há as seguintes possibilidades:

1. a base do Bob é diferente da base da Alice.

2. a base do Bob é igual a da Alice e igual a da Eva

3. a base do Bob é igual a da Alice, mas diferente da Eva

1. No caso da base do Bob ser diferente da base da Alice, os bits são descartados, logo a taxa de ruído e a presença do intruso não são relevantes.

2. Se a base dos três coincide, então acontecerá o seguinte:

- Alice envia o bit $b$. 
- Até chegar a Eva, o bit pode ser alterado com chance X\%.

- Eva não altera o bit pela sua leitura já que a sua base é igual a da Alice, e o resultado é reenviado para o Bob.

- Até chegar ao Bob, o bit enviado por Eva pode ser alterado pelo ruído com chance X\%.

Logo o bit do Bob será igual ao da Alice com chance $\mathrm{X}^{2}$ (2 alterações) + (1-X) ${ }^{2}$ (nenhuma alteração). Ou seja, a chance de o bit ser igual é :

$$
2 X^{2}-2 X+1
$$

O bit será diferente apenas se houver uma inversão, e a chance disto ocorrer é:

$$
2 X(1-X)
$$

isto é,

$$
2 X-2 X^{2}
$$

3. No caso em que a base de Eva é diferente das demais tem-se a seguinte situação: Alice envia o bit b.

Até chegar a Eva, o bit pode ser alterado com chance X\%.

a leitura de Eva pode alterar o bit com $50 \%$ de chance.

$\mathrm{O}$ ruído pode alterar novamente o bit com chance $\mathrm{X} \%$.

A leitura de Bob pode alterar novamente o bit em $50 \%$.

O bit de Bob será igual ao da Alice se houver um número par de alterações ( 0,2 ou 4) já que $\overline{\bar{b}}=b$.

Somando estas probabilidades tem-se:

$$
\frac{1}{4}\left[(1-X)^{2}+4(1-X) \cdot X+(1-X)^{2}+X^{2}+X^{2}\right]
$$


isto é igual a,

$$
\frac{1}{4}\left[2(1-X)^{2}+4(1-X) \cdot X+2 X^{2}\right]
$$

fazendo os devidos cortes, tem-se que o resultado final é $1 / 2$, independentemente do valor de $\mathrm{X}$, ou seja, sempre a chance do Bob ter o mesmo bit da Alice na presença de intruso é de $50 \%$.

Portanto, a alteração causada pelo intruso somando todas as possibilidades (casos 2 e 3) passa de $25 \%$ para

$$
\frac{0,5+2 X \cdot(1-x)}{2}
$$

esta divisão por dois ocorre porque cada caso ocorre metade das vezes, resultando na seguinte expressão final

$$
X \cdot(1-X)+0,25
$$




\section{Capítulo 4}

\section{Protocolo de Estados Não}

\section{Ortogonais}

Também chamado de protocolo B92, por ter sido proposto por Charles Bennett em 1992 [Ben92], este criptosistema usa apenas dois Estados Não Ortogonais ao invés de quatro no caso do BB84. Cada estado corresponde a um ângulo de inclinação do polarizador. Logo há apenas uma base para definir qual é a polarização do fóton e também uma única base para a leitura do mesmo. Por isso, não há bases diferentes para serem escolhidas, mas apenas se escolhe o valor de leitura/gravação da polarização.

Uma implementação deste protocolo pode ser encontrada em $\left[\mathrm{HLM}^{+} 96\right]$.

\subsection{Descrição Geral}

Considerando que o emissor se chama Alice e o receptor Bob, abaixo pode-se ver de um modo geral a seqüência de passos do protocolo B92:

1. Transmissão de uma seqüência de bits aleatórios 
(a) Geração dos estados do Bob;

(b) Geração de seqüência de bits pela Alice;

(c) Envio da seqüência de bits de acordo com a Tabela 4.1 da Alice;

(d) Bob lê a seqüência usando seus estados verificando os bits que atravessaram o polarizador.

2. Reconciliação

(a) Bob publica a posição dos bits que passaram.

3. Deteç̧ão de intruso e correção de erros

(a) Bob envia uma sub-parte da informação em que as bases coincidiram;

(b) Alice verifica se a taxa de erro está dentro do esperado.

4. Amplificação da Privacidade

(a) Alice escolhe uma função de espalhamento e envia os parâmetros para Bob;

(b) Bob recebe estes parâmetros, e ambos amplicam sobre suas seqüências.

\subsubsection{Transmissão de uma seqüência de bits aleatórios}

No protocolo BB84, Alice precisa gerar duas seqüências de bits aleatórios: uma para servir de mensagem e outra para servir de base para a polarização. Neste modelo, ela cria apenas uma das seqüências e envia os fótons polarizados segundo a Tabela 4.1. Isto significa que haverá apenas dois ângulos possíveis para a polarização dos fótons em vez de quatro do $\mathrm{BB} 84$. Outra diferença em relação ao protocolo visto anteriormente é o fato de que, nesta fase, a codificação dos bits é feita de forma diferenciada para a Alice e para o Bob.

$$
\begin{aligned}
& 0 \Leftrightarrow \downarrow \\
& 1 \Leftrightarrow \swarrow
\end{aligned}
$$

Tabela 4.1: Codificação de cada bit pelo emissor 


$$
\begin{aligned}
& 0 \Leftrightarrow \nwarrow \\
& 1 \Leftrightarrow \leftrightarrow
\end{aligned}
$$

Tabela 4.2: Codificação de cada bit pelo receptor

\begin{tabular}{|l|llllllllllllllll|}
\hline Escolha da mensagem & 0 & 1 & 0 & 1 & 0 & 0 & 1 & 0 & 0 & 1 & 1 & 1 & 0 & 1 & 0 & 1 \\
Polarização das partículas & $\uparrow$ & $\swarrow$ & $\downarrow$ & $\swarrow$ & $\downarrow$ & $\downarrow$ & $\swarrow$ & $\downarrow$ & $\downarrow$ & $\swarrow$ & $\swarrow$ & $\nearrow$ & $\downarrow$ & $\nearrow$ & $\downarrow$ & $\swarrow$ \\
\hline
\end{tabular}

Tabela 4.3: Um exemplo da atuação de Alice na fase de Envio da Mensagem

Alice envia seus fótons polarizados, e Bob lê de acordo com os estados que escolheu $\left(\nwarrow_{\searrow}\right.$ ou $\leftrightarrow$ ) para cada fóton, utilizando a decodificação da Tabela 4.2. Ao ler o canal quântico, se o fóton passou pelo seu polarizador, isto significa que o ângulo de polarização não é ortogonal em relação ao ângulo do polarizador da Alice. Logo se o seu ângulo é de $-45^{\circ}(\nwarrow)$, então o polarizador da Alice é de $90^{\circ}(\uparrow)$ e o conteúdo da mensagem é 0 . Se o seu ângulo de polarização for $0^{\circ}(\leftrightarrow)$, então o da Alice é $+45^{\circ}(\swarrow)$ e ela enviou um 1 . Se a partícula não passou pelo polarizador do Bob então não se pode saber com certeza qual foi a polarização usada pela Alice. Se os estados forem perpendiculares entre si (caso em que Alice escolheu 0 e Bob escolheu 1 ou vice-versa) então a partícula não passa nunca, mas se ambos escolherem o mesmo

\begin{tabular}{|c|c|c|c|c|c|c|c|c|c|c|c|c|c|c|c|c|}
\hline Escolha da mensagem pela Alice & 0 & 1 & 0 & 1 & 0 & 0 & 1 & 0 & 0 & 1 & 1 & 1 & 0 & 1 & 0 & 1 \\
\hline Polarização da Alice & $\uparrow$ & $\swarrow$ & $\uparrow$ & $\swarrow$ & $\downarrow$ & $\downarrow$ & $\swarrow$ & $\downarrow$ & $\downarrow$ & $\swarrow$ & $\nearrow$ & $\swarrow$ & $\uparrow$ & $\swarrow$ & $\uparrow$ & $\swarrow$ \\
\hline Escolha dos estados do Bob & $\leftrightarrow$ & $\leftrightarrow$ & $\nwarrow_{\searrow}$ & $\leftrightarrow$ & $\nwarrow$ & $\nwarrow$ & $\nwarrow_{\searrow}$ & $\nwarrow$ & $\nwarrow$ & $\leftrightarrow$ & $\leftrightarrow$ & $\searrow$ & $\nwarrow$ & $\leftrightarrow$ & $\nwarrow$ & $\nwarrow$ \\
\hline Codificação equivalente & 1 & 1 & 0 & 1 & 0 & 0 & 0 & 0 & 0 & 1 & 1 & 0 & 0 & 1 & 0 & 0 \\
\hline Passaram pelo polarizador & & $\sqrt{ }$ & $\sqrt{ }$ & & & $\sqrt{ }$ & & & $\sqrt{ }$ & $\sqrt{ }$ & & & & & $\sqrt{ }$ & \\
\hline Informação obtida pelo Bob & & 1 & 0 & & & 0 & & & 0 & 1 & & & & & 0 & \\
\hline
\end{tabular}
valor, então haverá $50 \%$ de chance da partícula não passar porque a diferença de ângulo é de $45^{\circ}$.

Tabela 4.4: Bob recebe a mensagem da Alice 


\subsubsection{Reconciliação}

Do que foi dito anteriormente, pode-se concluir que se a partícula passou, então significa que o ângulo de polarização está correto, isto é, Bob sabe quais os bits lidos do canal quântico que estão corretos, a menos que tenha havido erro de transmissão ou a presença de intruso, caso que será analisado mais adiante. No BB84, esta informação somente estaria disponível na etapa seguinte (reconciliação), depois que Bob publicasse suas bases, e Alice dissesse quais destas estavam corretas. Mas isto não significa que neste protocolo, B92, não haja necessidade de reconciliação, pois Alice ainda não sabe qual a sub-parte da mensagem que o Bob conseguiu recuperar.

Bob não pode publicar a seqüência de estados que escolheu para ler a informação, pois isto significaria tornar pública a mensagem para o intruso. Por isso, Bob informa a Alice apenas sobre a posição das partículas que atravessaram o polarizador. Desta forma, Alice fica sabendo qual a informação que Bob possui, e ao mesmo tempo nada foi revelado a qualquer estranho. É importante ressaltar que também neste protocolo é importante ter certeza da autenticidade da informação trafegada nesta fase, do contrário Eva consegue ter uma seqüência em comum com Alice fazendo-se passar pelo Bob. E também consegue uma seqüência em comum com Bob, fazendo-se passar pela Alice.

\begin{tabular}{|c|c|c|c|c|c|c|c|c|c|c|c|c|c|c|c|c|}
\hline Escolha da mensagem pela Alice & 0 & 1 & 0 & 1 & 0 & 0 & 1 & 0 & 0 & 1 & 1 & 1 & 0 & 1 & 0 & 1 \\
\hline Polarização da Alice & $\downarrow$ & $\nearrow$ & $\downarrow$ & $\nearrow$ & $\downarrow$ & $\downarrow$ & $\nearrow$ & $\downarrow$ & $\downarrow$ & $\swarrow$ & $\swarrow$ & $\swarrow$ & $\downarrow$ & $\swarrow$ & $\downarrow$ & $\swarrow$ \\
\hline Escolha dos estados do Bob & $\leftrightarrow$ & $\leftrightarrow$ & $\nwarrow$ & $\leftrightarrow$ & $\nwarrow$ & $\nwarrow$ & $\nwarrow$ & $\nwarrow$ & $\nwarrow$ & $\leftrightarrow$ & $\leftrightarrow$ & $\nwarrow$ & $\nwarrow$ & $\leftrightarrow$ & $\nwarrow$ & $\nwarrow$ \\
\hline Codificação equivalente & 1 & 1 & 0 & 1 & 0 & 0 & 0 & 0 & 0 & 1 & 1 & 0 & 0 & 1 & 0 & 0 \\
\hline Passaram pelo polarizador & & $\sqrt{ }$ & $\sqrt{ }$ & & & $\sqrt{ }$ & & & $\sqrt{ }$ & $\sqrt{ }$ & & & & & $\sqrt{ }$ & \\
\hline Informação comum & & 1 & 0 & & & 0 & & & 0 & 1 & & & & & 0 & \\
\hline
\end{tabular}

Tabela 4.5: Bob indica à Alice a posição das partículas que passaram 


\section{Presença de um intruso}

Se porventura um intruso (Eva) resolver ler o canal quântico para tentar descobrir a chave que está sendo combinada, ele possui uma força maior do que no protocolo anterior pois ao ler o canal quântico como se fosse o receptor autêntico, ele consegue obter com certeza, salvo erros de transmissão, parte da informação do emissor. Esta informação é devida àquelas partículas que atravessaram o seu polarizador. E pelo menos esta parte da mensagem Eva consegue transmitir corretamente. Mas em relação às partículas que não atravessaram o seu polarizador, Eva não tem certeza do seu conteúdo, pois existe $33,33 \%$ de chance de sua polarização estar correta e $66,66 \%$ de chance de estar errada. Logo, ao repassar esta informação ao Bob, ela acaba potencialmente alterando a informação original. Como há uma chance maior de sua polarização estar errada, ela deve inverter a polarização dos fótons que não passaram pelo polarizador. Estas porcentagens seguem do seguinte fato: há três possibilidades : 1) o polarizador estar correto e o fóton passar, 2) o polarizador estar correto e o fóton não passar, 3) o polarizador estar inclinado incorretamente e por conseqüência o fóton não passa. A proporção de ocorrência entre o caso 2 e 3 (casos em que o fóton não passa) é de 1:2, resultando em 33,33\% de a polarização estar correta e $66,66 \%$ para o outro caso.

\begin{tabular}{|c|c|c|c|c|c|c|c|c|c|c|c|c|c|c|c|c|c|}
\hline & Escolha da mensagem & 0 & 1 & 0 & 1 & 0 & 0 & 1 & 0 & 0 & 1 & 1 & 1 & 0 & 1 & 0 & 1 \\
\hline Alice & Polarização & $\downarrow$ & $\swarrow$ & $\downarrow$ & $\swarrow$ & $I$ & \pm & $\swarrow$ & $\downarrow$ & $I$ & $\swarrow$ & $\swarrow$ & $\swarrow$ & $\downarrow$ & $\swarrow$ & $\downarrow$ & $\swarrow$ \\
\hline \multirow{5}{*}{ Eva } & Escolha dos estados & $\searrow$ & $\leftrightarrow$ & $\searrow$ & $\leftrightarrow$ & $\leftrightarrow$ & $\nwarrow$ & $\nwarrow$ & $\leftrightarrow$ & $\nwarrow$ & $\searrow$ & $\leftrightarrow$ & $\nwarrow$ & $\leftrightarrow$ & $\leftrightarrow$ & $\leftrightarrow$ & $\nwarrow$ \\
\hline & Codificação equivalente & 0 & 1 & 0 & 1 & 1 & 0 & 0 & 1 & 0 & 0 & 1 & 0 & 1 & 1 & 1 & 0 \\
\hline & Passaram pelo polarizador & & $\sqrt{ }$ & $\sqrt{ }$ & & & & & & $\checkmark$ & & & & & $\sqrt{ }$ & & \\
\hline & Recodificação & $\swarrow$ & $\swarrow$ & $\uparrow$ & $\downarrow$ & $\uparrow$ & $\swarrow$ & $\swarrow$ & $\downarrow$ & $\downarrow$ & $\swarrow$ & $\downarrow$ & $\swarrow$ & $\downarrow$ & $\swarrow$ & $£$ & $\nearrow$ \\
\hline & Código equivalente & 1 & 1 & 0 & 0 & 0 & 1 & 1 & 0 & 0 & 1 & 0 & 1 & 0 & 1 & 0 & 1 \\
\hline \multirow{3}{*}{ Bob } & Escolha dos estados & $\leftrightarrow$ & $\leftrightarrow$ & $\nwarrow$ & $\leftrightarrow$ & $\searrow$ & $\nwarrow$ & $\nwarrow$ & $\nwarrow$ & $\nwarrow$ & $\leftrightarrow$ & $\leftrightarrow$ & $\nwarrow$ & $\nwarrow$ & $\leftrightarrow$ & $\nwarrow$ & $\nwarrow$ \\
\hline & Codificação equivalente & 1 & 1 & 0 & 1 & 0 & 0 & 0 & 0 & 0 & 1 & 1 & 0 & 0 & 1 & 0 & 0 \\
\hline & Passaram pelo polarizador & $\sqrt{ }$ & & & & $\sqrt{ }$ & & & $\sqrt{ }$ & & & & & & $\sqrt{ }$ & $\sqrt{ }$ & \\
\hline
\end{tabular}

Tabela 4.6: Eva entra no meio da comunicação 


\subsubsection{Detecção de intruso e correção de erros}

Nesta fase, assim como na fase análoga do BB84, Bob possui uma seqüência que será igual à da Alice (descontando os erros de transmissão) caso não haja intruso. Por isso, se ele usar o mesmo procedimento que foi descrito para o BB84, ele pode identificar em quais posições sua informação não coincide com a da Alice.

O resultado deste procedimento sobre o exemplo dado pode ser visto na Tabela 4.7.

\begin{tabular}{|c|c|}
\hline$\pi$ & $(1 \rightarrow 3),(5 \rightarrow 4),(8 \rightarrow 2),(14 \rightarrow 5),(15 \rightarrow 1)$ \\
\hline Seq. Bob & $(0,0,0,0,1,0,1)=5$ \\
Seq. Alice & $(0,0,0,0,0,0,1)=1$ \\
\hline$f(x)$ & $a x^{2}+b x+c \bmod m$ \\
parâmetros da f & $a=7, b=3, c=4, m=11$ \\
f(Seq Bob) & $7 \cdot(5)^{2}+3 \cdot 5+5 \bmod 11=8$ \\
$\mathrm{f}$ (Seq Alice) & $7 \cdot(1)^{2}+3 \cdot 1+4 \bmod 11=0$ \\
\hline
\end{tabular}

Tabela 4.7: Resultado da função de espalhamento

Como o resultado de $f$ da Alice foi diferente do Bob no exemplo dado, então há pelo menos um bit diferente entre as suas seqüências.

\subsubsection{Amplificação da Privacidade}

Também no B92, o intruso pode ter lido menos informação para não ser percebido. Por isso, também neste protocolo, é interessante aplicar os procedimentos de Amplificação de Privacidade para que ele não possua nenhuma informação sobre a chave.

A forma de aplicar tais procedimentos é a mesma do BB84. 


\section{Capítulo 5}

\section{Protocolo EPR}

Ao mesmo tempo que o primeiro protocolo quântico estava sendo concebido, Artur Ekert, inspirado nas idéias de David Deutsch da Universidade de Oxford, elaborava outro sistema de criptografia, baseado principalmente em correlações quânticas [BBE92].

O principal princípio utilizado por este protocolo é o efeito EPR, explicado no Capítulo 2.

A presença de intruso seria detectada através da verificação da desigualdade de Bell, explicada no Capítulo 2, cuja violação da mesma indicaria a existência de uma correlação quântica provocada por uma medição [CHSH69].

Massimo Palma, da Universidade de Palermo, John Rarity, Paul Tapster e Owens da British Defence Research Agency mostram experimentos da violação da desigualdade de Bell para distâncias razoavelmente longas, mais de 4 quilômetros [TRO94].

O protocolo EPR é de difícil implementação pois requer que os fótons fiquem armazenados por um período de tempo relativamente grande e a tecnologia que se possui no momento não permite que se armazene um fóton por mais de uma fração de segundo [BBE92].

Mas a dificuldade maior encontrada até o momento para implementar tal protocolo é o fato da dificuldade de se testar a desigualdade de Bell. Tanto é assim que alguns experi- 
mentos que já foram realizados entram em contradição com outros, já que em alguns casos a desigualdade de Bell não foi violada nas condições previstas pela Mecânica Quântica [d'E79].

\subsection{Descrição geral}

O protocolo EPR funciona da seguinte forma:

1. Transmissão

(a) Alice e Bob geram suas seqüências aleatorias de estados para ler os fótons, de acordo com a Tabela 5.1.

(b) A fonte emite uma seqüência de pares de fótons EPR (em cada par um deles para Alice e outro para Bob).

2. Reconciliação

Alice e Bob publicam a orientação dos seus polarizadores para cada partícula.

3. Deteç̧ão de intruso

Verificam a anti-correlação, lendo o valor das partículas.

Cada medida, em 0,5 $\hbar$ unidades, pode dar dois resultados:

+1 (spin up)

-1 (spin down)

revelando potencialmente 1 bit de informação.

4. Guardam as medidas das partículas e as orientações do polarizador.

5. Correção de erros

6. Amplificação da Privacidade 


$$
\begin{array}{lccc}
\text { Alice : } & \Phi_{1}^{a}=0 & \Phi_{2}^{a}=\pi / 4 & \Phi_{3}^{a}=\pi / 2 \\
\text { Bob : } & \Phi_{1}^{b}=\pi / 4 & \Phi_{2}^{b}=\pi / 2 & \Phi_{3}^{b}=3 \pi / 4
\end{array}
$$

Tabela 5.1: Estados usados pelas partes para ler os fótons da fonte EPR

\subsection{Detecção de intruso}

Caso Alice e Bob tenham usado o mesmo ângulo de polarização: $\left(\Phi_{1}^{a}, \Phi_{2}^{b}\right)$ ou $\left(\Phi_{2}^{a}, \Phi_{1}^{b}\right)$, os valores obtidos devem ser anti-correlatados, isto é, $E\left(a^{i}, b^{j}\right)=a^{i} \cdot b^{j}=-1$, onde $E\left(a^{i}, b^{j}\right)$ é o coeficiente de correlação definido pela expressão:

$$
E\left(a^{i}, b^{j}\right)=P_{++}\left(a^{i}, b^{j}\right)+P_{--}\left(a^{i}, b^{j}\right)-P_{+-}\left(a^{i}, b^{j}\right)+P_{-+}\left(a^{i}, b^{j}\right),
$$

sendo $P_{ \pm \pm}\left(a^{i}, b^{j}\right)$ a probabilidade de $a^{i}$ possuir o primeiro sinal e $b^{j}$ o segundo.

Definindo $S$ da seguinte forma:

$$
S=E\left(a^{1}, b^{1}\right)-E\left(a^{1}, b^{3}\right)+E\left(a^{3}, b^{1}\right)+E\left(a^{3}, b^{3}\right),
$$

pela Mecânica Quântica tem-se que $S$ deve ser igual a $-2 \sqrt{2}$ se as partículas estiverem correlacionadas, caso contrário, o valor encontrado para $S$ é:

$$
-\sqrt{2} \leq S \leq \sqrt{2}
$$

Logo, se as partículas da Alice e do Bob não fizerem parte do mesmo par EPR então o valor encontrado para $S$ deve ser este último.

É importante observar que, ao contrário do BB84 e do B92, no protocolo EPR as partículas que serão usadas para verificar a presença de intruso não são as mesmas que serão usadas na chave criptográfica. 


\subsection{Protocolo EPR sem a utilização da desigualdade de Bell}

Em 1992, Bennett, Brassard e Mermin fizeram uma variação do protocolo EPR que não utilizava a desigualdade de Bell para verificar a presença de intrusos [BBM92]. Neste mesmo artigo os autores mostram que o protocolo EPR desta forma é equivalente ao protocolo de Bases Conjugadas. 


\section{Capítulo 6}

\section{Outras Aplicações}

Além da combinação de chaves criptográficas, a criptografia quântica possui outras aplicações como por exemplo: geração de números aleatórios.

Há várias situações em que é necessário ter números gerados ao acaso (aleatórios), como por exemplo a simulação de eventos não-determinísticos. Os próprios protocolos de distribuição de chaves descritos nos capítulos anteriores necessitam fortemente de seqüências de bits aleatórios.

\subsection{Geração de números aleatórios}

Como a chance de um fóton atravessar um polarizador é $\cos ^{2} \alpha$, onde $\alpha$ é diferença angular entre o fóton e a inclinação do polarizador, pode-se gerar números aleatórios com $n$ bits da seguinte forma:

1. Para $\mathrm{i} \Leftarrow 1$ a $n$ faça

2. polariza-se o fóton horizontalmente

3. aplica-se um polarizador com inclinação de $45^{\circ}$ 
4. Se fóton atravessar

então devolva 1

senão devolva 0

É importante observar que o resultado é realmente aleatório e não pseudo-aleatório, isto é, cada execução do algoritmo é completamente independente das anteriores e a chance de um número qualquer ocorrer é $\frac{1}{2^{n}}$.

\subsection{Bit comprometido}

Usando as características de transmissão do BB84, é possível implementar um sistema através do qual um usuário envia uma informação para outro, cujo conteúdo permanece oculto e inalterado até o momento em que o primeiro quiser revelar. Esta técnica chamada de Bit Comprometido (Bit Commitment( é útil em vários casos, como por exemplo, "caracoroa por telefone" (coin-tossing protocol), provar um determinado conhecimento sem revelá-lo (zero-knowledge) [MLD98]

A seguir, os passos para Alice enviar um bit $b$ de forma comprometida:

1. Alice escolhe uma mensagem $M$ aleatoriamente.

2. Bob gera aleatoriamente uma seqüência de bases para ler a mensagem.

3. Alice envia $M$ pelo canal com a base $\uparrow$ se o bit $b$ é igual a 0 e $\mathbb{Z}$ se igual a 1 .

4. Bob lê a mensagem do canal quântico.

Quando Alice quiser revelar o bit que escolheu, basta utilizar o procedimento abaixo.

1. Alice envia $b$ e $M$ pelo canal autêntico. 
2. Bob confere se nas posições em que suas bases coincidem com $b$ o que leu é coerente com M.

Esta técnica, porém, não possui segurança incondicional, pois o remetente pode trapacear usando partículas EPR no lugar de fótons simples. Se Alice enviar os fótons para Bob a partir de uma fonte EPR, então basta ela esperar Bob ler a mensagem e em seguida ler os fótons que permaneceram consigo com a base diferente. Mas em termos práticos, esta possibilidade ainda não é viável pois ainda não há tecnologia para reter um fóton por mais de décimos de segundos sem lê-lo [BBE92]. 


\section{Capítulo 7}

\section{Análise Comparativa entre o BB84 e o B92}

\subsection{Comparação teórica}

\subsubsection{Definição dos parâmetros de comparação}

Nem sempre é fácil afirmar que um determinado algoritmo é melhor do que o outro, pois às vezes um algoritmo pode ser mais eficiente em alguns casos e ser menos em outros. Há vários fatores que podem influenciar neste resultado.

Dois critérios que comumente são considerados para analisar um algoritmo é a complexidade de tempo e de espaço, ou seja, quanto tempo o algoritmo demora para resolver o problema e qual a quantidade de memória usada para isso.

Em geral, esta complexidade está relacionada com o tamanho dos dados de entrada, mas algumas vezes pode depender do tamanho do resultado final (output sensitive). A complexidade de tempo não é dada em valores absolutos tais como segundos, minutos entre outros, mas sim em número de operações. Não é necessário saber o número exato de operações, mesmo 
porque este valor varia dependendo da arquitetura da máquina, mas é importante saber a sua classe de complexidade, isto é, se possui complexidade linear, quadrática ou exponencial entre outras.

No caso de algoritmos para segurança de informações, há outro critério de crucial importância: resistência do algoritmo para os diversos tipos de ataques possíveis. Não adianta o algoritmo ser rápido se ele não é seguro.

É importante ressaltar que os resultados são dados em termos de probabilidade e não de valores exatos. Isto porque os algoritmos que estão sendo aqui analisados não são determinísticos mas sim probabilísticos.

\subsubsection{Complexidade}

Cada bit enviado pelo canal (quântico ou autêntico) será considerado como sendo uma operação elementar, pois é o procedimento de maior custo computacional, e além disso está presente em todas as etapas do processo.

Na comunicação são usados dois canais distintos: o quântico e o público que assegura autenticação. Num caso real, estes canais podem ter velocidades distintas, mas aqui é feita esta distinção.

A entrada de ambos protocolos é o tamanho da seqüência $n$ que servirá de base para a comunicação, isto é, tamanho da seqüência a partir da qual sairá a chave criptográfica final.

A análise da complexidade mostrada nesta seção é feita sobre os algoritmos execBB84 e execB92 descritos no capítulo anterior e que foram usados nas simulações. 
$1^{a}$ etapa: Transmissão

A geração de números aleatórios utilizando o algoritmo descrito no Capítulo 6, possui custo computacional $n$, onde $n$ é a quantidade de bits do número gerado.

A primeira etapa do BB84 necessita de duas seqüências de $n$ bits para Alice, uma é a seqüência que será transmitida (passo 2) e a outra é a seqüência de bases (passo 3). Bob também precisa gerar a seqüência de bases (passo 10). A transmissão em si possui gasto $2 n: n$ para Alice colocar a mensagem no canal (passo 4) e $n$ para Bob ler (passo 11). Logo, o gasto total nesta etapa é $5 n$.

Alice no protocolo B92 precisa gerar apenas uma seqüência (passo 2). Bob também precisa gerar uma seqüência para ler a mensagem (passo 9). O gasto com a transmissão em si (passos 3 e 10) é o mesmo do BB84: $2 n$, resultando em um custo total desta fase de: $4 n$.

\section{$2^{a}$ etapa: Reconciliação}

No BB84, esta fase consiste simplesmente de Bob informar que bases usou (passos 14 e 18) e Alice responder quais destas bases estão corretas (passos 20 e 25). Logo, o custo é de $4 n$.

O B92 economiza um envio/recepção em relação ao BB84, pois Alice não precisa responder ao Bob. Por isso, o custo é apenas de $2 n$.

\section{$3^{a}$ etapa: Correção de erros e deteção de intrusos}

A partir desta fase, o custo dos algoritmos não depende apenas do tamanho da seqüência de entrada e também o seu valor não pode ser conhecido exatamente de antemão. Pode se apenas afirmar que é limitado superiormente por $n$. Isso acontece porque a quantidade de bits trafegados depende principalmente do número de bits que foram lidos corretamente por Bob. 
Os procedimentos desta fase são idênticos em ambos os protocolos. Apesar disto, a complexidade não é a mesma pois o número de bits coincidentes entre Bob e Alice resultantes da etapa anterior é aproximadamente $\frac{n}{2}$ no BB84 e $\frac{n}{4}$ no B92.

O custo desta etapa é basicamente o dos cálculos da função de espalhamento combinado com as transmissões.

Sabendo qual é a taxa de ruído do canal, divide-se a seqüência em blocos de tamanho $m$ de forma que em cada bloco haja apenas um bit alterado. Por exemplo, se a taxa de ruído for de $2 \%$, o tamanho do bloco pode ser de 50 bits. Se houver intruso, a taxa de alteração será de $28,92 \%$ ou seja, em cada bloco de 50 bits haverá aproximadamente 14 bits invertidos.

O custo de verificação de cada bloco de tamanho $m$ é $m \cdot C_{m, i}$, onde $C_{m, i}$ é a combinação de $\mathrm{m}$ tomados $i$ a $i$, onde $i$ é o número de bits a ser corrigidos pelo procedimento bit twiddling, explicado no Capítulo 3. Caso se deseje corrigir até dois bits em cada bloco o custo é, então, $m^{2}(m-1)$.

Pode se corrigir mais bits dentro de um bloco dividindo-o em tamanhos menores e aplicando o mesmo procedimento. Desta forma, é possível saber o número exato de erros e corrigí-los todos, mas o tempo de processamento de cada bloco passa a ser $O\left(m^{2}(m-1) \cdot \log m\right)$, pois seriam necessárias $\log m$ iterações recursivas, resultando num custo total desta fase de

$$
O\left(\left\lceil\frac{n}{m}\right\rceil \cdot m^{3} \cdot \lg m\right)
$$

Deste resultado, deduz-se que quanto menor o tamanho do bloco, menor a complexidade, mas torna mais fácil também de o intruso descobrir o resultado, pois o custo para o intruso é proporcional ao número de combinações que ele precisa fazer para verificar qual delas é a correta.

Unindo o custo computacional de todas as fases, tem-se que a complexidade do protocolo de Bases Conjugadas é $9 \cdot n+k \cdot\left\lceil\frac{n}{m}\right\rceil \cdot m^{3} \cdot l g m$ e a complexidade de protocolo de Estados Não Ortogonais é de $6 \dot{n}+k \cdot\left\lceil\frac{n}{m}\right\rceil \cdot m^{3} \cdot \lg m$. Aparentemente, a complexidade de ambos 
algoritmos parece ser cúbica, devido ao fator $m^{3}$, mas deve-se lembrar que o tamanho do bloco $m$ é pequeno, dependendo apenas da alteração causada por ruído e pelo intruso, independente do tamanho inicial, ou seja, pode ser considerada uma constante, por isso a complexidade de ambos algoritmos é linear.

\subsubsection{Resistência a ataques}

Este é um dos pontos em que os protocolos analisados mais se diferenciam. O ataque de Breidbart não pode ser aplicado ao B92, o que é uma grande vantagem pois é o único ataque conhecido que dá ao intruso mais de $75 \%$ de informação.

Já o ataque de divisão de feixe pode ser aplicado aos dois protocolos indistintamente, revelando a mesma quantidade de informação. O sucesso é difícil de ser mensurado pois depende intrinsecamente da potência que se usa na fonte luminosa.

$\mathrm{O}$ ataque mais comum, que consiste em interceptar o fóton, ler seu conteúdo e retransmitilo, aparentemente funciona da mesma forma nos dois protocolos, mas o tipo de informação que o intruso obtém em ambos é muito diverso. No BB84, o intruso lê o canal quântico, reenvia a mensagem e somente depois da etapa de reconciliação saberá quais bits leu corretamente. Já no B92, ao ler o canal, ele sabe que nas situações em que o fóton atravessou o polarizador, a sua informação está correta. E isto acontece em $25 \%$ dos casos, como é explicado no Capítulo 4.

No BB84, o intruso possui por volta de $75 \%$ da seqüência compartilhada entre Alice e Bob ou aproximadamente $85 \%$ da seqüência, mas desconhecendo a posição destes bits. No ataque ao B92, o intruso sabe com certeza apenas $25 \%$ e possui mais $50 \%$ de bits coincidentes mas sem saber suas posições. Por isso, neste aspecto, o B92 mostra-se mais seguro. 


\subsection{Comparação baseada no resultado da simulação}

\subsubsection{Características das simulações}

Para cada uma das informações desejadas foram feitas 1000 iterações do algoritmo.

Os tamanhos utilizados para seqüência inicial foram: 64, 256, 1000 e 5000.

Para haver homogenidade no tempo medido, todas as execuções do algoritmo foram feitas na mesma máquina, um computador Pentium $200 \mathrm{Mhz}$.

A seguir são apresentados os principais resultados das simulações.

\subsubsection{Tempo gasto}

As tabelas 7.1 à 7.4 contém os tempos de execução para as iterações do algoritmo.

Os tempos são dados em milisegundos com precisão de 10 milisegundos, por isso alguns valores são nulos.

BB84

\begin{tabular}{|l|c|c|c|}
\hline \multirow{2}{*}{$\begin{array}{c}\text { tamanho } \\
\text { original }\end{array}$} & \multicolumn{3}{|c|}{ Tempo } \\
\cline { 2 - 4 } & mínimo & média & máximo \\
\hline 64 & 0 & 0,85 & 60 \\
256 & 0 & 3,40 & 60 \\
1000 & 0 & 13,60 & 170 \\
5000 & 20 & 73,12 & 220 \\
\hline
\end{tabular}

B92

\begin{tabular}{|l|c|c|c|}
\hline \multirow{2}{*}{$\begin{array}{l}\text { tamanho } \\
\text { original }\end{array}$} & \multicolumn{3}{|c|}{ Tempo } \\
\cline { 2 - 4 } & mínimo & média & máximo \\
\hline 64 & 0 & 0,66 & 60 \\
256 & 0 & 1,88 & 60 \\
1000 & 0 & 6,22 & 60 \\
5000 & 0 & 34,58 & 110 \\
\hline
\end{tabular}

Tabela 7.1: tempo gasto pelos protocolos sem intruso e sem ruído

São colocadas tabelas com ruído e sem ruído para mostrar que a duração não varia tanto com o ruído. Mas comparando as tabelas sem intruso ( 7.1 e 7.2) com as que há a presença de intruso ( 7.3 e 7.4 ) pode se ver que o intruso faz com que o processamento seja mais lento, 
BB84

\begin{tabular}{|l|c|c|c|}
\hline \multirow{2}{*}{$\begin{array}{l}\text { tamanho } \\
\text { original }\end{array}$} & \multicolumn{3}{|c|}{ Tempo } \\
\cline { 2 - 4 } & mínimo & média & máximo \\
\hline 64 & 0 & 1,37 & 60 \\
256 & 0 & 3,92 & 60 \\
1000 & 0 & 14,61 & 60 \\
5000 & 50 & 77,05 & 280 \\
\hline
\end{tabular}

Tabela 7.2: tempo gasto pelos protocolos sem intruso e com $10 \%$ de ruído

BB84

\begin{tabular}{|l|c|c|c|}
\hline \multirow{2}{*}{$\begin{array}{l}\text { tamanho } \\
\text { original }\end{array}$} & \multicolumn{3}{|c|}{ Tempo } \\
\cline { 2 - 4 } & mínimo & média & máximo \\
\hline 64 & 0 & 2,19 & 60 \\
256 & 0 & 37,11 & 60 \\
1000 & 50 & 97.18 & 280 \\
5000 & 430 & 509.56 & 1971 \\
\hline
\end{tabular}

Tabela 7.3: tempo gasto pelos protocolos com intruso e sem ruído

BB84

\begin{tabular}{|l|c|c|c|}
\hline \multirow{2}{*}{$\begin{array}{c}\text { tamanho } \\
\text { original }\end{array}$} & \multicolumn{3}{|c|}{ Tempo } \\
\cline { 2 - 4 } & mínimo & média & máximo \\
\hline 64 & 0 & 2,07 & 60 \\
256 & 0 & 6,87 & 60 \\
1000 & 0 & 25,49 & 60 \\
5000 & 100 & 136,73 & 220 \\
\hline
\end{tabular}

Tabela 7.4: tempo gasto pelos protocolos com intruso e com $10 \%$ de ruído
B92

\begin{tabular}{|l|c|c|c|}
\hline \multirow{2}{*}{$\begin{array}{l}\text { tamanho } \\
\text { original }\end{array}$} & \multicolumn{3}{|c|}{ Tempo } \\
\cline { 2 - 4 } & mínimo & média & máximo \\
\hline 64 & 0 & 1,10 & 60 \\
256 & 0 & 7.46 & 60 \\
1000 & 0 & 48,49 & 110 \\
5000 & 210 & 252,64 & 330 \\
\hline
\end{tabular}

\begin{tabular}{|l|c|c|c|}
\hline \multirow{2}{*}{$\begin{array}{l}\text { tamanho } \\
\text { original }\end{array}$} & \multicolumn{3}{|c|}{ Tempo } \\
\cline { 2 - 4 } & mínimo & média & máximo \\
\hline 64 & 0 & 0,82 & 60 \\
256 & 0 & 2,15 & 60 \\
1000 & 0 & 7,52 & 60 \\
5000 & 0 & 40,03 & 110 \\
\hline
\end{tabular}


os blocos elevando o tempo de processamento.

\subsubsection{Resistência a ataques - porcentagem de sucesso na detecção de intruso}

Há dois tipos de falhas que podem ocorrer com os algoritmos em relação à deteç̧ão de intrusos. Pode haver intruso e ele não ser identificado (Tabelas 7.5 à 7.7) ou então o algoritmo pode informar que há intrusos, quando na realidade os erros foram causados por ruídos (Tabelas 7.8 à 7.11).

BB84

\begin{tabular}{|l|c|}
\hline $\begin{array}{l}\text { tamanho } \\
\text { original }\end{array}$ & $\begin{array}{c}\text { detectou } \\
\text { falsamente(\%) }\end{array}$ \\
\hline 64 & $0 \%$ \\
256 & $0 \%$ \\
1000 & $0 \%$ \\
5000 & $0 \%$ \\
\hline
\end{tabular}

B92

\begin{tabular}{|l|c|}
\hline $\begin{array}{l}\text { tamanho } \\
\text { original }\end{array}$ & $\begin{array}{c}\text { detectou } \\
\text { falsamente(\%) }\end{array}$ \\
\hline 64 & $100 \%$ \\
256 & $0 \%$ \\
1000 & $0 \%$ \\
5000 & $0 \%$ \\
\hline
\end{tabular}

Tabela 7.5: taxa de erro na detecção de intruso sem a presença de intruso e sem ruído

BB84

\begin{tabular}{|l|c|c|}
\hline \multirow{2}{*}{$\begin{array}{l}\text { tamanho } \\
\text { original }\end{array}$} & \multicolumn{2}{|c|}{ detectou falsamente(\%) } \\
\cline { 2 - 3 } & intrusos & suspeitos \\
\hline 64 & $50,9 \%$ & $0 \%$ \\
256 & $0 \%$ & $0 \%$ \\
1000 & $0 \%$ & $0 \%$ \\
5000 & $0 \%$ & $0,2 \%$ \\
\hline
\end{tabular}

B92

\begin{tabular}{|l|c|c|}
\hline \multirow{2}{*}{$\begin{array}{l}\text { tamanho } \\
\text { original }\end{array}$} & \multicolumn{2}{|c|}{ detectou falsamente(\%) } \\
\cline { 2 - 3 } & intrusos & suspeitos \\
\hline 64 & $100 \%$ & $0 \%$ \\
256 & $0,8 \%$ & $0 \%$ \\
1000 & $0 \%$ & $0 \%$ \\
5000 & $0 \%$ & $0 \%$ \\
\hline
\end{tabular}

Tabela 7.6: taxa de erro na deteç̧ão de intruso sem a presença de intruso e com $5 \%$ de ruído

Nas Tabelas 7.6 à 7.11 há duas colunas uma chamada intrusos e outra chamada suspeitos. A primeira indica que provavelmente houve um intruso e ele tentou ler toda a seqüência transmitida e a segunda (suspeitos) indica que algum intruso pode ter lido o canal quântico 
BB84

\begin{tabular}{|l|c|c|}
\hline \multirow{2}{*}{$\begin{array}{l}\text { tamanho } \\
\text { original }\end{array}$} & \multicolumn{2}{|c|}{ detectou falsamente(\%) } \\
\cline { 2 - 3 } & intrusos & suspeitos \\
\hline 64 & $52,8 \%$ & $0 \%$ \\
256 & $0 \%$ & $0 \%$ \\
1000 & $0 \%$ & $0 \%$ \\
5000 & $0 \%$ & $0,2 \%$ \\
\hline
\end{tabular}

B92

\begin{tabular}{|l|c|c|}
\hline \multirow{2}{*}{$\begin{array}{l}\text { tamanho } \\
\text { original }\end{array}$} & \multicolumn{2}{|c|}{ detectou falsamente(\%) } \\
\cline { 2 - 3 } & intrusos & suspeitos \\
\hline 64 & $100 \%$ & $0 \%$ \\
256 & $5,8 \%$ & $0 \%$ \\
1000 & $0 \%$ & $0 \%$ \\
5000 & $0 \%$ & $0,1 \%$ \\
\hline
\end{tabular}

Tabela 7.7: taxa de erro na deteç̧ão de intruso sem a presença de intruso e com $10 \%$ de ruído pois apesar da alteração não ter sido tão grande, ela está acima da que seria causada apenas pelo ruído. A soma das duas colunas seria a quantidade total de intrusos.

Nas Tabelas 7.5, 7.6 e 7.7 o processo de detecção de intruso mostrou-se muito falho quando o tamanho da mensagem original é de 64 bits. É natural que seja assim, pois trata-se de um processo estatístico e 64 é um valor muito pequeno, com o desvio-padrão muito alto, inclusive porque a quantidade média de informação comum é de 32 bits no BB84 e 16 no B92.

\section{BB84}

\begin{tabular}{|l|c|c|}
\hline \multirow{2}{*}{$\begin{array}{l}\text { tamanho } \\
\text { original }\end{array}$} & \multicolumn{2}{|c|}{ detectou corretamente(\%) } \\
\cline { 2 - 3 } & intrusos & suspeitos \\
\hline 64 & $100 \%$ & $0 \%$ \\
256 & $99,9 \%$ & $0 \%$ \\
1000 & $100 \%$ & $0 \%$ \\
5000 & $99,8 \%$ & $0,2 \%$ \\
\hline
\end{tabular}

B92

\begin{tabular}{|l|c|c|}
\hline \multirow{2}{*}{$\begin{array}{l}\text { tamanho } \\
\text { original }\end{array}$} & \multicolumn{2}{|c|}{ detectou corretamente(\%) } \\
\cline { 2 - 3 } & intrusos & suspeitos \\
\hline 64 & $100 \%$ & $0 \%$ \\
256 & $99,9 \%$ & $0 \%$ \\
1000 & $100 \%$ & $0 \%$ \\
5000 & $99,9 \%$ & $0,1 \%$ \\
\hline
\end{tabular}

Tabela 7.8: taxa de sucesso na detecção de intruso pelos protocolos sem ruído 
BB84

\begin{tabular}{|l|c|c|}
\hline \multirow{2}{*}{$\begin{array}{l}\text { tamanho } \\
\text { original }\end{array}$} & \multicolumn{2}{|c|}{ detectou corretamente(\%) } \\
\cline { 2 - 3 } & intrusos & suspeitos \\
\hline 64 & $100 \%$ & $0 \%$ \\
256 & $100 \%$ & $0 \%$ \\
1000 & $99,9 \%$ & $0,1 \%$ \\
5000 & $99,9 \%$ & $0,1 \%$ \\
\hline
\end{tabular}

B92

\begin{tabular}{|l|c|c|}
\hline \multirow{2}{*}{$\begin{array}{l}\text { tamanho } \\
\text { original }\end{array}$} & \multicolumn{2}{|c|}{ detectou corretamente(\%) } \\
\cline { 2 - 3 } & intrusos & suspeitos \\
\hline 64 & $100 \%$ & $0 \%$ \\
256 & $99,9 \%$ & $0 \%$ \\
1000 & $100 \%$ & $0 \%$ \\
5000 & $100 \%$ & $0 \%$ \\
\hline
\end{tabular}

Tabela 7.9: taxa de sucesso na detecção de intruso pelos protocolos com $5 \%$ de ruído

BB84

\begin{tabular}{|l|c|c|}
\hline \multirow{2}{*}{$\begin{array}{l}\text { tamanho } \\
\text { original }\end{array}$} & \multicolumn{2}{|c|}{ detectou corretamente(\%) } \\
\cline { 2 - 3 } & intrusos & suspeitos \\
\hline 64 & $99,9 \%$ & $0 \%$ \\
256 & $100 \%$ & $0 \%$ \\
1000 & $99,9 \%$ & $0,1 \%$ \\
5000 & $99,9 \%$ & $0,1 \%$ \\
\hline
\end{tabular}

B92

\begin{tabular}{|l|c|c|}
\hline \multirow{2}{*}{$\begin{array}{l}\text { tamanho } \\
\text { original }\end{array}$} & \multicolumn{2}{|c|}{ detectou corretamente(\%) } \\
\cline { 2 - 3 } & intrusos & suspeitos \\
\hline 64 & $100 \%$ & $0 \%$ \\
256 & $100 \%$ & $0 \%$ \\
1000 & $100 \%$ & $0 \%$ \\
5000 & $100 \%$ & $0 \%$ \\
\hline
\end{tabular}

Tabela 7.10: taxa de sucesso na detecção de intruso pelos protocolos com $10 \%$ de ruído

BB84

\begin{tabular}{|l|c|c|c|c|c|c|}
\hline \multirow{2}{*}{$\begin{array}{l}\text { tamanho } \\
\text { original }\end{array}$} & \multicolumn{5}{|c|}{ detectou corretamente(\%) } \\
\cline { 2 - 7 } & \multicolumn{2}{|c|}{ sem ruído } & \multicolumn{2}{c|}{$5 \%$ de ruído } & \multicolumn{2}{c|}{$10 \%$ de ruído } \\
\hline \multirow{3}{*}{64} & intrusos & suspeitos & intrusos & suspeitos & intrusos & suspeitos \\
\cline { 2 - 7 } & $100 \%$ & $0 \%$ & $99,9 \%$ & $0 \%$ & $100 \%$ & $0 \%$ \\
256 & $100 \%$ & $0 \%$ & $99,9 \%$ & $0 \%$ & $100 \%$ & $0 \%$ \\
1000 & $100 \%$ & $0 \%$ & $100 \%$ & $0 \%$ & $99,8 \%$ & $0,2 \%$ \\
5000 & $99,9 \%$ & $0,1 \%$ & $100 \%$ & $0 \%$ & $99,7 \%$ & $0,3 \%$ \\
\hline
\end{tabular}

Tabela 7.11: taxa de sucesso na deteç̧ão de intruso com ataque de Breidbart 


\subsubsection{Alteração causada pelo intruso}

A detecção do intruso está ligada principalmente à quantidade de informação que ele não conseguiu repassar de forma intacta. Deve-se lembrar entretanto que pode haver alteração na transmissão sem haver intruso, mas causada por ruído.

Seja $x$ a taxa de erro, a porcentagem de bits diferentes sem intruso é $x$, mas com intruso, a porcentagem de bits diferentes é $x \cdot(1-x)+0,25$, conforme foi demonstrado no Capítulo 3 .

BB84

\begin{tabular}{|l|c|c|c|}
\hline \multirow{2}{*}{$\begin{array}{l}\text { tamanho } \\
\text { original }\end{array}$} & \multicolumn{3}{|c|}{ bits alterados(\%) } \\
\cline { 2 - 4 } & mínimo & média & máximo \\
\hline 64 & $0 \%$ & $5,16 \%$ & $20,0 \%$ \\
256 & $0 \%$ & $5,02 \%$ & $12,5 \%$ \\
1000 & $1,80 \%$ & $5,03 \%$ & $9,88 \%$ \\
5000 & $3,59 \%$ & $4,99 \%$ & $6,32 \%$ \\
\hline
\end{tabular}

B92

\begin{tabular}{|l|c|c|c|}
\hline \multirow{2}{*}{$\begin{array}{l}\text { tamanho } \\
\text { original }\end{array}$} & \multicolumn{3}{|c|}{ bits corretos(\%) } \\
\cline { 2 - 4 } & mínimo & média & máximo \\
\hline 64 & $0 \%$ & $5,18 \%$ & $33,33 \%$ \\
256 & $0 \%$ & $5,05 \%$ & $14,29 \%$ \\
1000 & $1,25 \%$ & $4,94 \%$ & $9,6 \%$ \\
5000 & $3,09 \%$ & $4,99 \%$ & $6,84 \%$ \\
\hline
\end{tabular}

Tabela 7.12: Porcentagem de bit alterados pelo ruído (5\%) sem a leitura do intruso

Na Tabela 7.12 pode ser observado que para tamanhos muito pequenos, como por exemplo $n=64$, o ruído pode causar alterações de até $33 \%$, taxa maior do que a alteração média causada pelo intruso (Tabelas 7.13 a 7.15). Disto deriva a dificuldade de detectar a presença real de intrusos. Por outro lado, para tamanhos grandes, como $n=5000$, o maior erro causado pelo ruído foi menor do que o menor erro causado pelo intruso. 
BB84

\begin{tabular}{|l|c|c|c|}
\hline \multirow{2}{*}{$\begin{array}{l}\text { tamanho } \\
\text { original }\end{array}$} & \multicolumn{3}{|c|}{ bits alterados(\%) } \\
\cline { 2 - 4 } & mínimo & média & máximo \\
\hline 64 & $3,23 \%$ & $25,32 \%$ & $50,0 \%$ \\
256 & $12,50 \%$ & $24,95 \%$ & $37,9 \%$ \\
1000 & $19,64 \%$ & $24,98 \%$ & $31,28 \%$ \\
5000 & $21,55 \%$ & $24,99 \%$ & $27,97 \%$ \\
\hline
\end{tabular}

B92

\begin{tabular}{|l|c|c|c|}
\hline \multirow{2}{*}{$\begin{array}{l}\text { tamanho } \\
\text { original }\end{array}$} & \multicolumn{3}{|c|}{ bits corretos(\%) } \\
\cline { 2 - 4 } & mínimo & média & máximo \\
\hline 64 & $0 \%$ & $24,98 \%$ & $60 \%$ \\
256 & $6,35 \%$ & $24,51 \%$ & $43,48 \%$ \\
1000 & $17,37 \%$ & $25,03 \%$ & $34,06 \%$ \\
5000 & $20,39 \%$ & $25,00 \%$ & $29,25 \%$ \\
\hline
\end{tabular}

Tabela 7.13: Porcentagem de bits alterados pela leitura do intruso sem a presença de ruído

BB84

\begin{tabular}{|l|c|c|c|}
\hline \multirow{2}{*}{$\begin{array}{c}\text { tamanho } \\
\text { original }\end{array}$} & \multicolumn{3}{|c|}{ bits alterados(\%) } \\
\cline { 2 - 4 } & mínimo & média & máximo \\
\hline 64 & $6,67 \%$ & $30,18 \%$ & $56,67 \%$ \\
256 & $18,6 \%$ & $29,61 \%$ & $42,02 \%$ \\
1000 & $22,74 \%$ & $29,66 \%$ & $35,90 \%$ \\
5000 & $26,41 \%$ & $29,76 \%$ & $33,90 \%$ \\
\hline
\end{tabular}

B92

\begin{tabular}{|l|c|c|c|}
\hline \multirow{2}{*}{$\begin{array}{c}\text { tamanho } \\
\text { original }\end{array}$} & \multicolumn{3}{|c|}{ bits corretos(\%) } \\
\cline { 2 - 4 } & mínimo & média & máximo \\
\hline 64 & $0 \%$ & $29,69 \%$ & $66,67 \%$ \\
256 & $10,34 \%$ & $29,39 \%$ & $50,00 \%$ \\
1000 & $21,74 \%$ & $29,78 \%$ & $38,43 \%$ \\
5000 & $25,80 \%$ & $29,73 \%$ & $34,72 \%$ \\
\hline
\end{tabular}

Tabela 7.14: Porcentagem de bit alterados pela leitura do intruso com $5 \%$ de ruído

BB84

\begin{tabular}{|l|c|c|c|}
\hline \multirow{2}{*}{$\begin{array}{l}\text { tamanho } \\
\text { original }\end{array}$} & \multicolumn{3}{|c|}{ bits alterados(\%) } \\
\cline { 2 - 4 } & mínimo & média & máximo \\
\hline 64 & $6,06 \%$ & $34,10 \%$ & $66,67 \%$ \\
256 & $22,6 \%$ & $34,10 \%$ & $50,00 \%$ \\
1000 & $27,59 \%$ & $34,02 \%$ & $41,19 \%$ \\
5000 & $31,05 \%$ & $34,06 \%$ & $36,96 \%$ \\
\hline
\end{tabular}

B92

\begin{tabular}{|l|c|c|c|}
\hline \multirow{2}{*}{$\begin{array}{l}\text { tamanho } \\
\text { original }\end{array}$} & \multicolumn{3}{|c|}{ bits corretos(\%) } \\
\cline { 2 - 4 } & mínimo & média & máximo \\
\hline 64 & $0 \%$ & $33,64 \%$ & $80 \%$ \\
256 & $17,65 \%$ & $34,15 \%$ & $54,29 \%$ \\
1000 & $26,67 \%$ & $34,16 \%$ & $43,38 \%$ \\
5000 & $30,21 \%$ & $34,10 \%$ & $38,39 \%$ \\
\hline
\end{tabular}

Tabela 7.15: Porcentagem de bit alterados pela leitura do intruso com 10\% de ruído

\subsubsection{Quantidade de informação do intruso}

Caso o intruso passasse despercebido nos algoritmos a quantidade de informação que possuiria é dada pelas Tabelas 7.16 à 7.19. 
São mostradas nas tabelas abaixo as taxas de bits que concidem entre as seqüências do intruso e dos outros comunicantes. Isto não significa que o intruso saiba quais posições estão corretas. Estes valores foram obtidos antes da etapa de amplificação da privacidade para mostrar a diferença do número de bits obtidos com o ataque convencional em contraste com o ataque de Breidbart.

BB84

\begin{tabular}{|l|c|}
\hline tamanho original & bits corretos(\%) \\
\hline 64 & $75,08 \%$ \\
256 & $75,12 \%$ \\
1000 & $74,95 \%$ \\
5000 & $74,99 \%$ \\
\hline
\end{tabular}

Tabela 7.16: Quantidade de informação do intruso sem ruído

BB84

\begin{tabular}{|l|c|}
\hline tamanho original & bits corretos(\%) \\
\hline 64 & $72,43 \%$ \\
256 & $72,74 \%$ \\
1000 & $72,61 \%$ \\
5000 & $72,49 \%$ \\
\hline
\end{tabular}

\begin{tabular}{|l|c|}
\hline tamanho original & bits corretos(\%) \\
\hline 64 & $79,49 \%$ \\
256 & $78,36 \%$ \\
1000 & $76,23 \%$ \\
5000 & $75,61 \%$ \\
\hline
\end{tabular}

Tabela 7.17: Quantidade de informação do intruso com 5\% de ruído

BB84

\begin{tabular}{|l|c|}
\hline tamanho original & bits corretos(\%) \\
\hline 64 & $70,12 \%$ \\
256 & $69,97 \%$ \\
1000 & $69,87 \%$ \\
5000 & $70,02 \%$ \\
\hline
\end{tabular}

B92

\begin{tabular}{|l|c|}
\hline tamanho original & bits corretos(\%) \\
\hline 64 & $77,72 \%$ \\
256 & $76,03 \%$ \\
1000 & $73,96 \%$ \\
5000 & $73,15 \%$ \\
\hline
\end{tabular}

Tabela 7.18: Quantidade de informação do intruso com $10 \%$ de ruído 
BB84

\begin{tabular}{|l|c|c|c|}
\hline \multirow{2}{*}{$\begin{array}{l}\text { tamanho } \\
\text { original }\end{array}$} & \multicolumn{3}{|c|}{ bits corretos(\%) } \\
\cline { 2 - 4 } & sem ruído & $5 \%$ ruído & $10 \%$ ruído \\
\hline 64 & $85,30 \%$ & $81,87 \%$ & $78,26 \%$ \\
256 & $85,40 \%$ & $81,79 \%$ & $78,24 \%$ \\
1000 & $85,26 \%$ & $81,88 \%$ & $78,22 \%$ \\
5000 & $85,32 \%$ & $81,80 \%$ & $78,30 \%$ \\
\hline
\end{tabular}

Tabela 7.19: Quantidade de informação do intruso com ataque de Breidbart

\subsubsection{Tamanho da Chave Criptográfica Gerada}

Nas Tabelas 7.20 à 7.22 se encontra o tamanho das chaves criptográficas resultantes no final do protocolo. Não foi aplicado o procedimento de amplificação de privacidade que reduziria um pouco mais o tamanho das mesmas.

\section{BB84}

\begin{tabular}{|l|c|c|c|}
\hline \multirow{2}{*}{$\begin{array}{l}\text { tamanho } \\
\text { original }\end{array}$} & \multicolumn{3}{|c|}{ Tamanho da Chave } \\
\cline { 2 - 4 } & mínimo & média & máximo \\
\hline 64 & 17 & 32,15 & 44 \\
256 & 105 & 128,06 & 159 \\
1000 & 445 & 499,99 & 562 \\
5000 & 2366 & 2500,26 & 2608 \\
\hline
\end{tabular}

B92

\begin{tabular}{|l|c|c|c|}
\hline \multirow{2}{*}{$\begin{array}{l}\text { tamanho } \\
\text { original }\end{array}$} & \multicolumn{3}{|c|}{ Tamanho da Chave } \\
\cline { 2 - 4 } & mínimo & média & máximo \\
\hline 64 & 5 & 16,15 & 26 \\
256 & 44 & 63,95 & 86 \\
1000 & 197 & 250,01 & 298 \\
5000 & 1161 & 1248,62 & 1339 \\
\hline
\end{tabular}

Tabela 7.20: Tamanho da chave criptográfica combinada sem a presença de ruído 
BB84

\begin{tabular}{|l|c|c|c|}
\hline \multirow{2}{*}{$\begin{array}{l}\text { tamanho } \\
\text { original }\end{array}$} & \multicolumn{3}{|c|}{ Tamanho da Chave } \\
\cline { 2 - 4 } & mínimo & média & máximo \\
\hline 64 & 20 & 32,06 & 46 \\
256 & 107 & 128,15 & 154 \\
1000 & 458 & 500,05 & 557 \\
5000 & 2382 & 2500,33 & 2620 \\
\hline
\end{tabular}

B92

\begin{tabular}{|l|c|c|c|}
\hline \multirow{2}{*}{$\begin{array}{l}\text { tamanho } \\
\text { original }\end{array}$} & \multicolumn{3}{|c|}{ Tamanho da Chave } \\
\cline { 2 - 4 } & mínimo & média & máximo \\
\hline 64 & 6 & 15,99 & 29 \\
256 & 40 & 64,03 & 84 \\
1000 & 203 & 250,26 & 293 \\
5000 & 1140 & 1249,04 & 1349 \\
\hline
\end{tabular}

Tabela 7.21: Tamanho da chave criptográfica combinada com a presença de $5 \%$ de ruído

\section{BB84}

\begin{tabular}{|l|c|c|c|}
\hline \multirow{2}{*}{$\begin{array}{l}\text { tamanho } \\
\text { original }\end{array}$} & \multicolumn{3}{|c|}{ Tamanho da Chave } \\
\cline { 2 - 4 } & mínimo & média & máximo \\
\hline 64 & 19 & 32,08 & 44 \\
256 & 102 & 127,86 & 151 \\
1000 & 454 & 500,20 & 552 \\
5000 & 2376 & 2499,53 & 2622 \\
\hline
\end{tabular}

B92

\begin{tabular}{|l|c|c|c|}
\hline \multirow{2}{*}{$\begin{array}{l}\text { tamanho } \\
\text { original }\end{array}$} & \multicolumn{3}{|c|}{ Tamanho da Chave } \\
\cline { 2 - 4 } & mínimo & média & máximo \\
\hline 64 & 6 & 16,03 & 27 \\
256 & 40 & 63,87 & 90 \\
1000 & 208 & 249,56 & 289 \\
5000 & 1162 & 1249,44 & 1345 \\
\hline
\end{tabular}

Tabela 7.22: Tamanho da chave criptográfica combinada com a presença de $10 \%$ de ruído

\subsubsection{Exemplos de Chaves Combinadas}

\section{BB84}

tamanho original: 64

tamanho da chave combinada: 32

Alice:11100100110000010010010111101001

Bob:11100100110000010010010111101001

tamanho original: 256

tamanho da chave combinada: 128 
00010100100011101100000010001001001111100110001110000010101000000100110011100 011010110000000110011110001000111001010010011011110

tamanho original: 1000

tamanho da chave combinada: 515

110100100010110001110111011001001010110010101001110101011010001000011011011111 010101010111000010101101010011011100101011000000101001000011000100010000000001 011100010010000111011100110111010011011100111010010011011010101111111010011000 001000101111101010100000101011011101000001010100110100001110001110101010001111 001100000111100100000111110000110100001111100010110001000000001001100101000101 001111101001010100100001010110101011001101010001001111001110001100100001001100 11010110010100100101001101100100011010101011110

tamanho original: 5000 tamanho da chave combinada: 2502 100100110010101000010111101100111101000010000000111000100001000011111101011000 100001011100010000011111111000101000101000100001111010001100000110000100000000 011111001011011010110011010100011110100010111101011111110000101010101000101101 001000001100010000001100101000001100011001110010101011100100011111100001001010 010100001101110111010011000111010110001101111100111110100000000011101001000111 010011011010111010100111110011011110011000011011011000001001101100110001101110 101011111110000111100000001001000101100001101000001110111100101000100011010111 111110011001010100001111010100011011001001010101110110100000000110100000110001 010010100001011111000110101111101011111001111010110010001111011011110111011111 011111000010100011001111010100101110100110110100001100011110010001101001001010 101101000000110010010100010001001110110010001100000001101001100110010101110000 001011000000011010111110000000111000010101011010111110100111101111001100100101 100000001101110011001110111000001010001110111101111000011101011000111101110001 000100111111100000010100100000111000100110010100000110111010100000000101110011 
101101001101011101001001000001011111011111100110011101111101100011001100111111 100100000100100011011001000110100010010001011111010111111101001100000000001011 001001101111000000100010111100001100011010101101010111000100100101001001110001 000000101111010111011101101101110111011011011101111100110110100101100000001111 110110000001110010110101000000000000010001100101000110110000010101011111011010 111111110010011110100000100011101100010110100000100011110100001000100011000000 000000011101110001111001001101100010010100111011001011001000001100101000011011 011101101101000110101001101000101011010000011110100010000101000110001110011101 100100100110001010111010000100001001100011011100100011011111010000111010011110 100010100101010111101100101001110111011101010110001011101111010001011001001001 011000100110001011001111010111011101101010100001001000100110010011010111111011 011011011110010100010011110100010011100110111100111011011100001000011101011110 011000110010100000101100000000111100011000110111001100001101010001100001100001 011100111100110101111010110100011101011010110001110001101111110110101010101101 111001101010111110010110110101000100000111110010011111110111100001100111101001 011111101111001110000101010011111111101101010010010000010100110101011111001000 001101110000001100100100011010000100000010010101010111100001110101100011111000 110000001001111000110001100110010010011001110011101000100010111010110100000100 100111

B92

tamanho original: 64 tamanho da chave combinada: 15 111110101001000 tamanho original: 256 
tamanho da chave combinada: 62

11011011100100101011111110111110111101101010111011001101110000

tamanho original: 1000

tamanho da chave combinada: 258

111111011011100100000110101100001101011011001100011111100110100010111111100011 101100101010010011011100000101011000011011100101100100010111100101101110000100 010110010111000111111100011110100101010101000110111100101110110101111100110111 010011100000000010110010

tamanho original: 5000

tamanho da chave combinada: 1241

101111000111011101100100111011100101110010111001001100000101011010101110111010 000010100000001000001111111101110100100010110110111010010111011001001001101010 011111100011100000111011110111110110111101001101010101001000010110000111010000 010100001101011101100100110001001011011000010000110000110111000000101111110010 001110100000101000011101110111111110001011100110101100001011101010111111001110 100111010001001000101111010111011101100111111000000101010001011101000000001100 110110110111101011101011111001011100011110100110001001010111010001100011010110 001000001111000100100100000111001110010010111110011010100001101011101101000111 011001110111110000101110001110001110010111100110110101110100001010001001001011 100110100011000000000111001001110110011110100011000010000010110001101100000010 001101000001110110111001111010000001011001000101001011010011011011111000000111 100011100000000101110101001111110111001010000001000001010011100010111111100101 010010110000010010000100011000110110100111000000000100110000011110111011100100 011000111010100101001110111010011111010101101011011111011000010001010000111110 101000000111000101010100011111001110010011101010011101000110111110011000000110 00010001001000100011101111101101111011111000010110010110011111010100000 


\subsubsection{Análise}

\section{Complexidade $\mathrm{x}$ tamanho da chave}

Tanto do ponto de vista teórico, como pelos resultados práticos, pode-se ver que o tempo gasto pelo protocolo de Estados Não Ortogonais é aproximadamente metade do protocolo de Bases Conjugadas. Por isso, tais protocolos são equivalentes em relação à classe de complexidade (linear).

Apesar de o tempo gasto ser diferente para os casos com e sem ruídoe com e sem intruso, os resultados das Tabelas 7.1 a 7.4 mostram que o temp gasto é linear em ambos protocolos.

Observando os dados das tabelas referentes ao tempo gasto, o que mais chama a atenção é a diferença de tempo entre os casos em que há intruso sem ruído em relação às demais possibilidades. Por exemplo, com tamanho original igual a 5000, o tempo gasto por ambos algoritmos quando há intruso mas sem ruído é aproximadamente sete vezes maior do que o caso sem intruso e sem ruído, enquanto que o tempo de processamento com intruso e com ruído de aproximadamente $10 \%$ é apenas $180 \%$ maior em relação ao caso sem intruso e sem ruído.

Isto acontece porque a taxa de alteração causada pelo ruído é conhecida pelos usuários. Os blocos são divididos de forma a que haja aproximadamente 1 erro em cada um deles baseado na taxa de ruído. Mas com o intruso, há muito mais de 1 erro por bloco e para identificar todos os erros é necessário subdividir recursivamente muitas vezes os blocos até que os blocos tenham no máximo dois erros. Não há diferença entre os algoritmos em relação a isto, pois a partir da etapa de deteç̧ão de intruso e correção de erros, os procedimentos são os mesmos.

Uma forma de minimizar este custo é utilizar um tamanho de bloco menor antes de compará-los, mas isto acarreta em um número maior de bits que devem ser descartados.

Pode-se estimar a quantidade de erros enviando alguns bits da seqüência comum e comparando-os com os do outro usuário. Quanto maior a quantidade de bits, maior é a precisão 
do número de erros, entretanto mais bits serão eliminados.

Mas no B92, o receptor ao ler a mensagem do canal já sabe qual será a chave criptográfica, enquanto que no BB84, o receptor terá esta informação apenas após o emissor confirmar quais das bases escolhidas estão corretas (fase de reconciliação). Isto economiza um envio de informações por parte do emissor.

Em ambos protocolos, o tamanho da chave final (Tabelas 7.20 a 7.22) é o mesmo da seqüência resultante da etapa de reconciliação, isto está de acordo com o esperado pois mesmo o ruído é corrigido com o procedimento bit twiddling. Como foi dito anteriormente pode-se usar um procedimento de amplificação de privacidade que tornaria a chave mais segura, sendo necessário descartar mais bits.

\section{Resistência a ataques}

Há um tipo de ataque que somente pode ser realizado no protocolo de Bases Conjugadas: ataque de Breidbart, explicado no Capítulo 3. Com ele, se não hover ruído, o intruso tem acesso a até $85 \%$ da informação comum entre o emissor e o receptor legítimo(vide Tabela 7.19). Com ruído a quantidade de informação do intruso cai para $85-\mathrm{r}(1-\mathrm{r})$, por isso que para $\mathrm{r}=10 \%$, a quantidade de informação é $78 \%$, conforme pode ser visto na Tabela 7.19. Mas mesmo com este tipo de ataque, ele altera aproximadamente $25 \%$ da informação que chega ao receptor.

Como a taxa de alteração da informação causada pelo ataque de Breidbart é a mesma do ataque convencional, a chance de deteç̧ão também continua sendo a mesma.

No caso do protocolo de Estados Não Ortogonais, para os fótons que passem pelo polarizador do intruso durante a sua leitura, ele tem a certeza de que a informação que leu está correta, salvo erros de transmissão. E no outro caso (fóton não passou), a chance de o valor ser o oposto é de $66 \%$, pois o fóton tem $25 \%$ de chance de passar, que é metade das vezes que o estado escolhido para leitura está correto. Logo, o intruso consegue reenviar $25 \%+66 \%-\cdot 66 \% \approx 69,44 \%$ da informação corretamente, o que pode ser comprovado pelos 
resultados dados.

Quanto maior o número de bits da seqüência inicial $n$, mais próximas ficam as taxas esperadas em relação aos resultados encontrados. Por exemplo, com $n=64$ sem ruído houve variação de até $23 \%$ sobre o valor esperado enquanto que para $n=5000$, as maiores variações foram de $3 \%$ nas mesmas condições. A melhor relação encontrada para mensurar esses valores extremos foi:

$$
f(n)=75 \%+\frac{200}{\sqrt{n}}
$$

onde $n$ é o número de bits da seqüência inicial. Este valor 200 é resultado de um ajuste empírico que mostrou bons resultados. Usando esta relação, o intruso foi detectado falsamente apenas 1 vez nas 1000 iterações do BB84 com $n=64$, mas para todos os outros tamanhos houve $100 \%$ de sucesso. O intruso não foi detectado em $45.8 \%$ para $n=64$, mas para todos os outros tamanhos houve $100 \%$ de sucesso.

Isto era esperado, pois com tamanhos pequenos, o desvio-padrão é muito grande proporcionalmente. Mas para tamanhos maiores o algoritmo mostrou-se $100 \%$ seguro, mesmo utilizando uma taxa de $10 \%$ de ruído que está muito acima do ruído real (aproximadamente 3\%) [BBB92]. 


\section{Conclusão}

A criptografia quântica está se mostrando cada vez mais importante dentro da Criptografia por realizar uma tarefa impossível às técnicas convencionais: detectar a presença de um intruso pelo simples fato de ele tentar ler uma mensagem enviada durante a combinação de uma chave criptográfica. Por isso, devem surgir muitos outras pesquisas baseadas nestes princípios ou em outros similares. Mas devem ser observadas certas condições para que funcione realmente, por exemplo, o tamanho da seqüência inicial não pode ser muito pequeno.

Os principais protocolos de troca quântica de chaves são praticamente equivalentes segundo diversos aspectos tais como complexidade e eficiência entre outros, mas o protocolo de estados não ortogonais mostrou-se mais robusto contra ataques. Caso o intruso não seja detectado, ele consegue obter até aproximadamente $85 \%$ da chave criptográfica no protocolo de Bases Conjugadas usando o ataque de Breidbart enquanto que pelos ataques conhecidos, no B92 ele obtém até por volta de $75 \%$.

Os resultados das simulações mostram que se pode confiar em ambos algoritmos pois se consegue combinar grandes chaves sem que o intruso consiga obter nenhuma informação dela, mesmo que ele tenha poder computacional infinito. E o desenvolvimento tecnológico está tornando cada vez mais plausível a utilização destes protocolos em larga escala. 


\section{Referências Bibliográficas}

[BB84] C. H. Bennett and G. Brassard. Quantum Cryptography: Public-key distribution and coin tossing. Proceedings of IEEE International Conference on Computers, Systems and Signal Processing, pages 175-179, december 1984.

[BBB92] C. H. Bennett, F. Bessette, and G. Brassard. Experimental Quantum Cryptography. Journal of Cryptology, 1(5):513-528, 1992.

[BBCM95] C. H. Bennett, G. Brassard, C. Crépeau, and U. M. Maurer. Generalized Privacy Amplification. IEEE Transaction on Information Theory, 41:1915-1923, november 1995.

[BBE92] C. H. Bennett, G. Brassard, and A. K. Ekert. Quantum Cryptography. Scientific American, pages 26-33, october 1992.

[BBM92] C. H. Bennett, G. Brassard, and N. David Mermin. Quantum Cryptography without Bell's Theorem. Physical Review Letters, 68(5):557-559, february 1992.

[BBR88] C. H. Bennett, G. Brassard, and J. Roberts. Privacy Amplification by Public Discussion. SIAM J. Computer, 17(2):210-229, april 1988.

[BCP82] V. B. Beretestskii, E. M. Cifshitz, and L. P. Pitaevskii. Quantum Electrodynamics - Course of theoretical physics, volume 4. Pergamon Press, second edition, 1982.

[Ben92] C. H. Bennett. Quantum Cryptography Using Any Two Nonorthogonal States. Physical Review Letters, 68(21):3121-3124, May 1992. 
[CHSH69] J. F. Clauser, M. A. Horne, A. Shimony, and R. A. Holt. Proposed Experiment To Test Local hidden-variables theories. Physical Review Letters, 23(15):880-883, october 1969.

[d'E79] B. d'Espagnat. The Quantum Theory and Reality. Scientific American, pages 128140, november 1979.

[DH76] W. Diffie and M. Hellman. New directions in cryptography. IEEE Trans. Inform. Theory IT-22, 6:644-654, november 1976.

[Eke91] A. K. Ekert. Quantum Cryptography Based on Bell's Theorem. Physical Review Letters, 67(6):661-663, august 1991.

[EPR35] A. Einstein, B. Podolsky, and N. Rosen. Quantum-Mechanical Description of Physical Reality Be Considered Complete? Phisical Review, 47:777-780, may 1935.

[ER85] R. Eisemberg and R. Resnick. Física Quântica. ed Campus, Rio de Janeiro - RJ, 1985.

[GGM84] O. Goldreich, S. Goldwasser, and S. Micali. How to construct random functions. Proc. $25^{t} h$ IEEE Symposium on Foundation of Computer Science, pages 464-479, 1984.

$\left[\mathrm{HLM}^{+} 96\right]$ R. J. Hughes, G. G. Luther, G. L. Morgan, C. G. Peterson, and C. Simmons. Quantum Cryptography over Underground Optical Fibers. Proceedings of Crypto'96, pages 329-341, 1996.

[MBG93] A. Muller, J. Breguet, and N. Gisin. Experimental demonstration of quantum cryptography. Europhysics Letters, 23:383-388, august 1993.

[MLD98] J. R. Monteiro, C. L. Lucchesi, and R. Dahab. Criptografia Quântica - Relatório Técnico IC-98-00, 1998.

[Ore79] J. Orear. Physics. Macmillian Publishing Co, New York - NY, 1979. 
[PT95] S. J. Phoenix and P. D. Townsend. Quantum Cryptography: Protecting our Future Network with Quantum Mechanics. Lecture Notes in Computer Science, 1025:513$528,1995$.

[RSA78] R. L. Rivest, A. Shamir, and L. Adleman. A Method for Obtaining Digital Signatures and Public- Key Cryptosystems. Communications of the ACM, 21:120-126, february 1978.

[Sha49] C. E. Shannon. Communication Theory of Systems. Bell Systems Techincal Journal, 28:656-715, 1949.

[Sti95] D. Stinson. Cryptography:Theory and Pratice. CRC Press, 1995.

[TRO94] P. R. Tapster, J. G. Rarity, and P. C. M. Owens. Violation of Bell's Inequality over 4 km of Optical Fiber. Physical Review Letters, 73(14):1923-1926, octuber 1994.

[TRT93] P. D. Toownsend, J. G. Rarity, and P. R. Tapster. Enhanced single photon fringe visibility in a $10 \mathrm{~km}$-long prototype quantum cryptography channel. Eletronics Letters, 29(14):1291-1293, july 1993.

[Ver26] G. S. Vernan. Cipher Printing Telegraph Systems for Secret Wire and Radio Telegraphic Communications. Journal American Institute of Electrical Engineers, XLV:109$115,1926$.

[Wie83] S. Wiesner. Conjugate Coding. Sigact News, 15(1):78-88, 1983. 
Apêndice A

\section{Combinação das bases no protocolo}

\section{BB84}

\begin{tabular}{|c|c|c|c|c|c|c|c|c|c|c|c|c|}
\hline Mensagem da Alice & 0 & 0 & 0 & 0 & 0 & 0 & 1 & 1 & 1 & 1 & 1 & 1 \\
\hline Base escolhida pela Alice & $\oplus$ & $\oplus$ & $\leftrightarrow$ & EX & 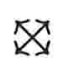 & X & 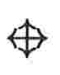 & $\$$ & $\mapsto$ & 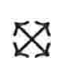 & $\sum$ & $\mathbb{Z}$ \\
\hline Polarização da Mensagem & $\leftrightarrow$ & $\leftrightarrow$ & $\leftrightarrow$ & $\nearrow$ & $\swarrow$ & $\nearrow$ & $\downarrow$ & $\downarrow$ & $\uparrow$ & $\nwarrow$ & $\nwarrow$ & $\nwarrow$ \\
\hline Base escolhida pelo Bob & $\leftrightarrow$ & $\mathbb{Z}$ & $\sum$ & $\leftrightarrow$ & $\uparrow$ & $\mathbb{Z}$ & $\uparrow$ & 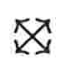 & 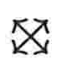 & $\leftrightarrow$ & $\oplus$ & 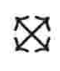 \\
\hline Mensagem recebida pelo Bob & 0 & 0 & 1 & 0 & 1 & 0 & 1 & 0 & 1 & 0 & 1 & 1 \\
\hline Combinações não descartadas & $\sqrt{ }$ & & & & & $\sqrt{ }$ & $\sqrt{ }$ & & & & & $\sqrt{ }$ \\
\hline
\end{tabular}

Tabela A.1: Possíveis combinações para um bit enviado. 


\section{Apêndice B}

\section{Combinação das bases no protocolo}

\section{B92}

\begin{tabular}{|l|c|c|c|c|c|c|}
\hline Mensagem da Alice & 0 & 0 & 0 & 1 & 1 & 1 \\
\hline Polarizações da Alice & $\uparrow$ & $\uparrow$ & $\uparrow$ & $\swarrow$ & $\swarrow$ & $\nearrow$ \\
\hline Estados do Bob & $\searrow$ & $\nwarrow$ & $\leftrightarrow$ & $\nwarrow$ & $\leftrightarrow$ & $\leftrightarrow$ \\
\hline resultado do Bob & passou & não passou & não passou & não passou & não passou & passou \\
\hline Mensagem do Bob & 0 & & & & & 1 \\
\hline
\end{tabular}

Tabela B.1: Combinações possíveis para um bit enviado 


\section{Apêndice C}

\section{Simulação dos protocolos quânticos}

\section{BB84 e B92}

A melhor forma de compreender os protocolos é observando a sua execução na prática. Mas nem sempre isto é possível pois requerem um aparato físico não muito simples. Como a idéia deste trabalho é fazer uma análise do ponto de vista computacional e não físico, optou-se aqui pela realização de simulações dos protocolos de Bases Conjugadas(BB84) e de Estados Não Ortogonais(B92). Não estão sendo feitas simulações do protocolo EPR porque ele ainda não mostrou nenhuma viabilidade prática. Tanto assim que não há nenhum grupo de pesquisa que tenha conseguido implementá-lo como foi explicado melhor no Capítulo 5.

Com uma simulação podem ser obtidos resultados muito próximos aos de uma montagem real dependendo de que tipo de informações se deseja, conforme pode ser observado com os simuladores de vôo ou câmaras em que se simulam a falta de gravidade. As experiências são de crucial importância para eventos estocásticos ou estatísticos.

Para que os resultados de uma simulação sejam verdadeiramente confiáveis é necessário que as suposições e premissas sejam obtidas da realidade, e que os resultados obtidos não estejam em contradição com outros obtidos de experimentos reais. 
As simulações aqui referidas visam encontrar a relação entre o volume de informação trocado com o tamanho da chave obtida e com a chance de um possível intruso ser detectado. O caso de haver perda de informação devido a erros de transmissão também estão sendo contemplados, segundo taxas de erro existentes nos canais reais.

\section{C.1 Descrição das Classes Implementadas}

O simulador foi implementado utilizando o compilador Borland $\mathrm{C}++$ Builder 3 da Borland Corporation. Foi utilizada a linguagem $\mathrm{C}$ orientada a objetos.

A seguir são descritas as classes e os principais métodos implementados para as simulações.

As principais classes do programa são:

- sequencia: classe que representa as seqüências de informações de cada usuário.

- BasesConjugadas: classe que simula o protocolo de Bases Conjugadas (BB84).

- EstadosNaoOrtogonais: classe que simula o protocolo de Estados Não Ortogonais (B92).

- usuario: classe responsável por representar cada um dos participantes da comunicação. 


\section{C.1.1 sequencia}

Propriedades:

msg : armazena uma seqüência binária

tam : armazena o tamanho da seqüência

Métodos:

Construtor : inicializa seqüência com tamanho 0

Tam : devolve o tamanho da seqüência

PreencheMsg : copia os valores de uma string para msg

MostraMsg : mostra a seqüência caso DEBUG seja diferente zero

Msg : devolve um ponteiro para o início da seqüência

Msg_i : devolve o valor de uma posição desejada

GeraMsg : preenche a seqüência com valores aleatórios

ZeraMsg : zera o valor de todas as posições da seqüência

Copia : copia para uma seqüencia elementos consecutivos da msg

ComparaMsg : verifica a distância de Hamming entre 2 seqüências

operador $=\quad$ : copia uma seqüência em outra

GravaMsg : escreve os valores da seqüência num arquivo 


\section{C.1.2 BasesConjugadas}

Propriedades:

$\begin{array}{ll}\text { Breidbart } & : \text { para indicar se intruso fará ataque de Breidbart } \\ \text { msg } & : \text { seqüência a partir da qual sairá a chave } \\ \text { base } & : \text { bases usadas para ler/escrever msg do/no canal } \\ \text { escolhidos } & : \text { guarda as bases que o outro (receptor) escolheu } \\ \text { posicao } & : \text { guarda as posições das bases coincidentes } \\ \text { certos } & : \text { onde são guardados os valores coincidentes } \\ \text { chave } & : \text { resultado final } \\ \text { a,b,c,h; } & : \text { parâmetros da função de espalhamento }\end{array}$

Métodos:

EnvioBB84 : envia a mensagem pelo canal de acordo com a polarização escolhida

RecepcaoBB84 : recebe a mensagem do canal de acordo com a polarização escolhida

EnvioAutentic : transmite a mensagem pelo canal com autenticação (público)

RecepcaoAutentic : retira a mensagem do canal público garantindo autenticidade

ConfereBB84 : verifica quais as bases do receptor que estão corretas

JuntaCertos : preenche o vetor certos com os valores cujas bases coincidem

VerificaIntruso : Verifica qual é a proporção de bits que foram alterados

MontaHash : escolhe parâmetros para função de espalhamento e envia pelo canal

TestaHash : verifica quais bits estão errados pelos resultado da função de espalhamento 


\section{C.1.3 EstadosNaoOrtogonais}

$\begin{array}{ll} & \text { Propriedades: } \\ \text { msg } & : \text { seqüência a partir do qual sairá a chave } \\ \text { estados } & : \text { indica quais os estados escolhidos pelo receptor para ler o canal quântico } \\ \text { chave } & : \text { resultado final } \\ \text { certos } & : \text { onde são guardados os valores coincidentes } \\ \text { escolhidos } & : \text { guarda as posições dos fótons que atravessaram o polarizador } \\ \text { a,b,c,h } & : \text { parâmetros da função de espalhamento } \\ & \text { Métodos: }\end{array}$

EnvioB92 : envia a mensagem para o canal de acordo com a polarização escolhida

RecepcaoB92 : recebe a mensagem do canal de acordo com a polarização escolhida

EnvioAutentic : envia uma mensagem pelo canal público garantindo autenticidade

RecepcaoAutentic : retira a mensagem do canal público garantindo autenticidade

JuntaCertos : preenche o vetor certos com os valores definidos emescolhidos

MontaHash : escolhe parâmetros para função de espalhamento e envia pelo canal

TestaHash : verifica quais bits estão errados pelo resultado da função de espalhamento

\section{C.1.4 usuario}

Propriedades:

BasesConjugadas BB84

EstadosNaoOrtogonais B92

Métodos:

Construtor : : indica se o ataque é do tipo Breidbart ou não.

AtaqueB92 : escolhe valores para os fótons que não atravessaram polarizador no B92. 


\section{C.2 Outras funções e constantes}

Além das classes anteriormente descritas, há algumas funções e procedimentos que não pertencem a nenhuma classe. Isto ocorre ou porque são apenas funções auxiliares como por exemplo a função hash, ou porque são a execução do protocolo que envolve todo o programa como é o caso das funções execBB84 e execB92.

\section{C.2.1 Funções}

hash: calcula a função de espalhamento do tipo $\mathrm{h}(\mathrm{x})=\mathrm{ax}+\mathrm{b}$ cujos parâmetros foram passados como argumento.

stol: converte 4 bytes em um long, é usado para ler um valor long do canal autêntico.

ltos: converte um long em 4 bytes, é usado para enviar um valor long pelo canal autêntico.

VerificaHash: Verifica se a seqüência de A é igual a de B, recursivamente.

execBB84: Implementação do Protocolo BB 84.

execB92: Implementação do Protocolo B 92.

\section{C.2.2 Constante usadas na autenticação}

Indicam o papel de cada usuário. Usados durante a transmisssão pelo canal com autenticação.

\section{EMISSOR}

RECEPTOR 


\section{C.2.3 Constantes para definir valores}

FLAGNAOPASSA: este valor indica, no protocolo B92, que o fóton não atravessou o polarizador.

BITANTIGO: são descartadas as posições na seqüência que possuem este valor.

\section{C.2.4 Constantes para definir tipos de ataque}

No B92, para as posições em que o fóton não atravessou o polarizador, o intruso deve escolher um valor. Estes valores são definidos segundo uma das abordagens abaixo:

ALEAT: o valor será escolhido aleatoriamente.

MANTEM: o valor referente ao eixo de polarização do intruso será mantido.

INV: o valor referente ao eixo de polarização do intruso será invertido.

\section{C.3 Descrição dos principais métodos e funções}

A seguir são descritas, na forma de pseudo-código, as principais funções implementadas.

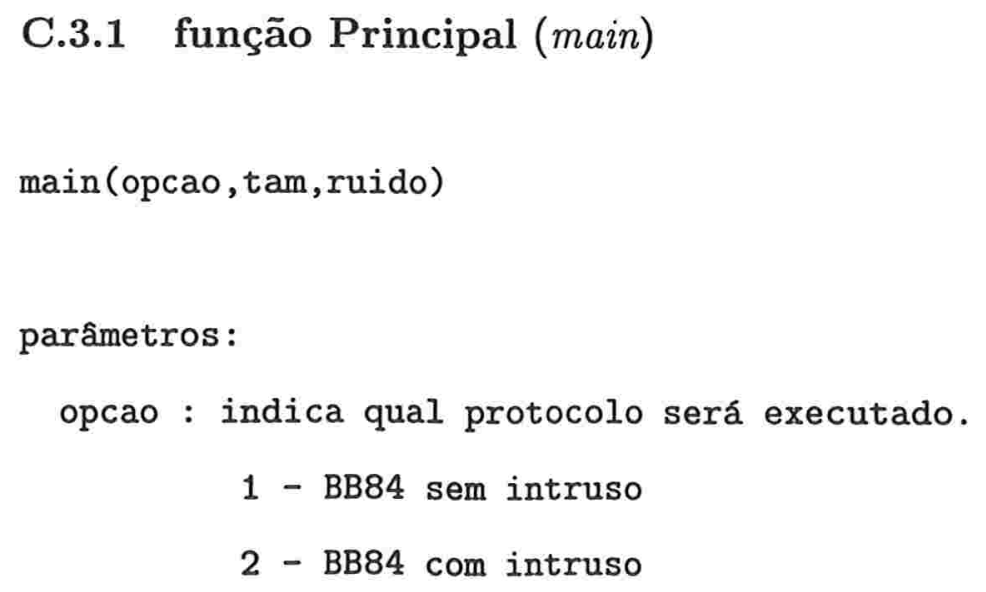




$$
\begin{aligned}
& 3 \text { - B92 sem intruso } \\
& 4 \text { - B92 com intruso } \\
& 5 \text { - BB84 com ataque de Breidbart }
\end{aligned}
$$

tam : tamanho da seqüência inicial usada para combinação da chave

ruido: taxa de ruido do canal (em porcentagem)

variáveis:

nome : nome dos arquivos com dados estatísticos e com a chave resultante.

0. BeginProgram

1. nome <- MontaNome (opcao, tam)

2. arq <- AbreArq(nome) > abre arquivo para guardar informações estatísticas

3. chaves<- AbreArq(nome+".key") > abre arquivo para armazenar chave resultante

4. dbg <- AbreArq(nome+".dbg") > abre arquivo para gravar dados intermediários

5. case opcao > verifica qual opção foi escolhida

6. $=1: \operatorname{execBB84}(0$, ruido, tam $)>B B 84$ sem intruso

7. $\quad=2: \operatorname{execBB84}(1$, ruido, tam $)>$ BB84 com intruso

8. $=3: \operatorname{execB92}(0$,ruido, tam $)>B 92$ sem intruso

9. $=4:$ execB92 ( 1 ,ruido, tam) > B92 com intruso

10. $=5: \operatorname{execBB84}(2$, ruido, tam $)>$ BB84 com ataque de Breidbart

11. FechaArq (arq)

12. FechaArq (chaves)

13. FechaArq (dbg)

14. EndProgram

C.3.2 função Execução do Protocolo BB84 (execBB84) 


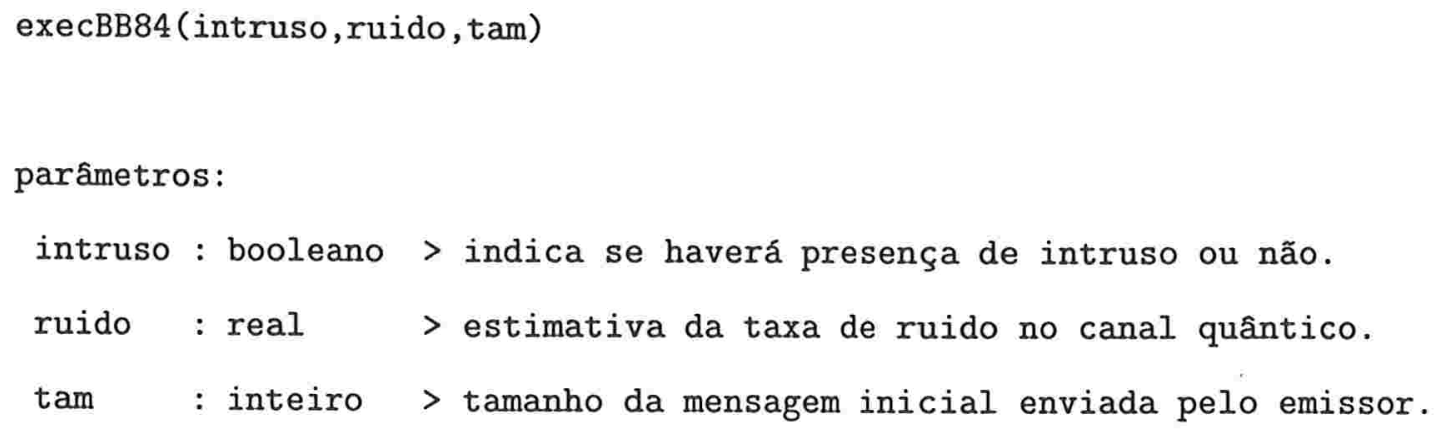

0. BeginProgram

1. > 1a fase - TRANSMISSÃO

2. Alice.Msg.Gera

$>$ Alice gera a Mensagem aleatoriamente com tamanho Tam

3. Alice.Bases.Gera

4. Alice.Msg.Envia

$>$ Alice gera suas bases para mandar Msg pelo canal

5. If intruso

6. Eva.Bases.Gera

$>$ Alice envia a mensagem pelo canal

7. Eva.Msg. Recebe

$>$ Eva também gera suas bases para ler a Msg do canal

$>$ Eva intercepta e retira a mensagem do canal 
8. Eva.Msg.Envia

9. EndIf

10. Bob.Bases.Gera

11. Bob.Msg. Recebe

12. > 2a fase - RECONCILIAÇÃO

13. Bob.escolhidos <- Bob.bases

14. Bob.escolhidos.EnvioAutentico > Bob indica quais bases escolheu para ler a Msg

15. If intruso

16. Eva.escolhidos.RecebeAutentico > Eva vê quais foram as bases escolhidas por Bob

17. EndIf

18. Alice.escolhidos.RecebeAutentico > Alice vê quais são as bases do Bob

19. Alice.JuntaCertos

20. Alice.certos.EnvioAutentico

21. If intruso

22. Eva.posicao.RecebeAutentico > Eva guarda as bases corretas

23. Eva.JuntaCertos > Eva verifica quais das suas bases estão corretas

24. EndIf

25. Bob.posicao.RecebeAutentico > Bob recebe a sequiência de bases corretas da Alice

26. Bob.JuntaCertos

$>$ Bob verifica quais das suas bases estão corretas

27. > 3a fase - Correção de erros e detecção de intruso

28. numBlocos <- chão(tamChave*ruido)/2 > verifica qual deve ser o tamanho dos blocos

29. pos <- 0 para percorrer os blocos

30. Do > calcula a distancia de Hamming entre as seqüências de Alice e Bob

31. PipeAutentic <- Bob.MontaHash > Bob calcula o hash de trechos do bloco e envia

32. If Intruso

33. Eva.TestaHash (PipeAutentic) $>$ Eva verifica qual foi o resultado da hash de Bob 34. EndIf

35. Alice.TestaHash (PipeAutentic) > Alice verifica se o resultado da hash é diferente 36. PipeAutentic <- Alice.dif > Alice indica quantos bits deu de diferença 


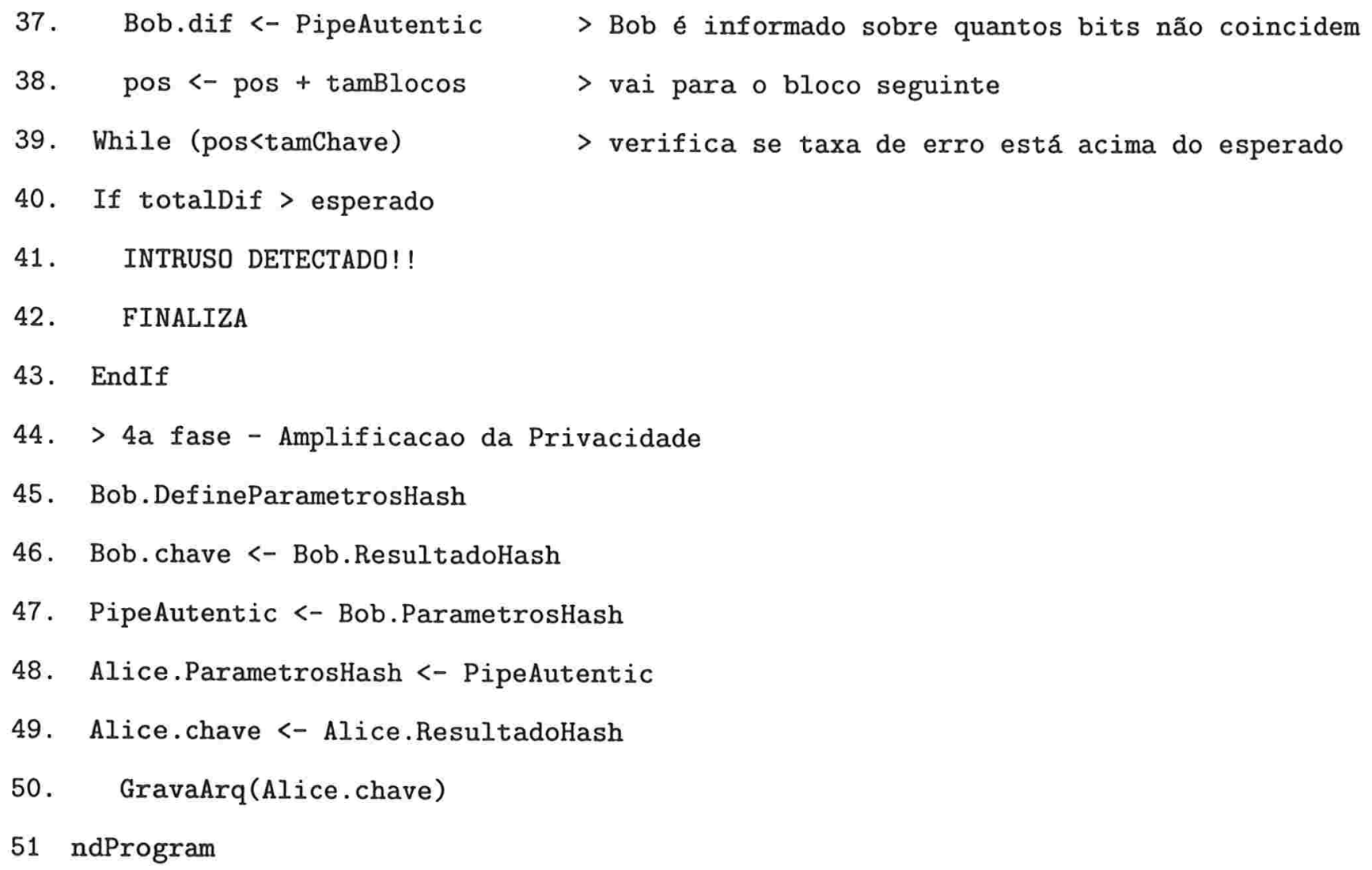

\section{C.3.3 função Execução do Protocolo B92 (execB92)}

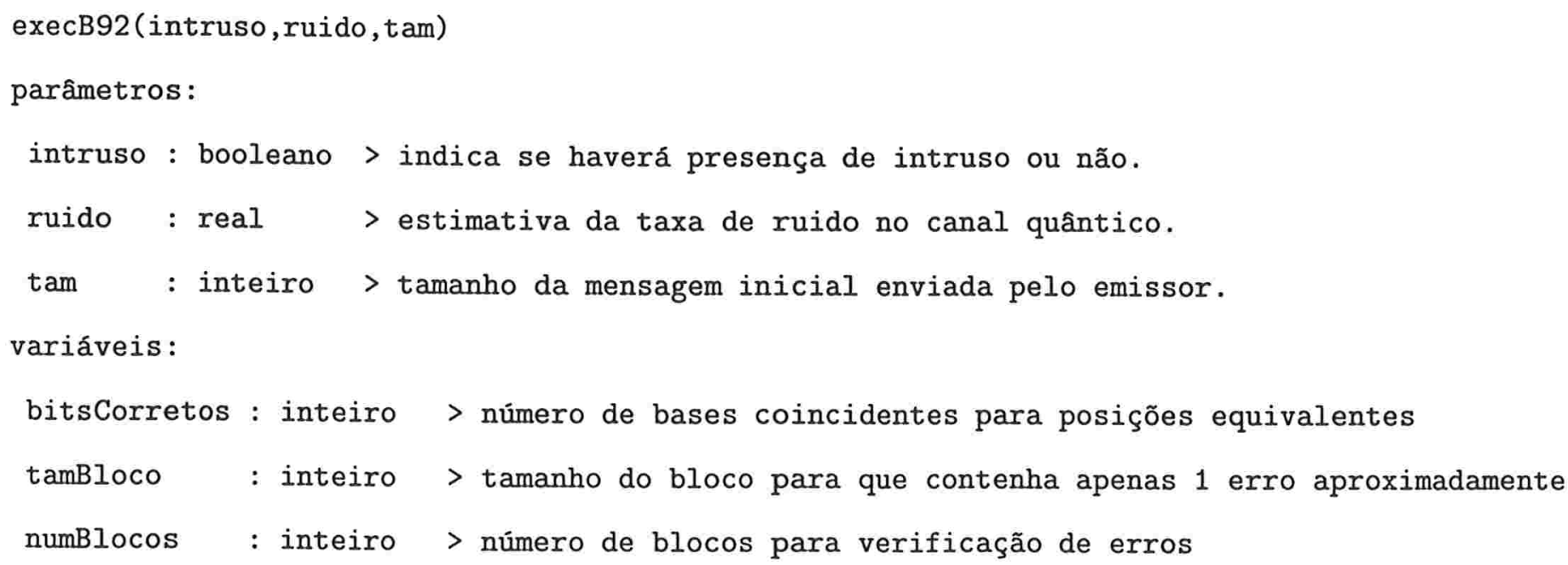




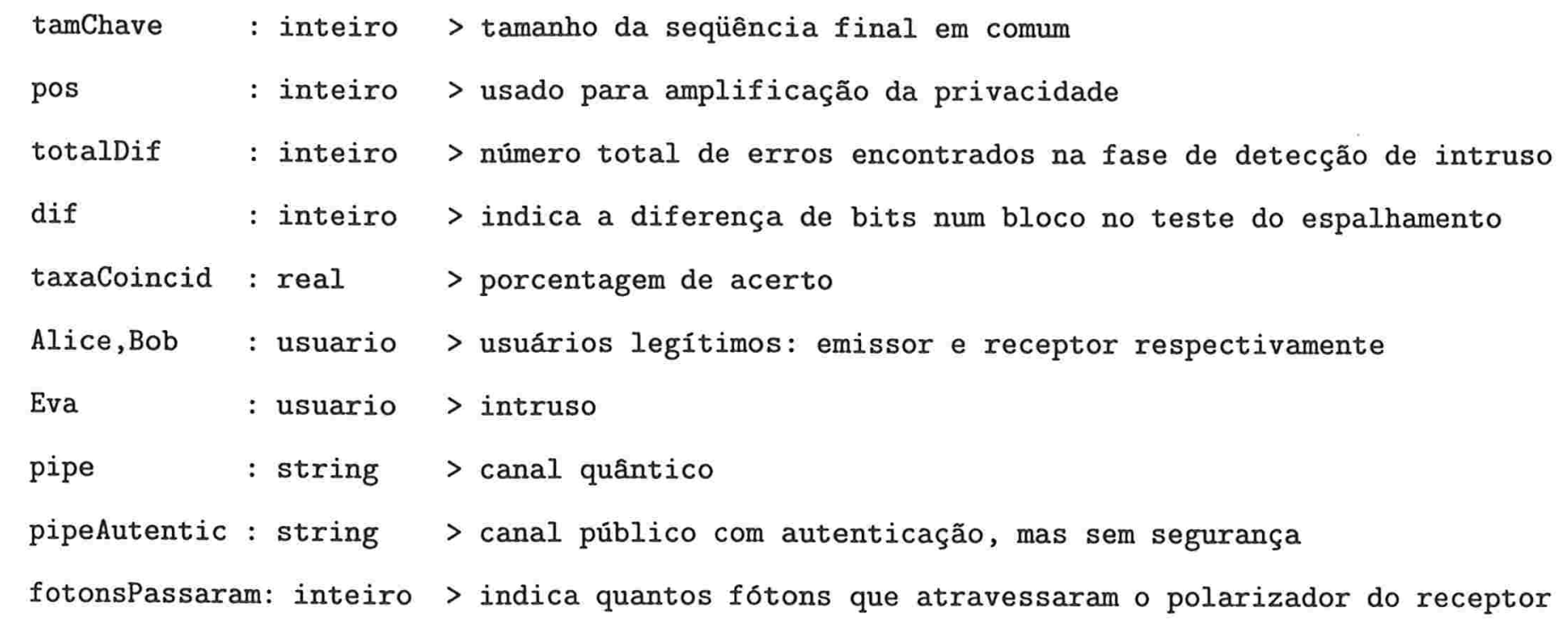

0. BeginProgram

1. > 1a fase - TRANSMISSÃO

2. Alice.Msg.Gera

$>$ Alice gera a Mensagem aleatoriamente com tamanho Tam

3. Alice.Msg.Envia

$>$ Alice envia a mensagem pelo canal

4. If intruso

5. Eva.Estados.Gera

> Eva gera seus eixos de polarização para ler a Msg

6. Eva.Msg. Recebe

$>$ Eva intercepta e retira a mensagem do canal

7. Eva.Msg.Envia

$>$ Eva reenvia a mensagem pelo canal

8. EndIf

9. Bob.Estados.Gera

> Bob escolhe os ângulos de polarização para ler canal

10. Bob.Msg.Recebe

$>$ Bob retira a mensagem do canal

11. > $2 \mathrm{a}$ fase - RECONCILIAÇÃO

12. Bob.Msg.EnvioAutentico

$>$ Bob indica quais fótons atravessaram seu polarizador

13. If intruso

14. Eva.escolhidos.RecebeAutentico > Eva vê a posição dos fótons que passaram pelo Bob

15. Eva.JuntaCertos > Eva verifica quais das suas bases estão corretas

16. EndIf

17. Alice.escolhidos. RecebeAutentico > Alice vê as posições dos fótons que Bob leu 
18. Alice.JuntaCertos

$>$ Alice verifica qual é a informação do Bob

19. > 3a fase - Correção de erros e deteç̧ão de intruso

20. numBlocos <- chão(tamChave*ruido)/2 > verifica qual deve ser o tamanho dos blocos

21. pos $<-0$

$>$ para percorrer os blocos

22. Do > verifica distância de Hamming do trecho cujas bases coincidem entre Alice e Bob

23. PipeAutentic <- Bob.MontaHash > Bob calcula o hash de trechos do bloco e envia

24. If Intruso

25. Eva.TestaHash (PipeAutentic) > Eva verifica qual foi o resultado da hash de Bob

26. EndIf

27. Alice.TestaHash (PipeAutentic) > Alice verifica se o resultado da hash é diferente

28. PipeAutentic <- Alice.dif > Alice indica quantos bits deu de diferença

29. Bob.dif <- PipeAutentic > Bob é informado sobre quantos bits não coincidiram

30. pos <- pos + tamBlocos > vai para o bloco seguinte

31. While (pos<tamChave)

$>$ verifica se taxa de erro está acima do esperado

32. If totalDif > esperado

33. INTRUSO DETECTADO!!

34. FINALIZA

35. EndIf

36. > 4a fase - Amplificacao da Privacidade

37. Bob.DefineParametrosHash

38. Bob.chave <- Bob.ResultadoHash

39. PipeAutentic <- Bob.ParametrosHash

40. Alice.ParametrosHash <- PipeAutentic

41. Alice.chave <- Alice.ResultadoHash

42. GravaArq(Alice.chave)

43. EndProgram 


\title{
Apêndice D
}

\section{Listagem do programa de simulação}

\section{dos protocolos}

\author{
* BB84 \& B92 \\ * Protocolos Criptograficos Quanticos para Distribuicao de Chaves \\ $*$ \\ * Luis Antonio Brasil Kowada
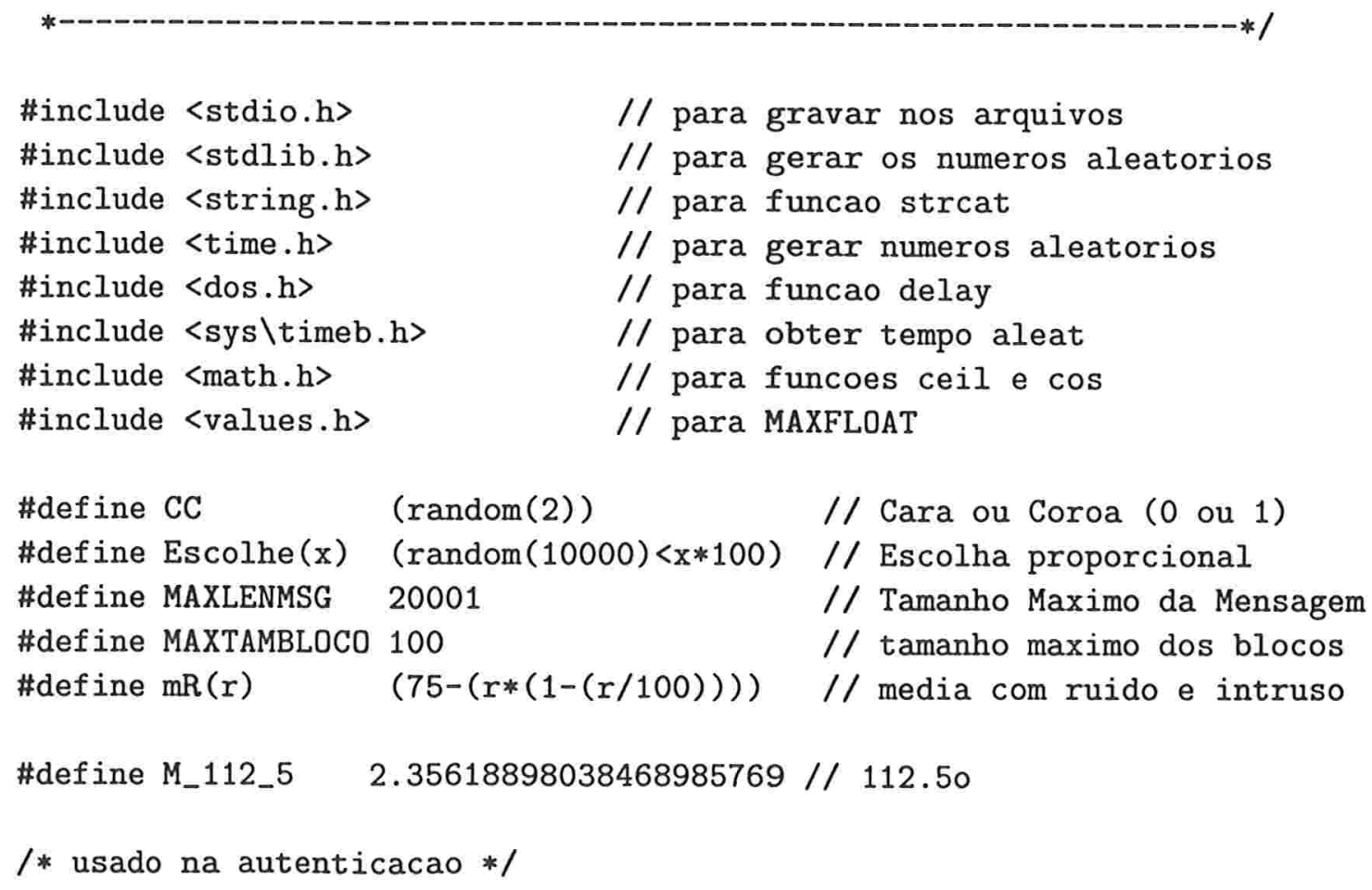
\};

class BasesConjugadas \{ public:

char Breidbart; // para indicar se intruso fara ataque de Breidbart sequencia msg, // sequencia a partir do qual saira' a chave

base, // bases usadas para ler/escrever msg do/no canal

chave, // resultado final

certos, // onde sao guardados os valores coincidentes

APpos, // posicao dos valores para Amplificacao da Privacidade escolhidos, // guarda as bases que o outro(receptor) escolheu posicao; // guarda as posicoes das bases coincidentes long $\quad \mathrm{a}, \mathrm{b}, \mathrm{c}, \mathrm{h}$; // para funcao Hash

/* primeira fase */

void EnvioBB84 (unsigned tam,char *Pipe,float ruido);

unsigned RecepcaoBB84 (unsigned tam, char *Pipe);

/* segunda fase */

void EnvioAutentic (sequencia m, unsigned tam, char *PipeAutentic);

void RecepcaoAutentic (sequencia *m, unsigned tam,char *PipeAutentic);

unsigned ConfereBB84 (void);

int JuntaCertos (void);

/* terceira fase */

void MontaHash (unsigned tam, unsigned pos, char *);

char TestaHash (char *PipeAutentic);

\};

class EstadosNaoOrtogonais \{

public:

sequencia msg, // sequencia a partir do qual saira' a chave

estados, // para medir sequencia

chave, // resultado final

certos, // onde sao guardados os valores coincidentes

APpos, // posicao dos valores para Amplificacao da Privacidade escolhidos, // guarda as posicoes dos fotons que atravessaram posicao; // guarda as posicoes das bases coincidentes

long a,b,c,h; // para funcao Hash

/* primeira fase */

void EnvioB92(unsigned tam, char *Pipe,float ruido);

unsigned RecepcaoB92 (unsigned tam, char *Pipe);

/* segunda fase */

void EnvioAutentic (sequencia m, unsigned tam,char *PipeAutentic);

void RecepcaoAutentic (sequencia *m, unsigned tam, char *PipeAutentic);

int JuntaCertos(void);

/* terceira fase */

void MontaHash (unsigned tam, unsigned pos, char *);

char TestaHash (char *PipeAutentic); 


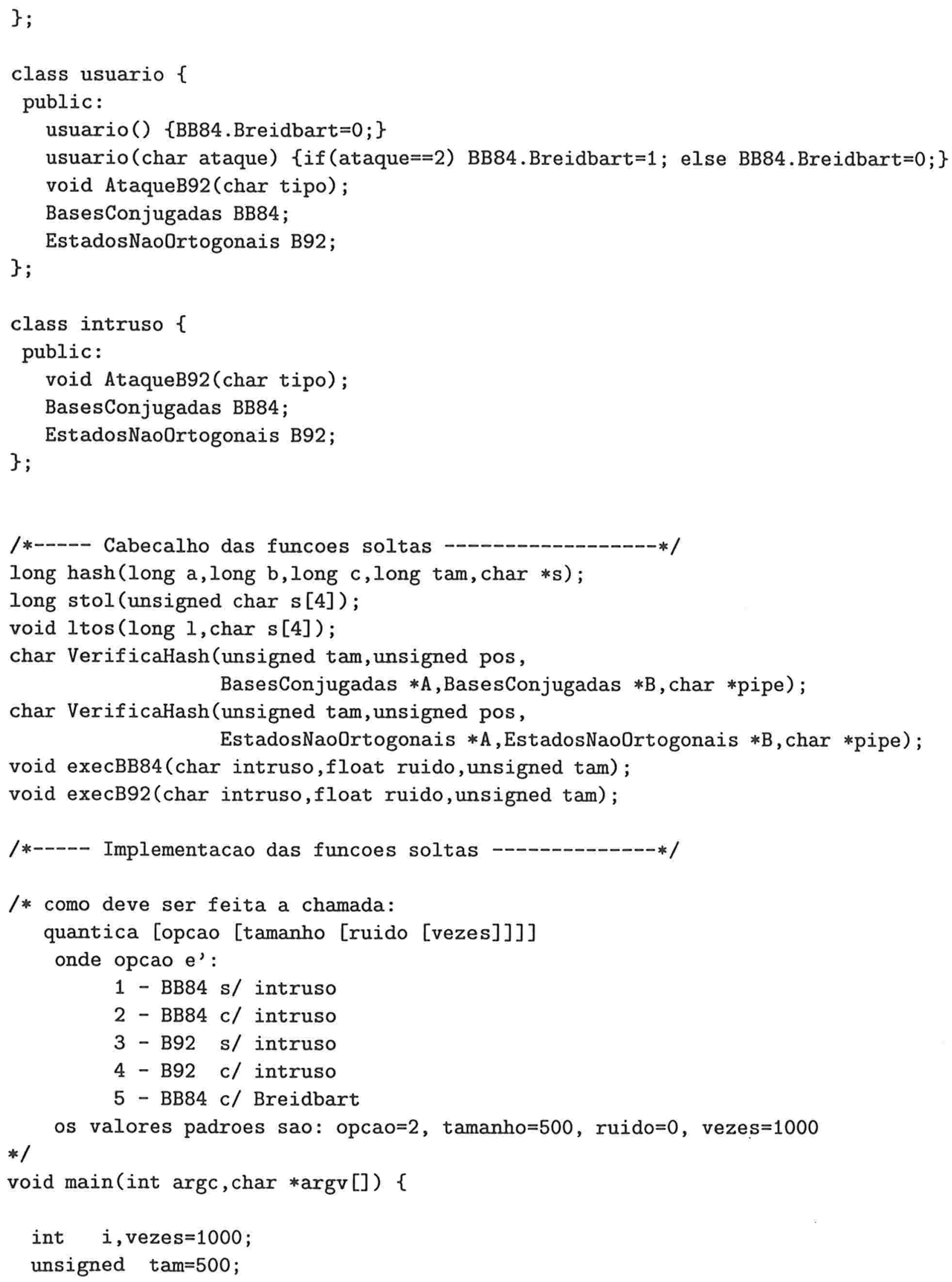




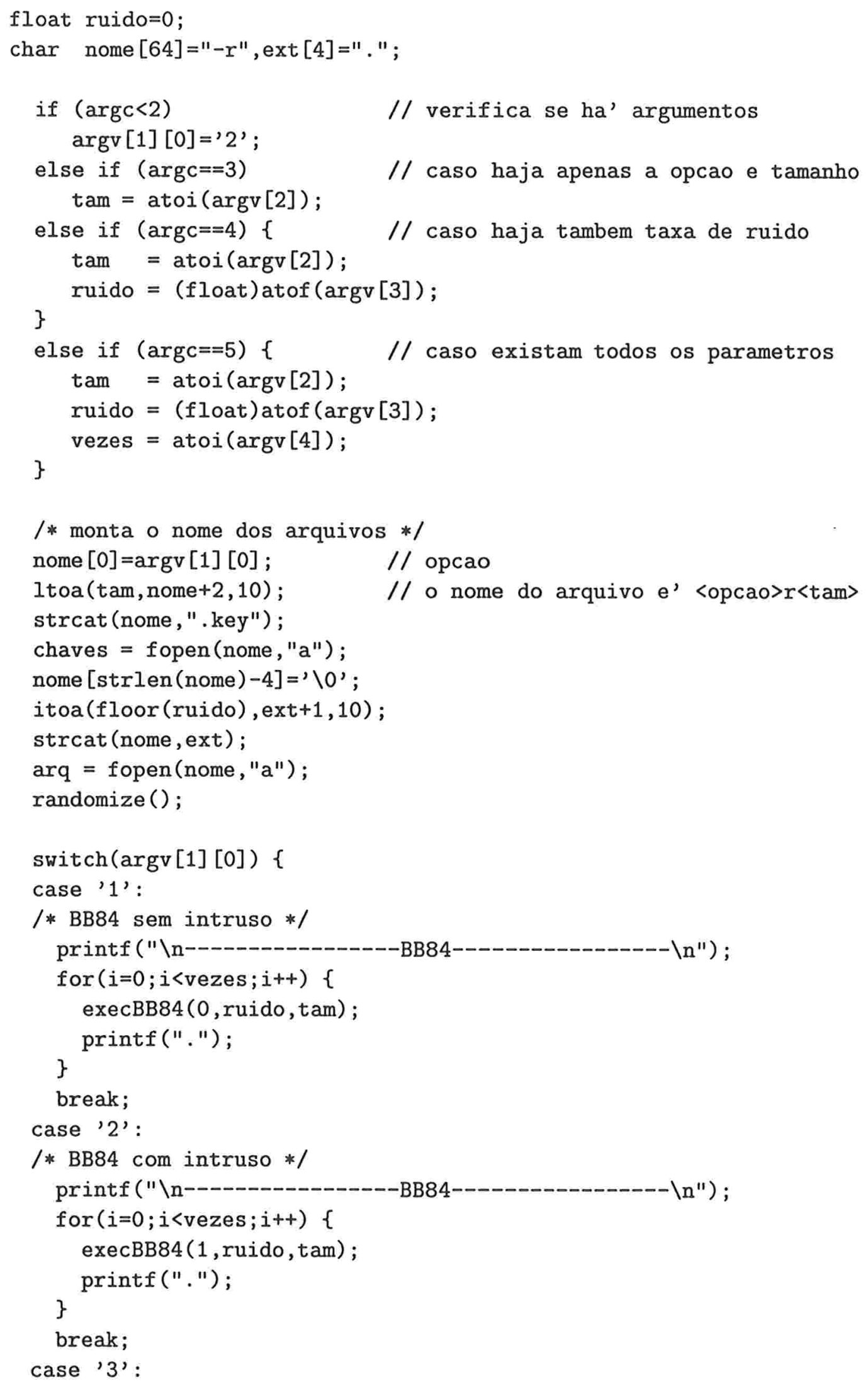




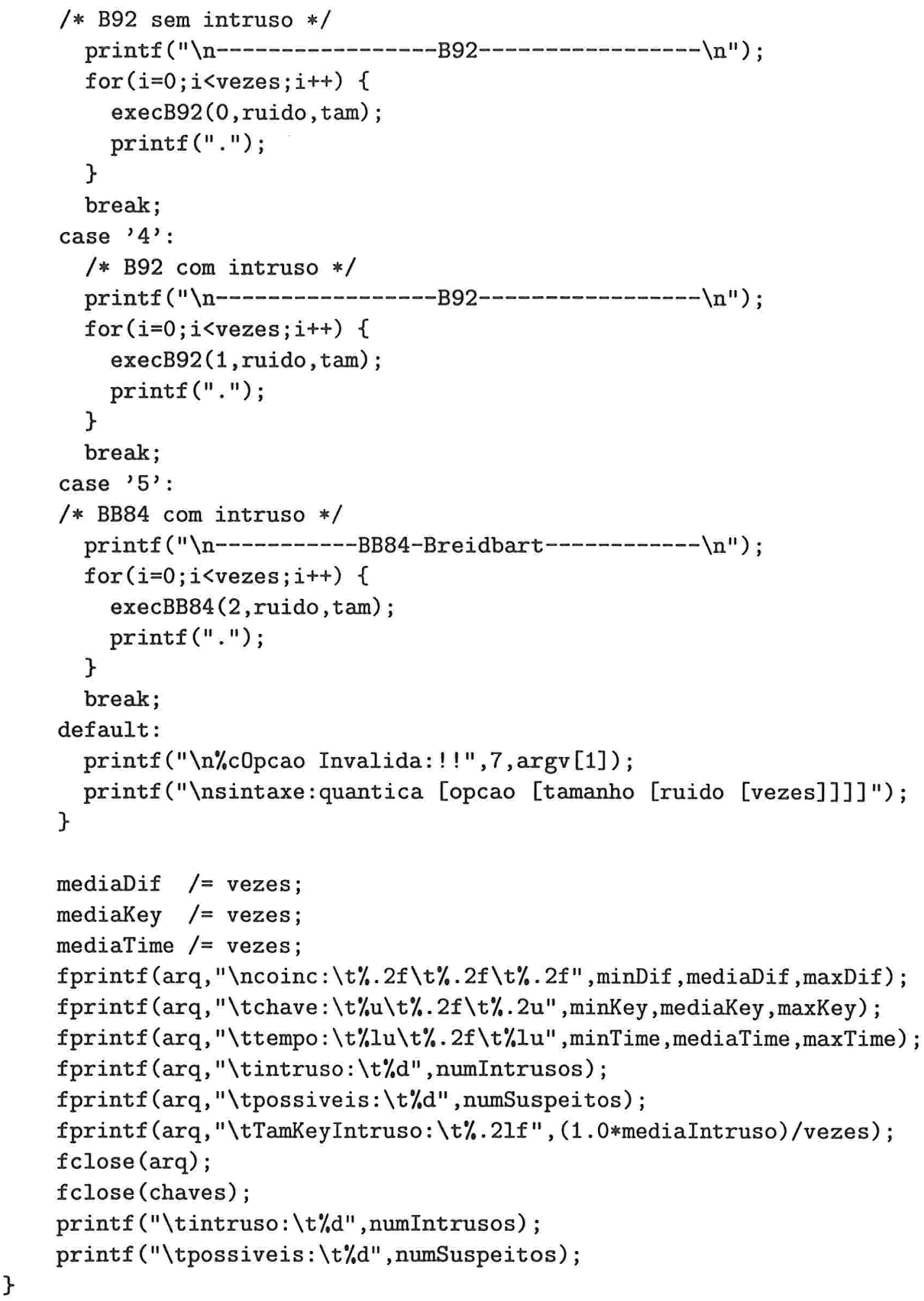




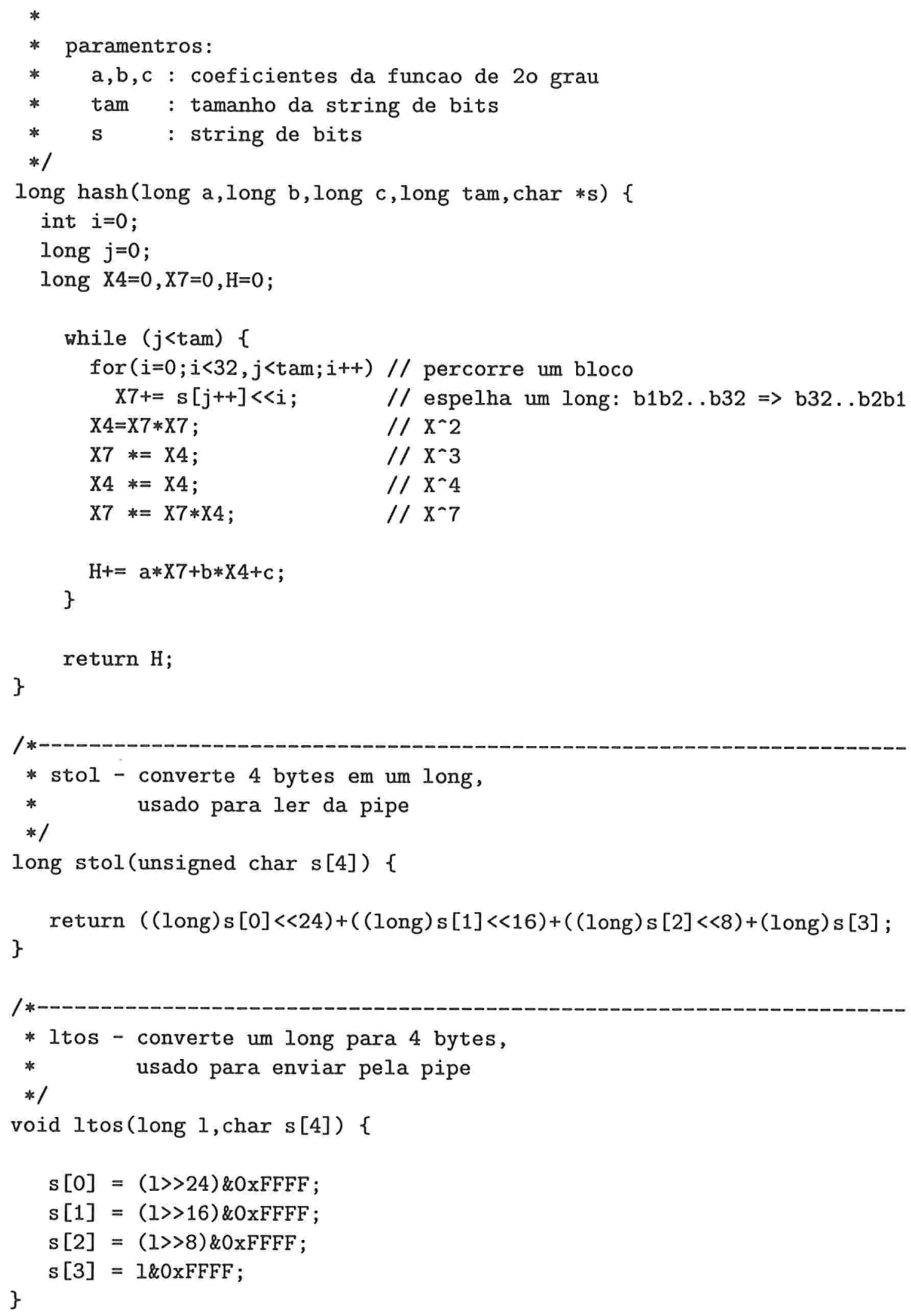




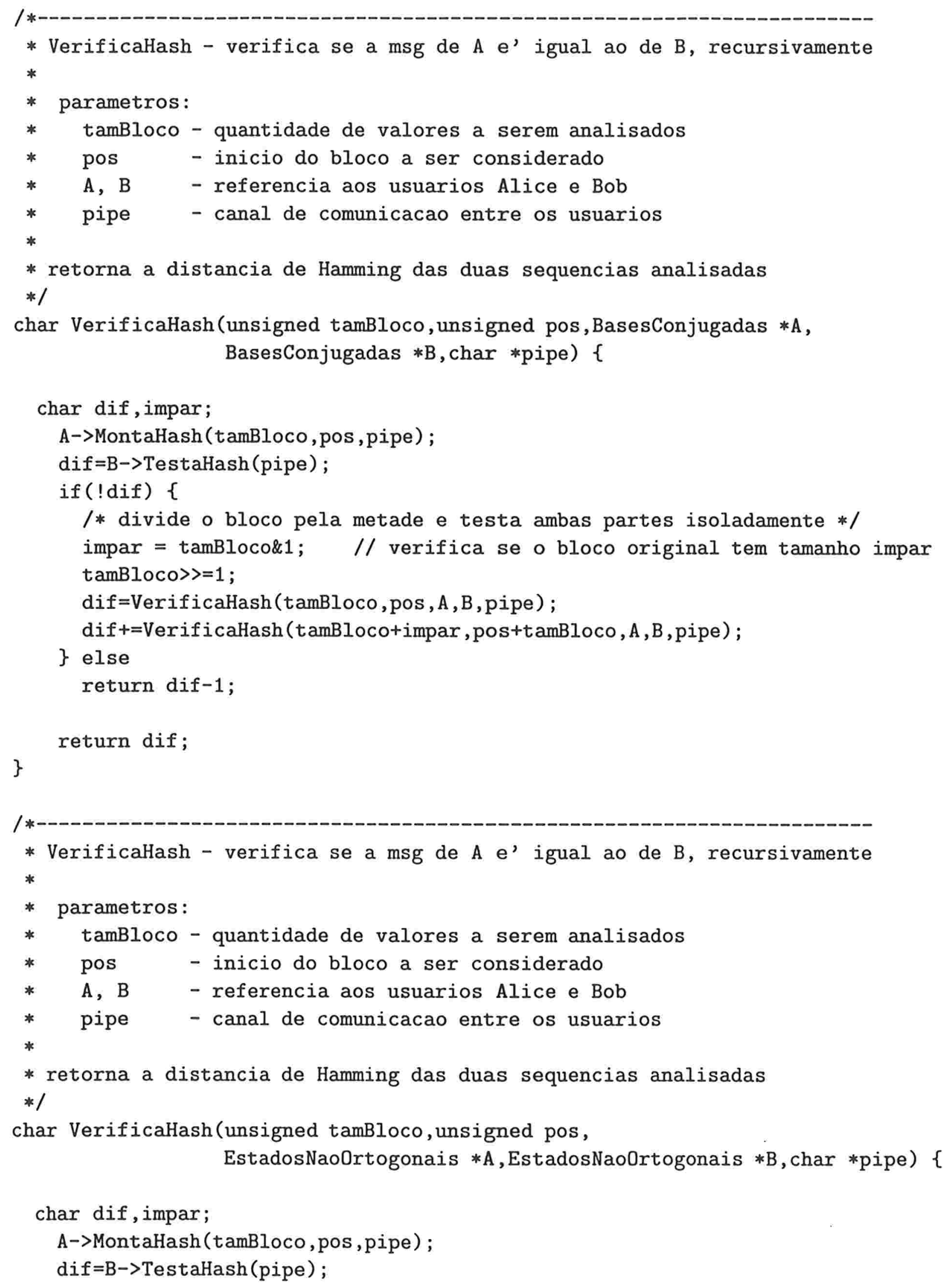




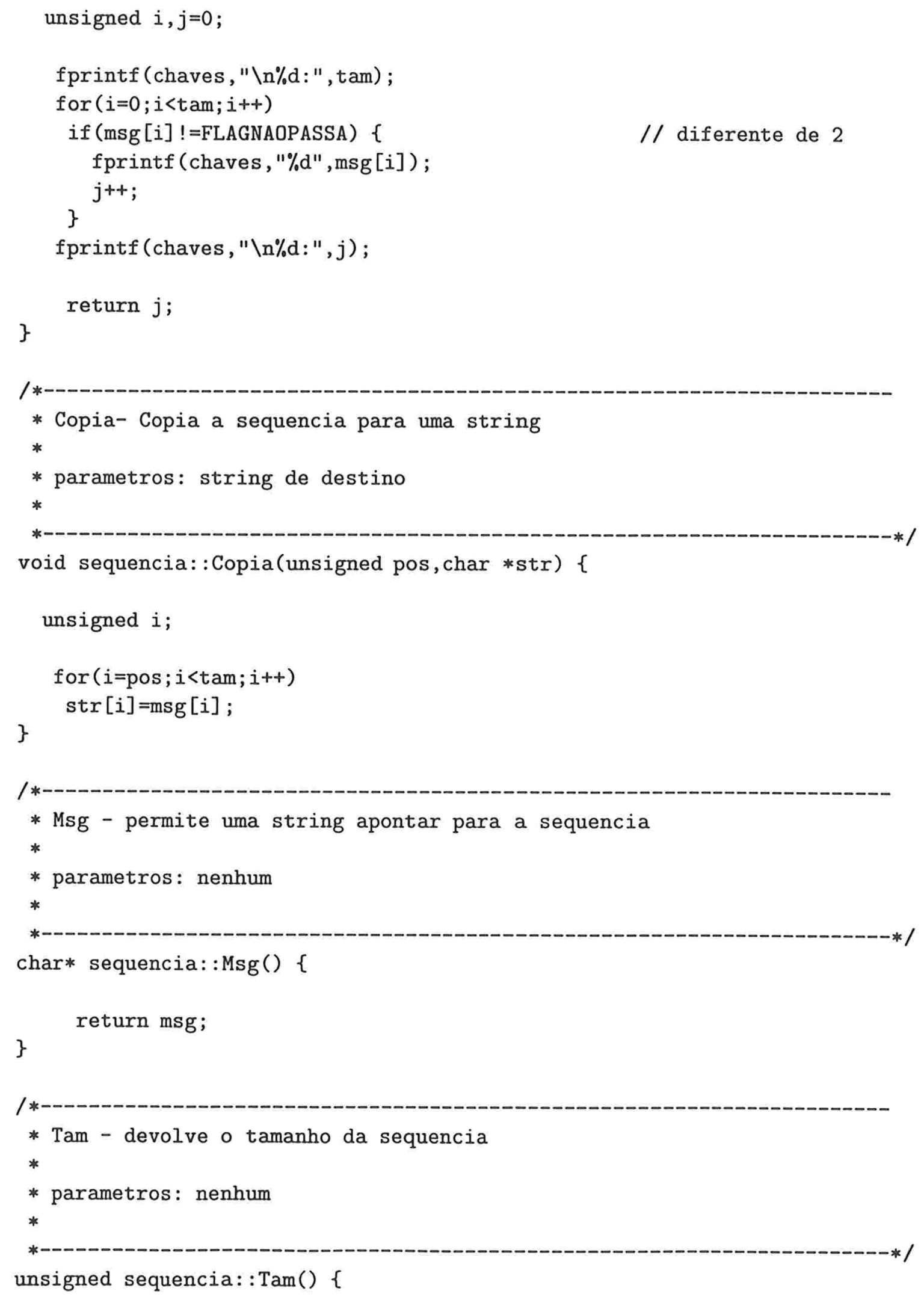




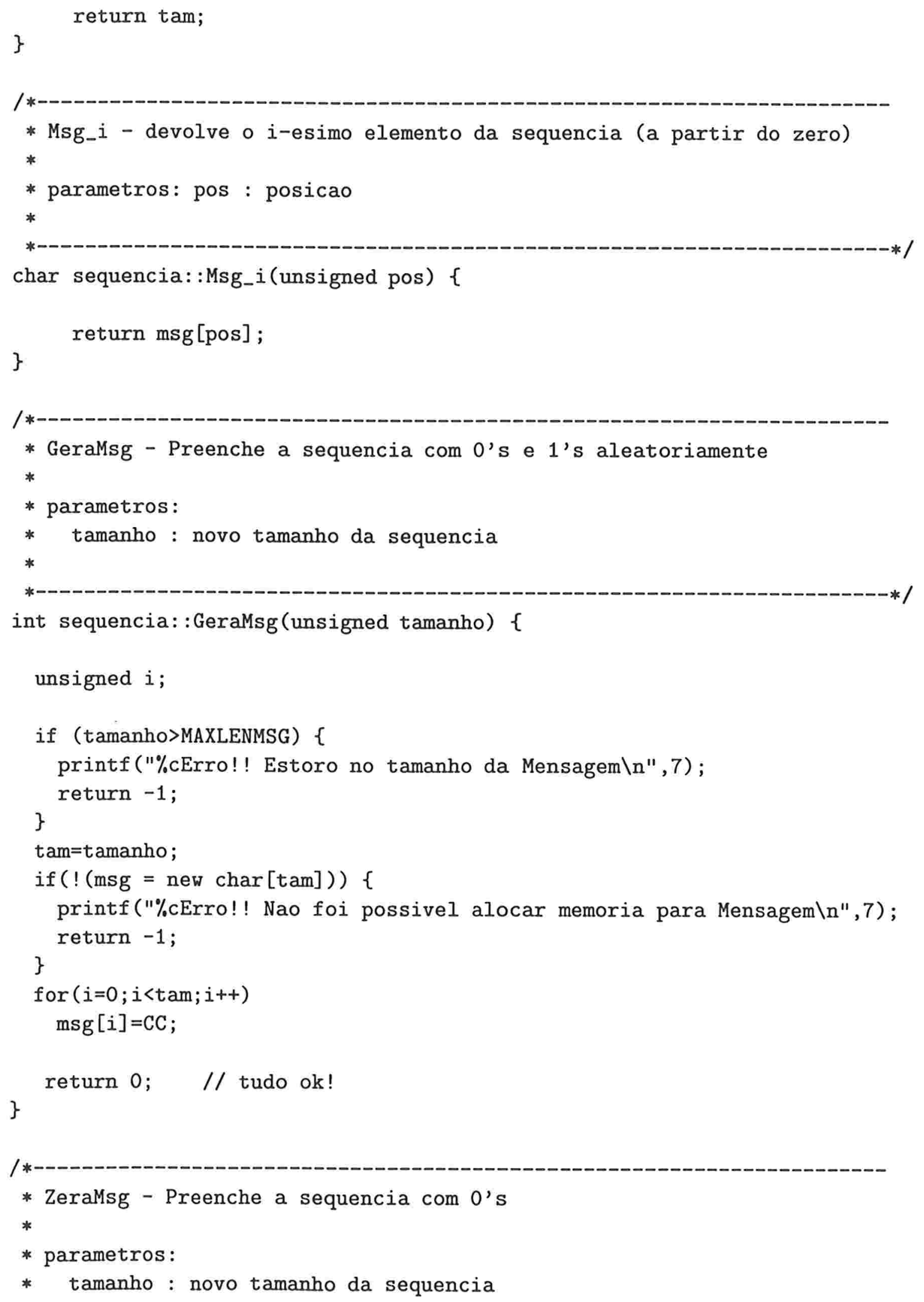




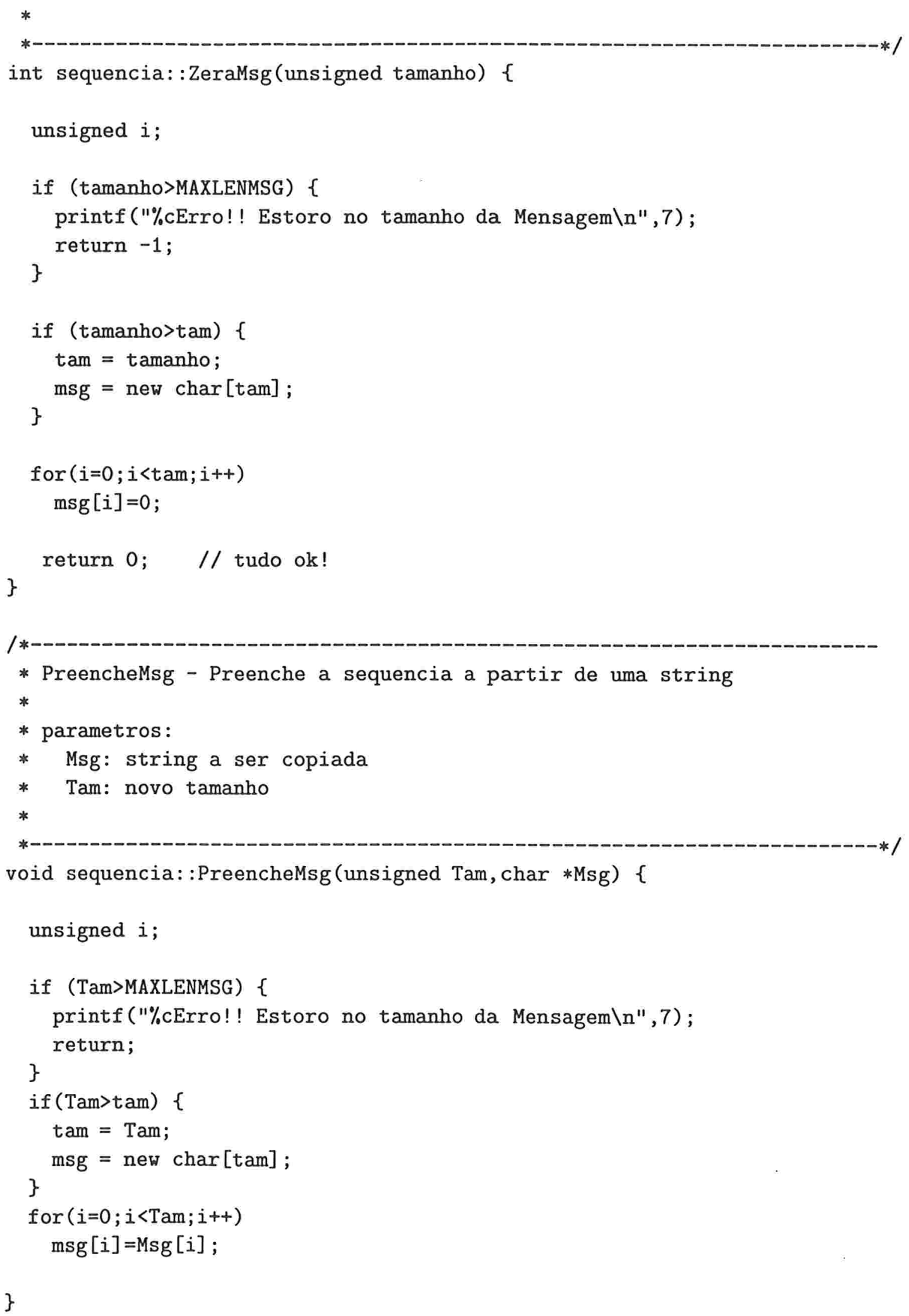




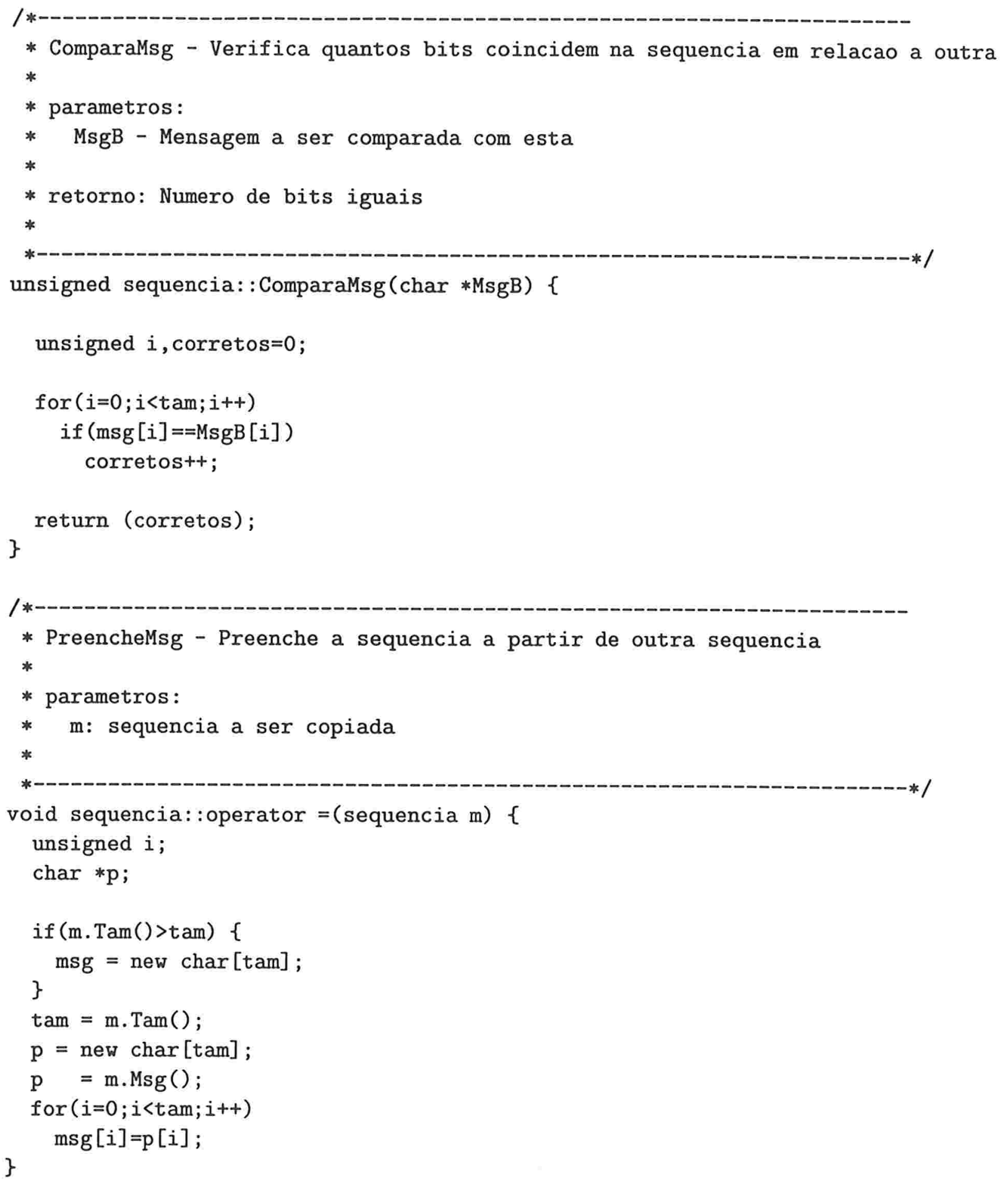



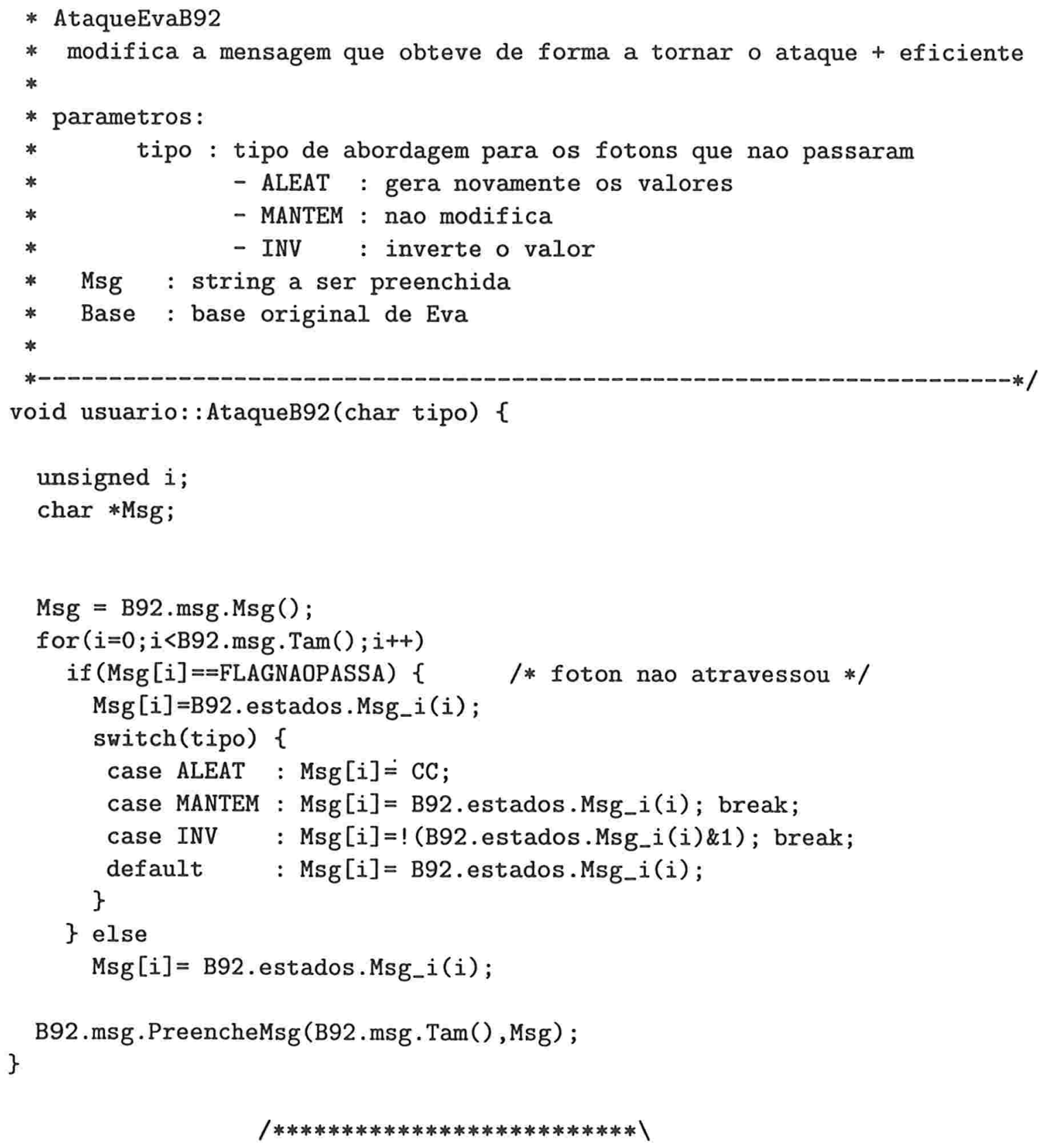

* classe BasesConjugadas *

$\backslash * * * * * * * * * * * * * * * * * * * * * * * * * * /$

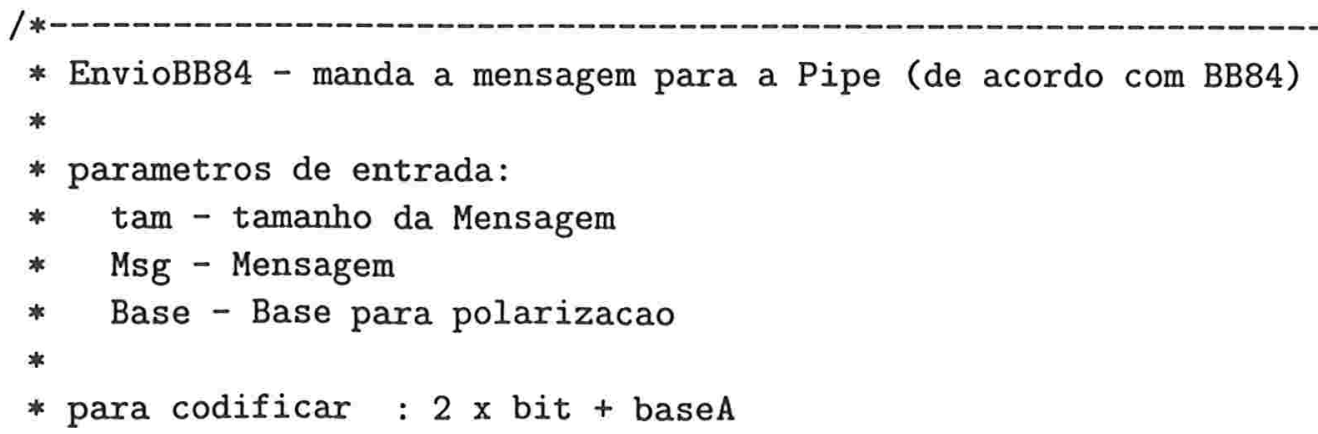




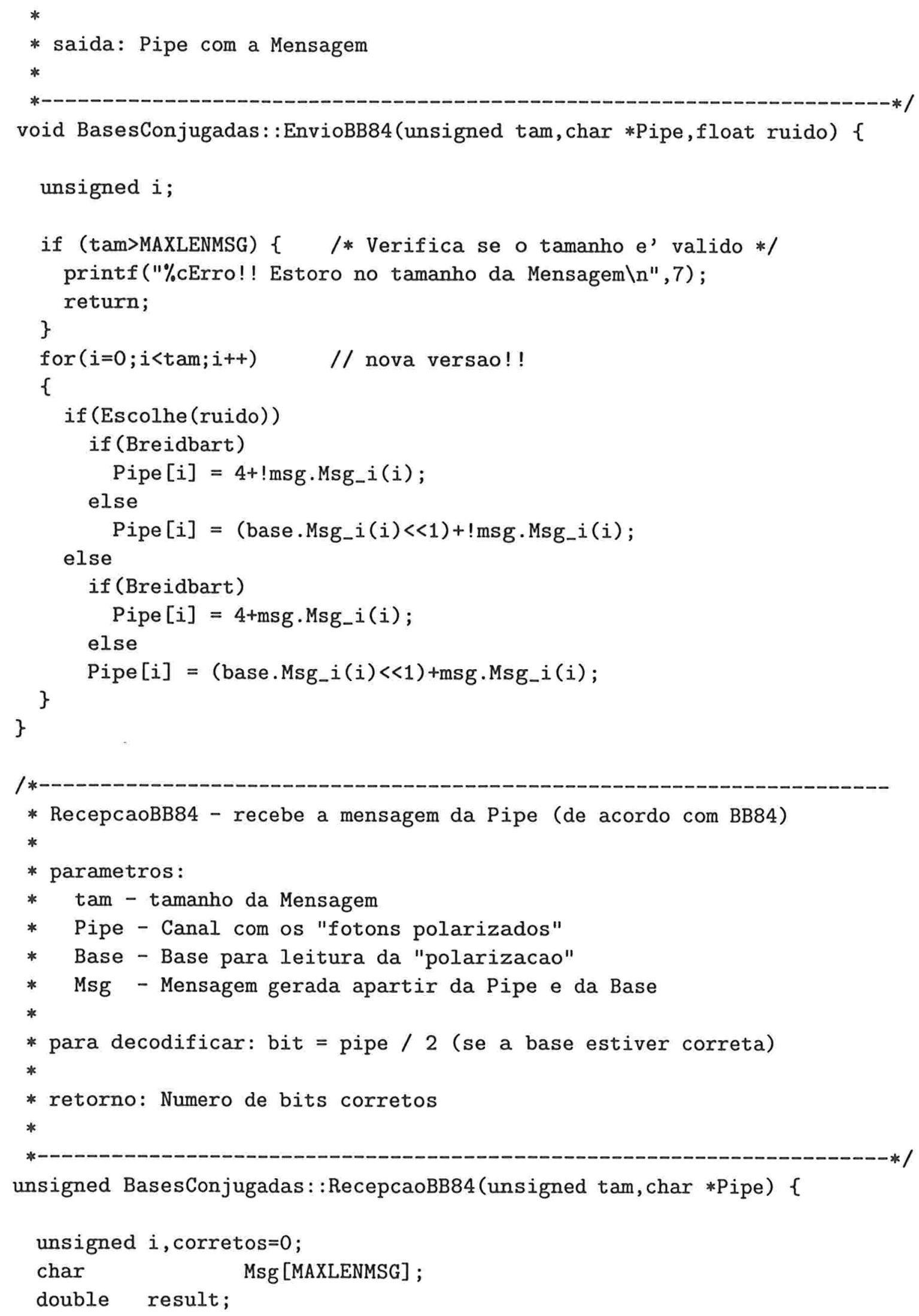




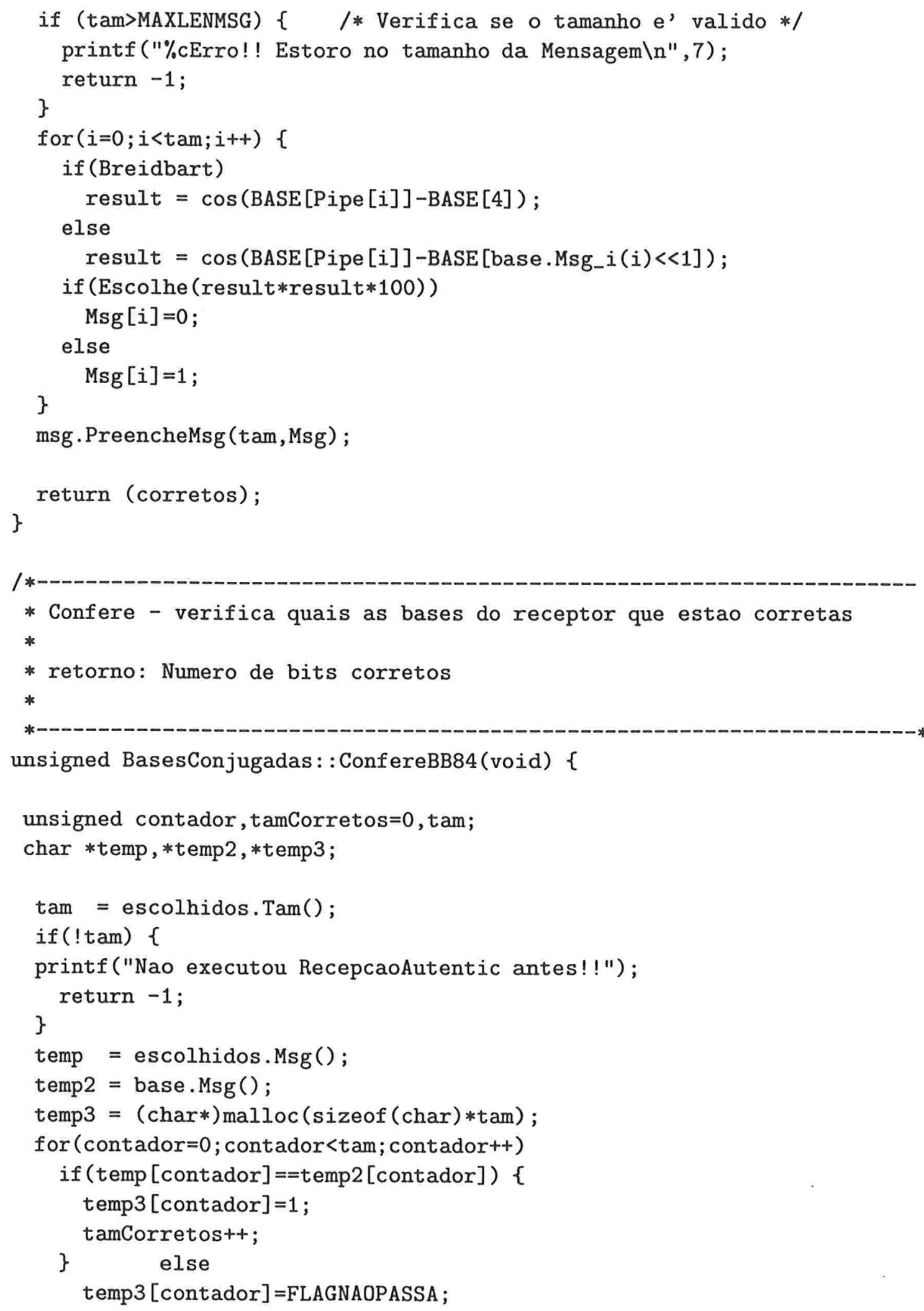




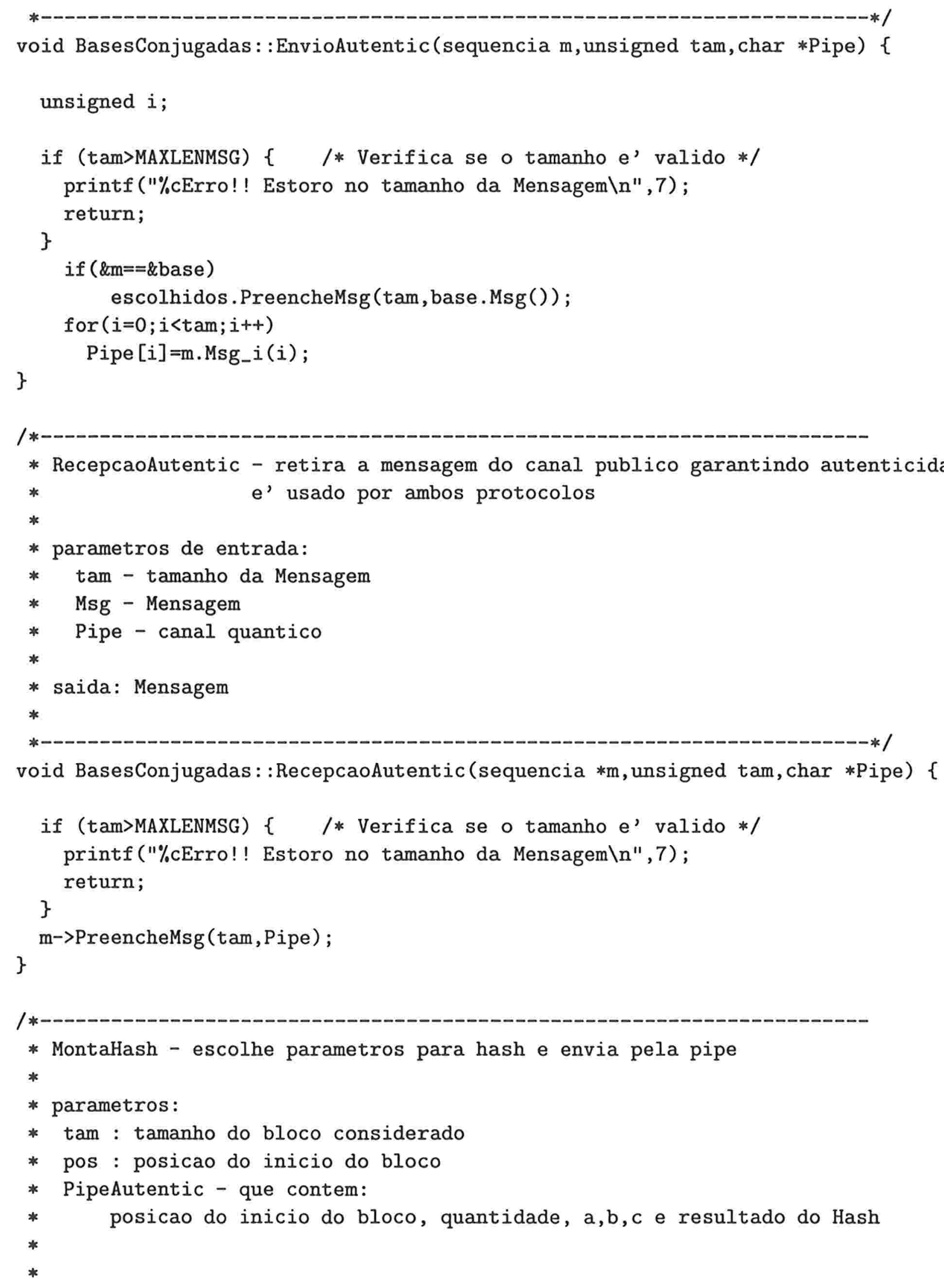




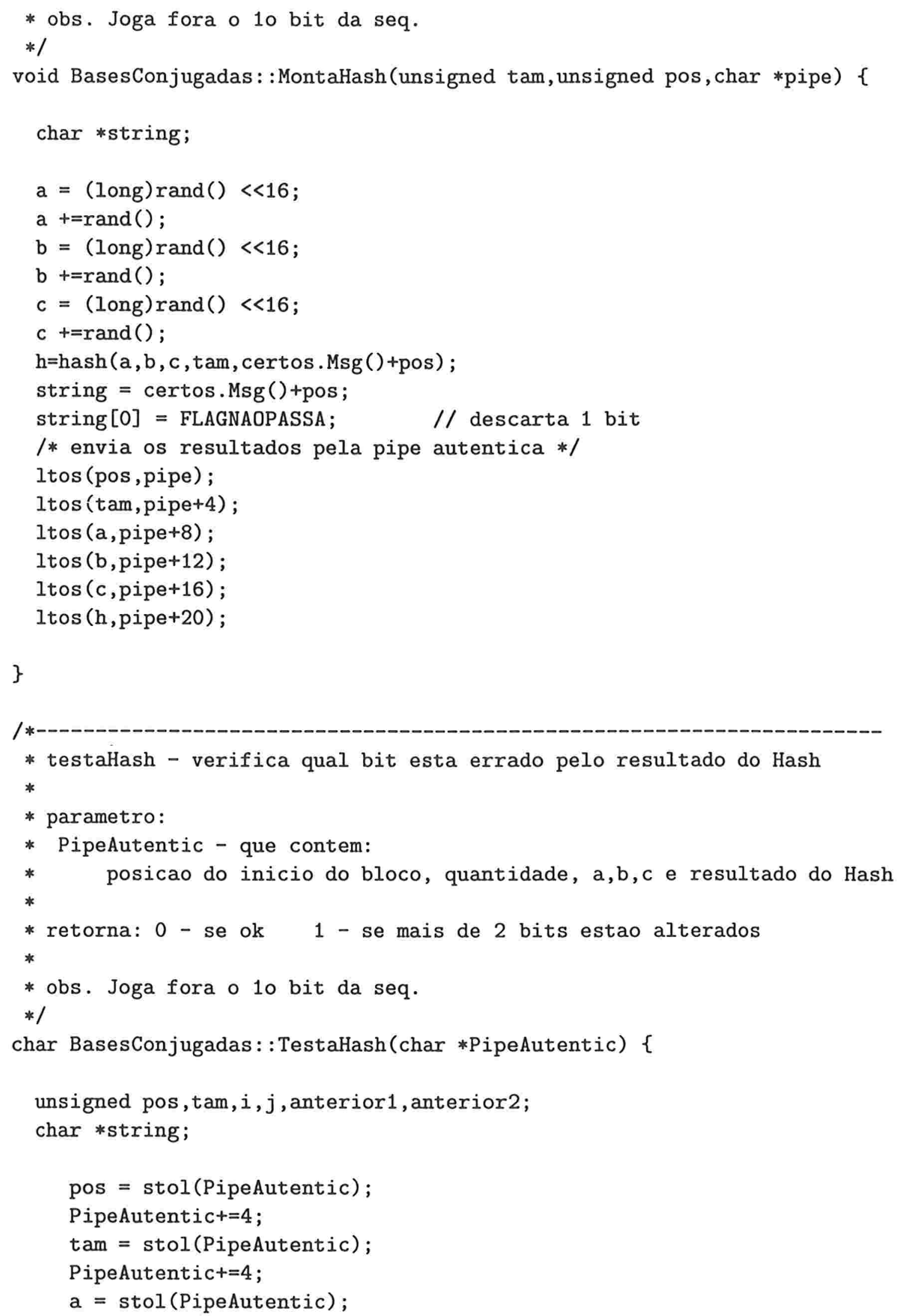


PipeAutentic $+=4$;

$\mathrm{b}=\operatorname{stol}$ (PipeAutentic);

PipeAutentic $+=4$;

$c=$ stol (PipeAutentic);

PipeAutentic $+=4$;

$\mathrm{h}=$ stol (PipeAutentic);

PipeAutentic+=4;

PipeAutentic-=24;

string $=$ certos $\operatorname{Msg}()+$ pos;

if ( $\mathrm{h}==\mathrm{hash}(\mathrm{a}, \mathrm{b}, \mathrm{c}$, tam, string $))\{$

string $[0]=$ FLAGNAOPASSA; / / descarta 1 bit do bloco

return 1;

\}

else \{

for $(i=0 ; i<t a m ; i++)\{/ /$ faz uma alteracao na string anterior $1=$ string $[i]$;

if(string $[i]==0) \quad / /$ inverte $\circ$ i-esimo bit string $[i]=1$;

else

string $[i]=0$;

if ( $h==h a s h(a, b, c$, tam, string $))\{/ /$ testa alteracao de 1 bit string $[0]=$ FLAGNAOPASSA; / / descarta 1 bit do bloco return 2;

\}

for $(j=i+1 ; j<$ tam $; j++)\{$

anterior $2=\operatorname{string}[j]$;

if (string $[j]==0) \quad / /$ inverte $\circ$ j-esimo bit, alem do i-esimo string $[j]=1$;

else

string $[j]=0$;

if ( $h==h a s h(a, b, c$, tam, string $))\{$

string [0] = FLAGNAOPASSA; // descarta 1 bit do bloco

return 3 ;

\}

string $[j]=$ =anterior 2 ; // volta o bit anterior para seu valor normal \}

string[i]=anterior1; // volta o bit anterior para seu valor normal \}

\}

string[0] = FLAGNAOPASSA; $\quad / /$ descarta 1 bit do bloco

return 0 ; 


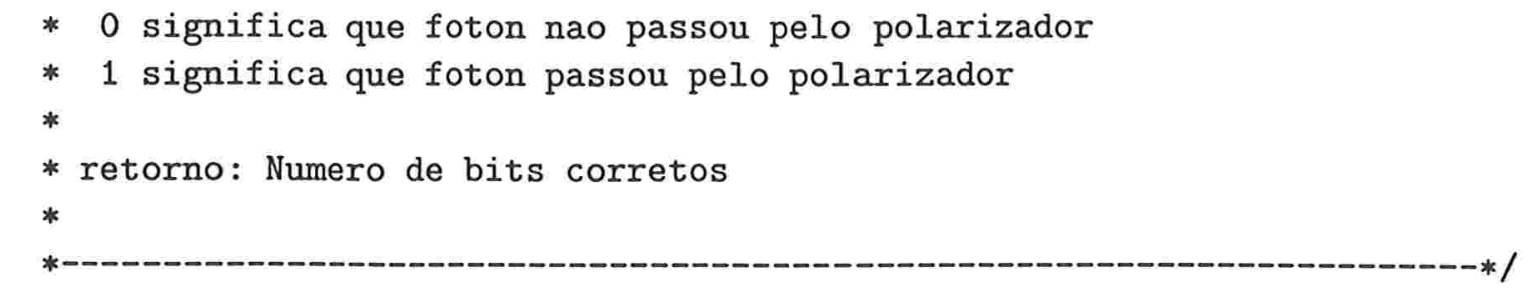

unsigned EstadosNaoOrtogonais: :RecepcaoB92 (unsigned tam, char *Pipe) \{

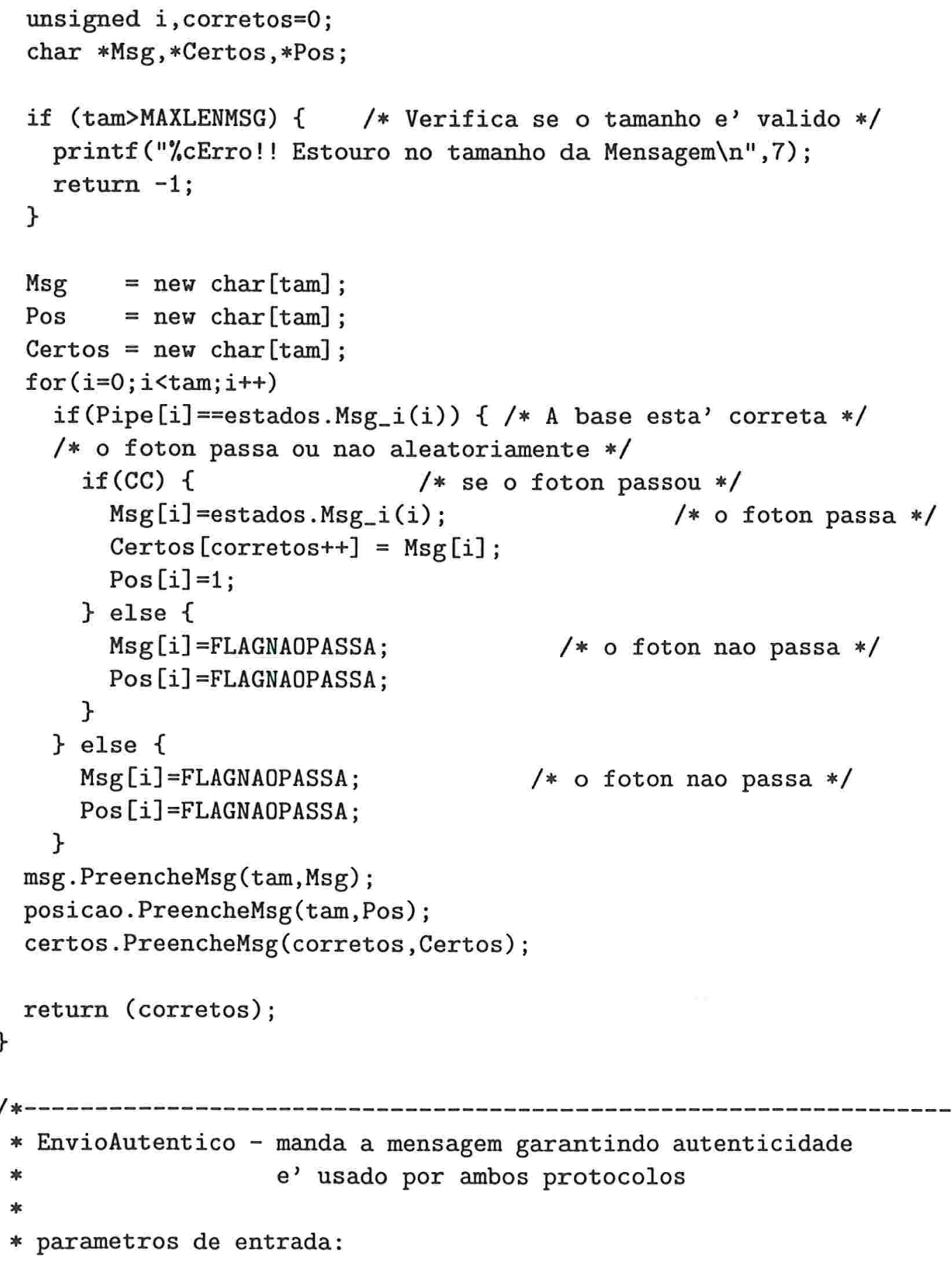




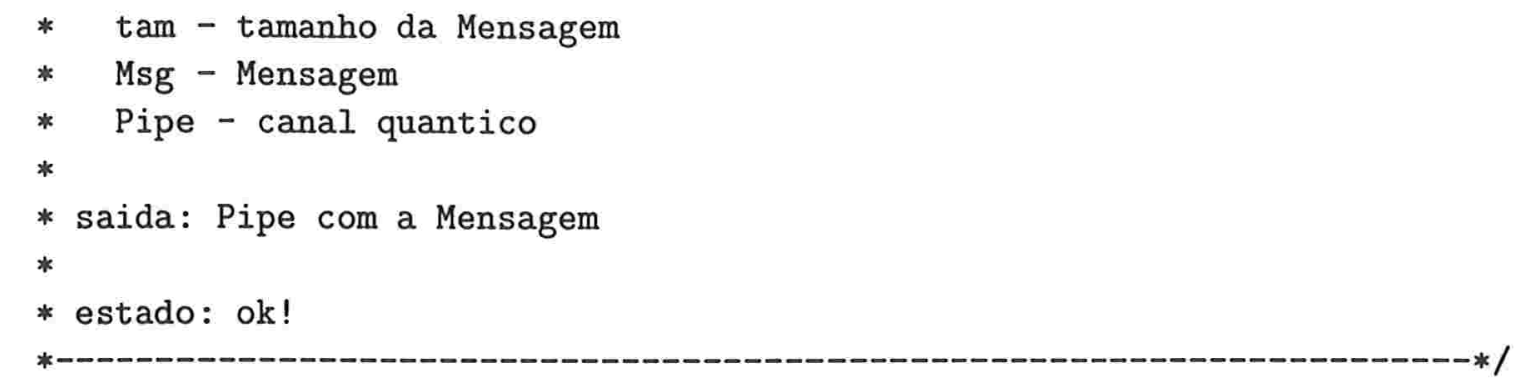

void EstadosNaoOrtogonais: :EnvioAutentic (sequencia m, unsigned tam, char *Pipe) \{

unsigned $i$;

if (tam>MAXLENMSG) $\{\quad / *$ Verifica se o tamanho e' valido $* /$ printf ("\%cErro!! Estoro no tamanho da Mensagem \n",7); return;

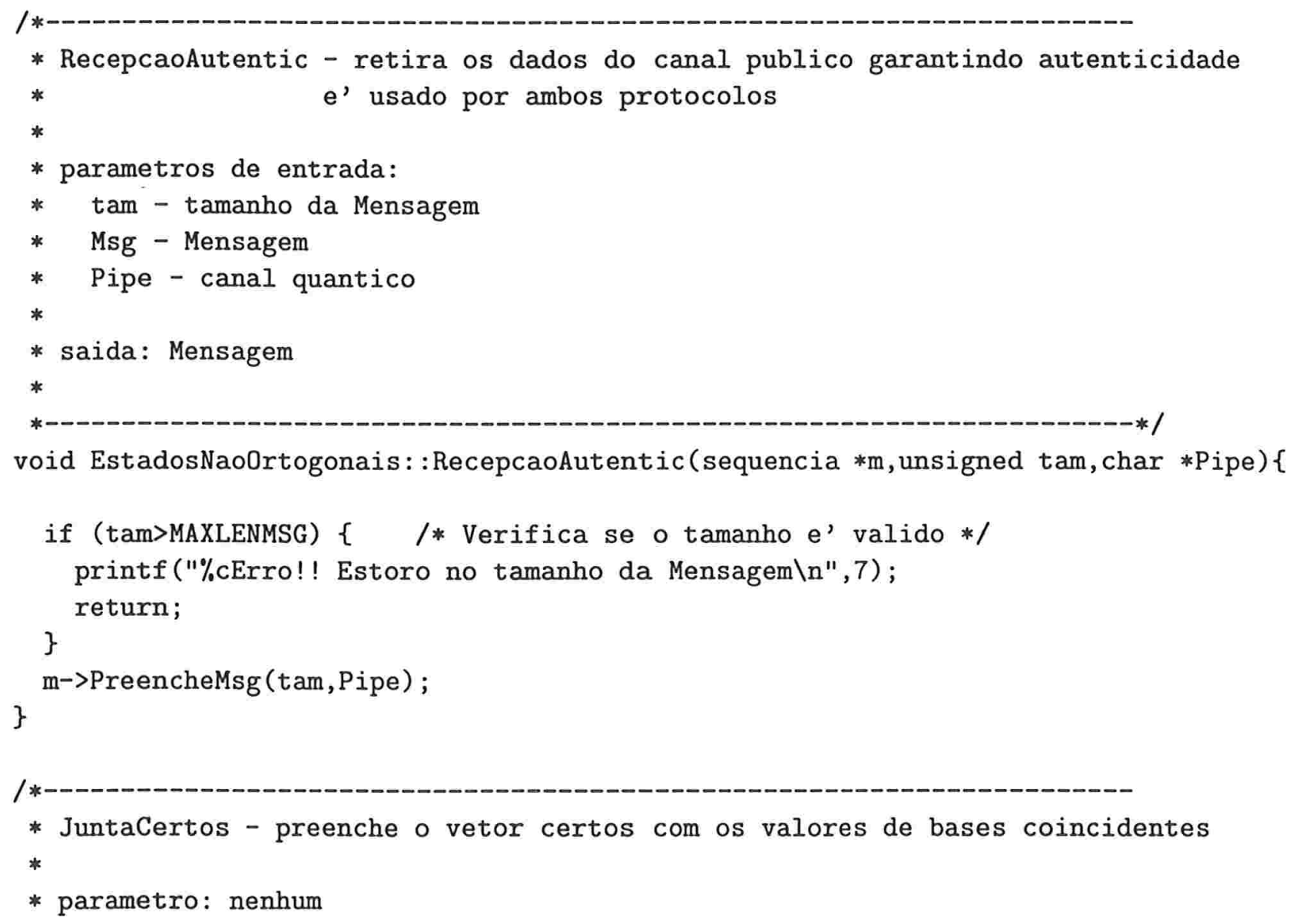




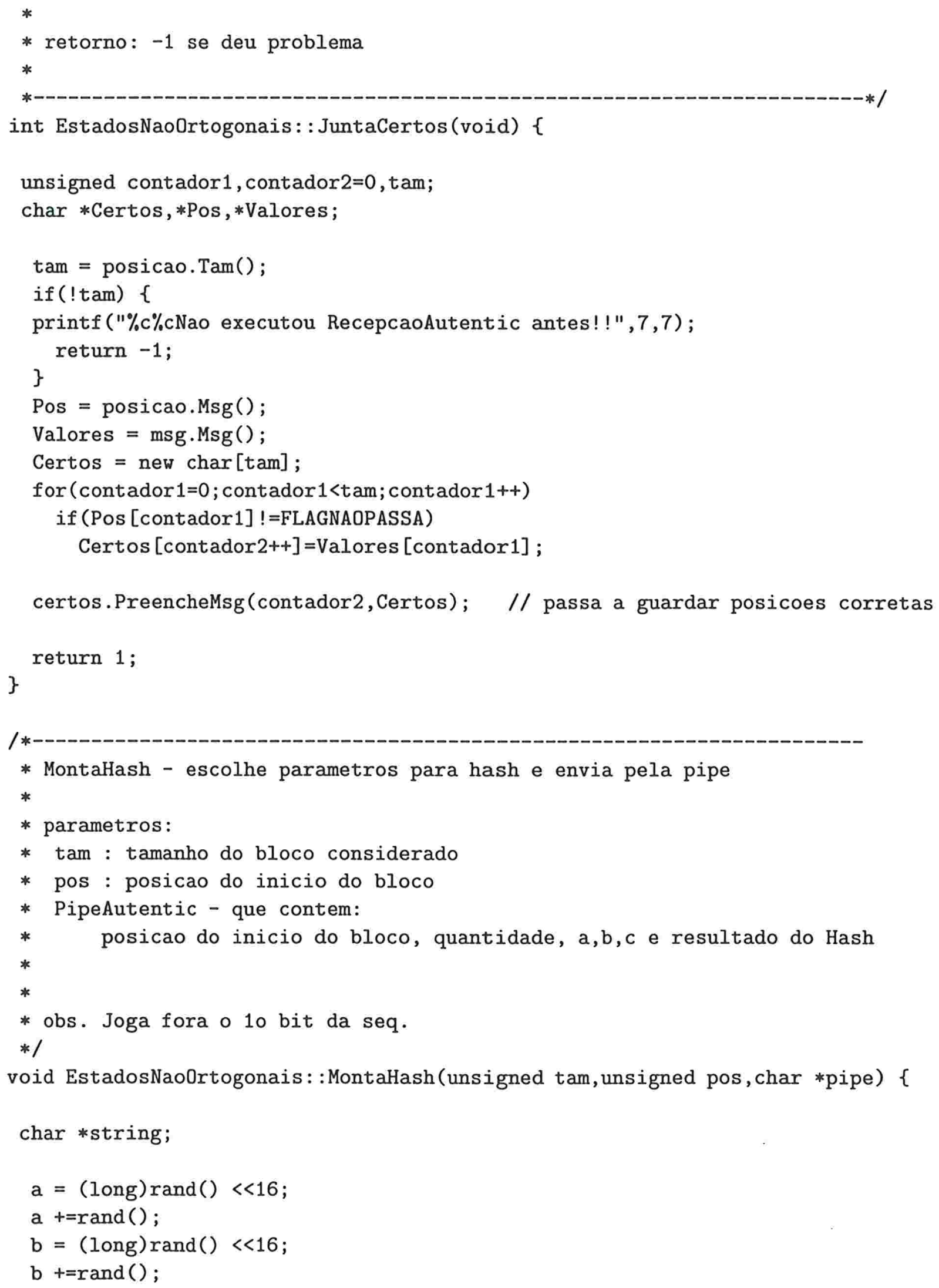




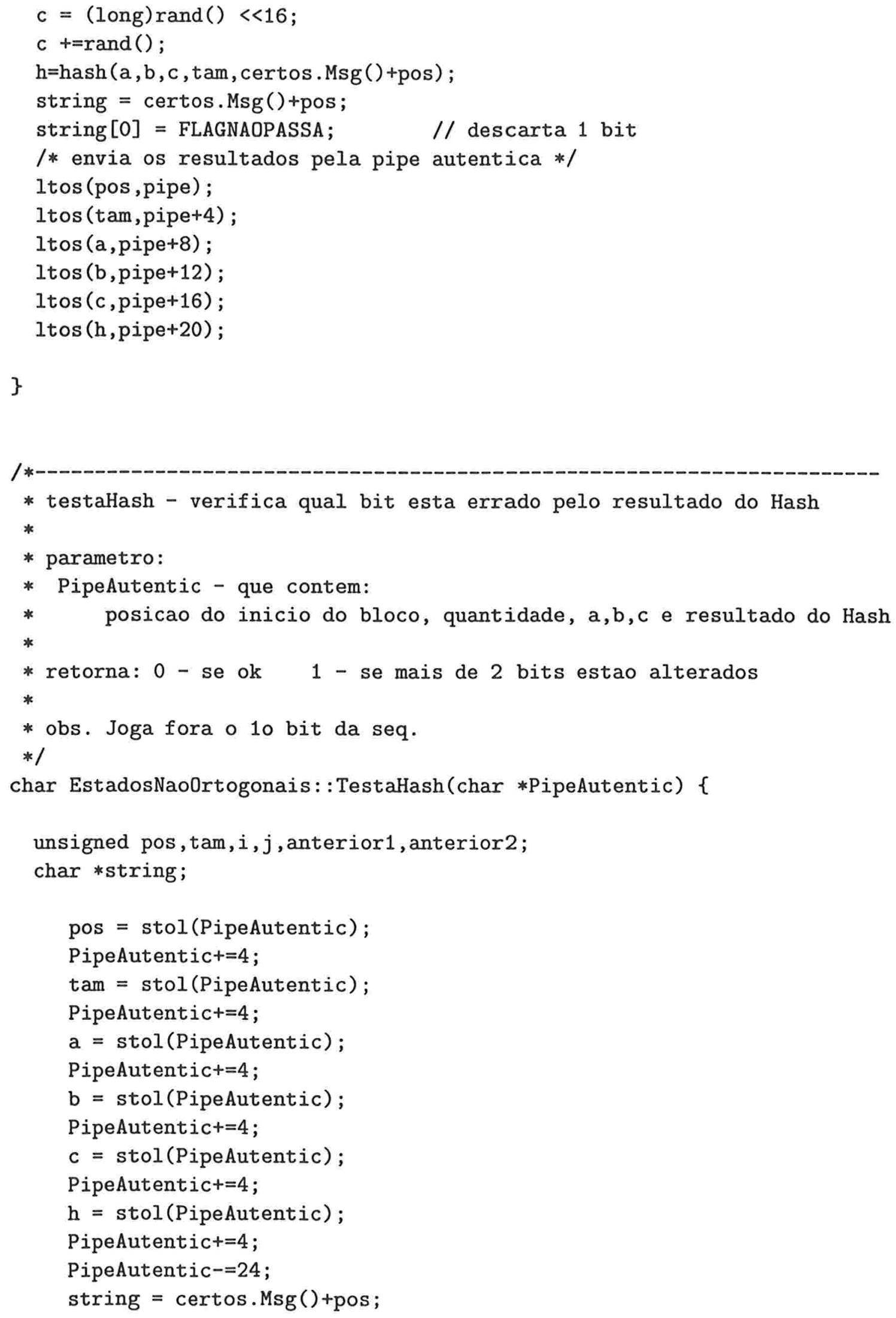


void execBB84(char intruso, float ruido, unsigned tam) \{

unsigned bitsCorretos, // Numero de bases em comum ( $\mathrm{p} /$ mesmas posicoes)

tamBloco, // Tamanho do bloco para que contenha apenas 1 erro aprox.

numBlocos, // Numero de blocos para verificacao de erros

tamChave, // tamanho da sequencia final em comum

pos, // para Amplificacao da Privacidade

totalDif=0, // numero total de erros encontrados na Amplific Priv

dif=0; // indica a diferenca de bits num bloco no teste do hashing

float taxaCoincid; // Porcentagem de acerto

usuario Alice, Bob;

usuario Eva(intruso);

char pipe [MAXLENMSG], // Canal quantico

pipeAutentic [MAXLENMSG]; // Canal publico com autenticacao

struct timeb ti,tf;

unsigned long tempo,tamIntruso;

ftime(\&ti);

/*-------- Primeira Fase - Envio e Recepcao da Mensagem ------------*/

Alice.BB84.msg .GeraMsg(tam); // Alice gera a Mensagem aleatoriamente

Alice.BB84.base.GeraMsg(tam); // Alice gera suas bases para mandar Msg pelo canal

Alice.BB84.EnvioBB84(tam,pipe,ruido); // Alice envia a mensagem pelo canal

if(intruso) \{ // Intercepcao de um intruso

Eva.BB84.base.GeraMsg(tam); // Eva tambem gera suas bases para ler a Msg do Pipe

Eva.BB84.RecepcaoBB84(tam,pipe); // Eva intercepta e retira a mensagem do canal \}

Eva.BB84.EnvioBB84(tam,pipe,ruido); // Eva reenvia a mensagem pelo canal

Bob. BB84.base.GeraMsg(tam); // Bob gera suas bases para ler a Msg do canal

/* Leitura por parte do usuario autorizado */

Bob.BB84.RecepcaoBB84(tam,pipe); // Bob retira a mensagem do canal

/*-------- Segunda Fase - Reconciliacao - -

Bob.BB84.escolhidos=Bob.BB84.base; // Bob indica quais sao suas bases

Bob.BB84.EnvioAutentic(Bob.BB84.escolhidos, tam, pipeAutentic);

/* Alice confere quais as bases coincidentes e diz para o Bob */

Alice.BB84. RecepcaoAutentic(\&Alice.BB84.escolhidos, tam,pipeAutentic);

Alice.BB84.ConfereBB84();

Alice.BB84.JuntaCertos();

if(intruso) // Eva tambem recebe as bases escolhidas por Bob

Eva.BB84.RecepcaoAutentic (\&Eva.BB84.escolhidos, tam, pipeAutentic);

// Alice diz quais as bases de Bob que estão corretas

Alice.BB84.EnvioAutentic (Alice.BB84.posicao, tam, pipeAutentic);

if(intruso) \{

// Eva fica sabendo quais bases corretas 


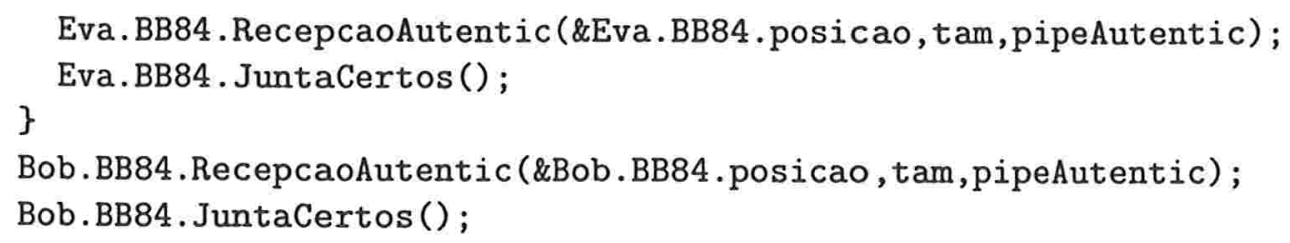




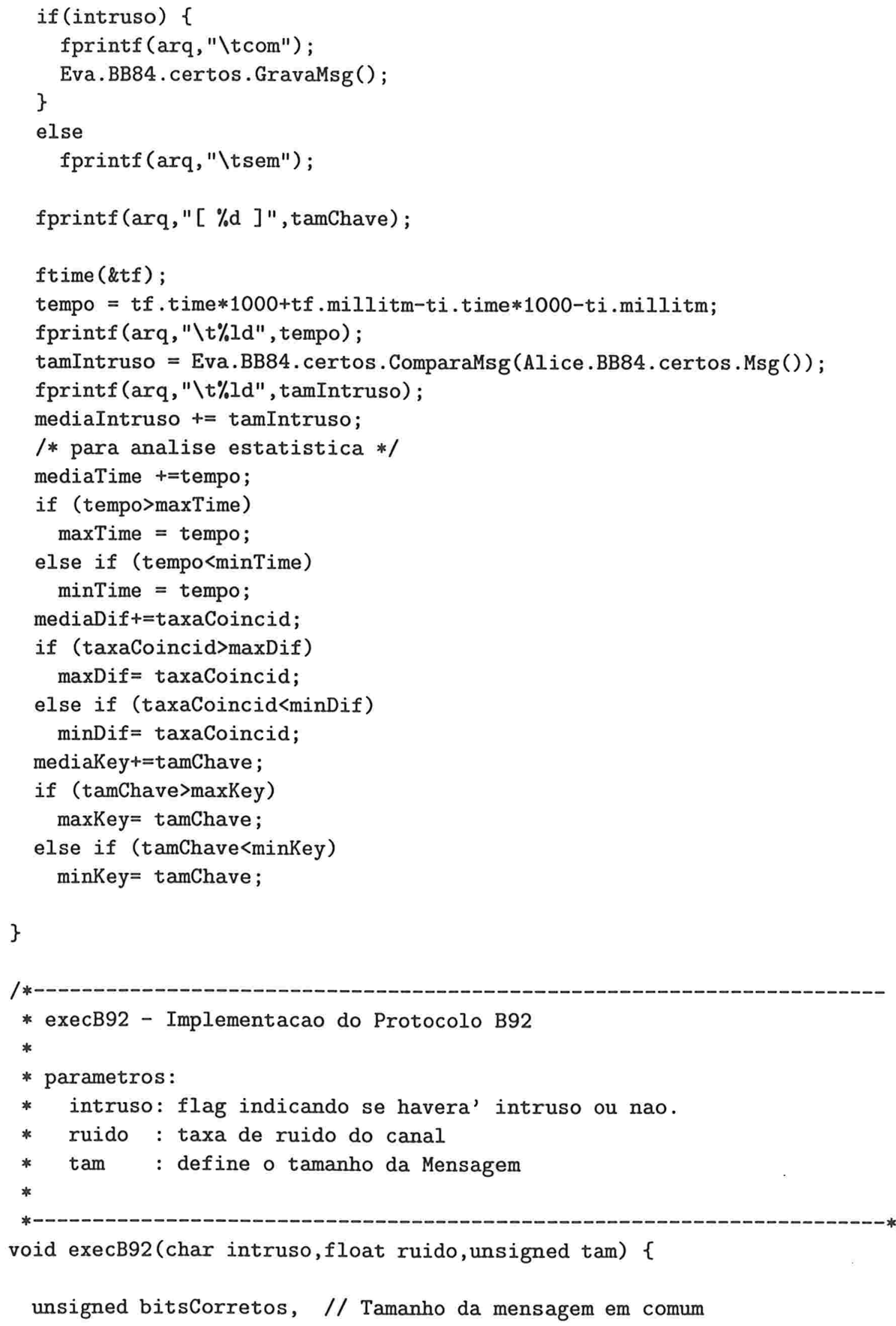


fotonsPassaram, // Numero de fotons que atravessaram o polarizador

tamChave, // tamanho da sequencia final em comum

tamBloco, // Tamanho do bloco para que contenha apenas 1 erro aprox.

numBlocos, // Numero de blocos para verificacao de erros

pos, // para Amplificacao da Privacidade

totalDif=0, // numero total de erros encontrados na Amplific Priv

dif=0; $\quad / /$ indica a diferenca de bits num bloco no teste do hashing

float taxaCoincid;

// Porcentagem de acerto

usuario Alice,Bob;

usuario Eva;

char pipe[MAXLENMSG], // Canal quantico

pipeAutentic[MAXLENMSG]; // Canal publico com autenticacao

struct timeb ti,tf;

unsigned long tempo,tamIntruso;

ftime(\&ti);

/* Primeira Fase - Envio e Recepcao da Mensagem */

Alice.B92.msg.GeraMsg (tam); /* Alice gera a Mensagem aleatoriamente */

if(intruso) \{ \}

Eva.B92.estados.GeraMsg(tam); // Eva gera seus eixos de polarizacao para ler a Msg

Bob.B92.estados.GeraMsg(tam); // Bob gera seus angulos de polarizacao para ler a Msg Alice.B92.EnvioB92(tam,pipe,ruido); // Alice envia a mensagem pelo canal

/* Intercepcao de um intruso */

if(intruso) \{

Eva.B92.RecepcaoB92(tam,pipe); // Eva intercepta e retira a mensagem do canal

Eva.AtaqueB92(INV); / * tipos:ALEAT, MANTEM, INV */ \}

Eva.B92.EnvioB92(tam,pipe,ruido); // Eva reenvia a mensagem pelo canal

/* Leitura por parte do usuario autorizado */

Bob.B92.RecepcaoB92(tam,pipe); // Bob retira a mensagem do canal

bitsCorretos $=$ Alice.B92.msg.ComparaMsg(Bob.B92.estados.Msg( ));

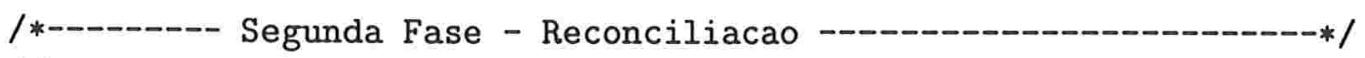

// Bob indica quais as posições dos fotons passaram pelo seu polarizador

Bob.B92.EnvioAutentic (Bob.B92.posicao, tam, pipeAutentic);

/* Alice recebe as posicoes que passaram */

Alice.B92.RecepcaoAutentic(\&Alice.B92.posicao, tam, pipeAutentic);

Alice.B92. JuntaCertos();

if(intruso) \{ 


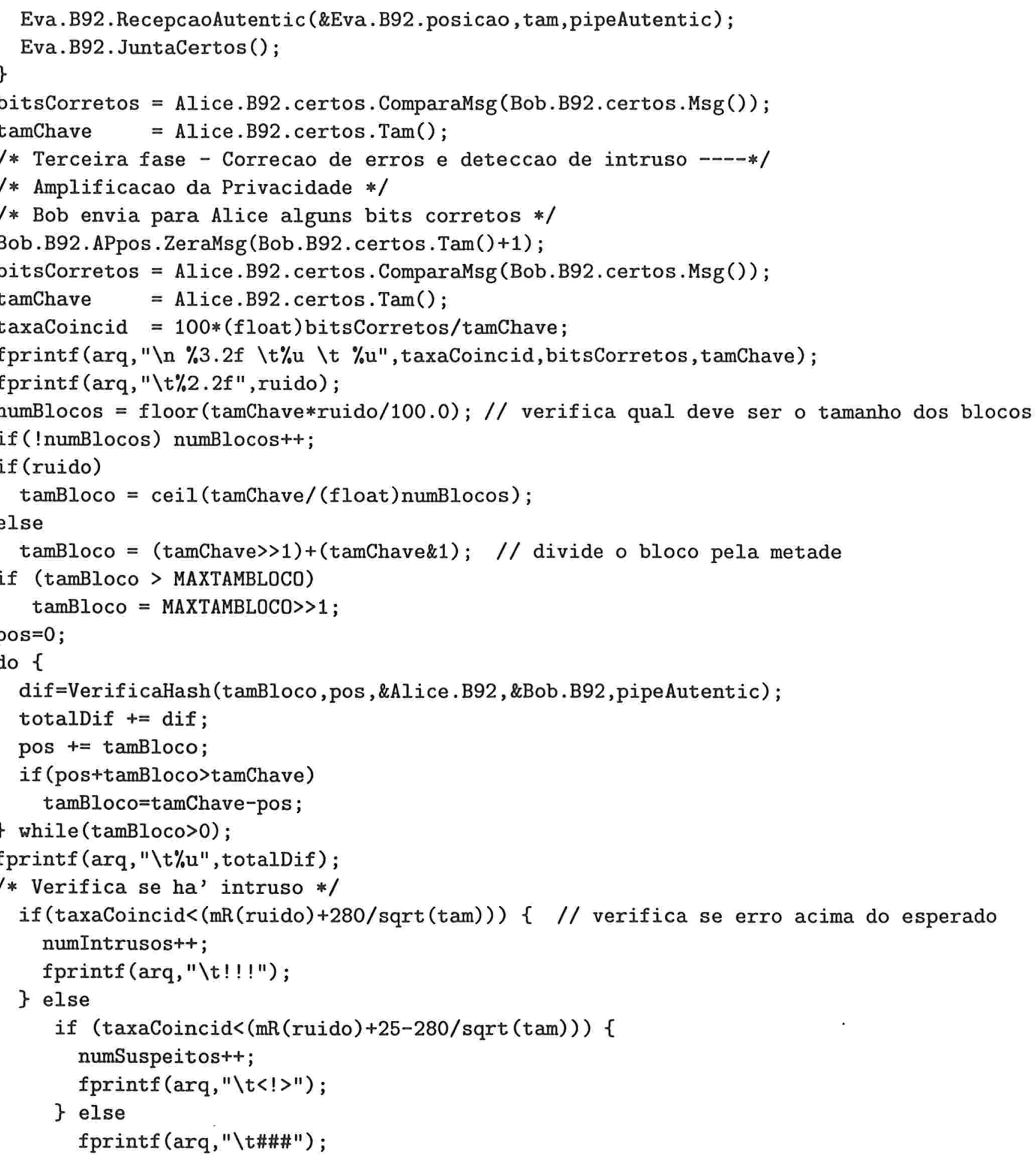

Alice.B92.certos.GravaMsg();

tamChave=Bob. B92 . certos. GravaMsg();

if (intruso) \{ 


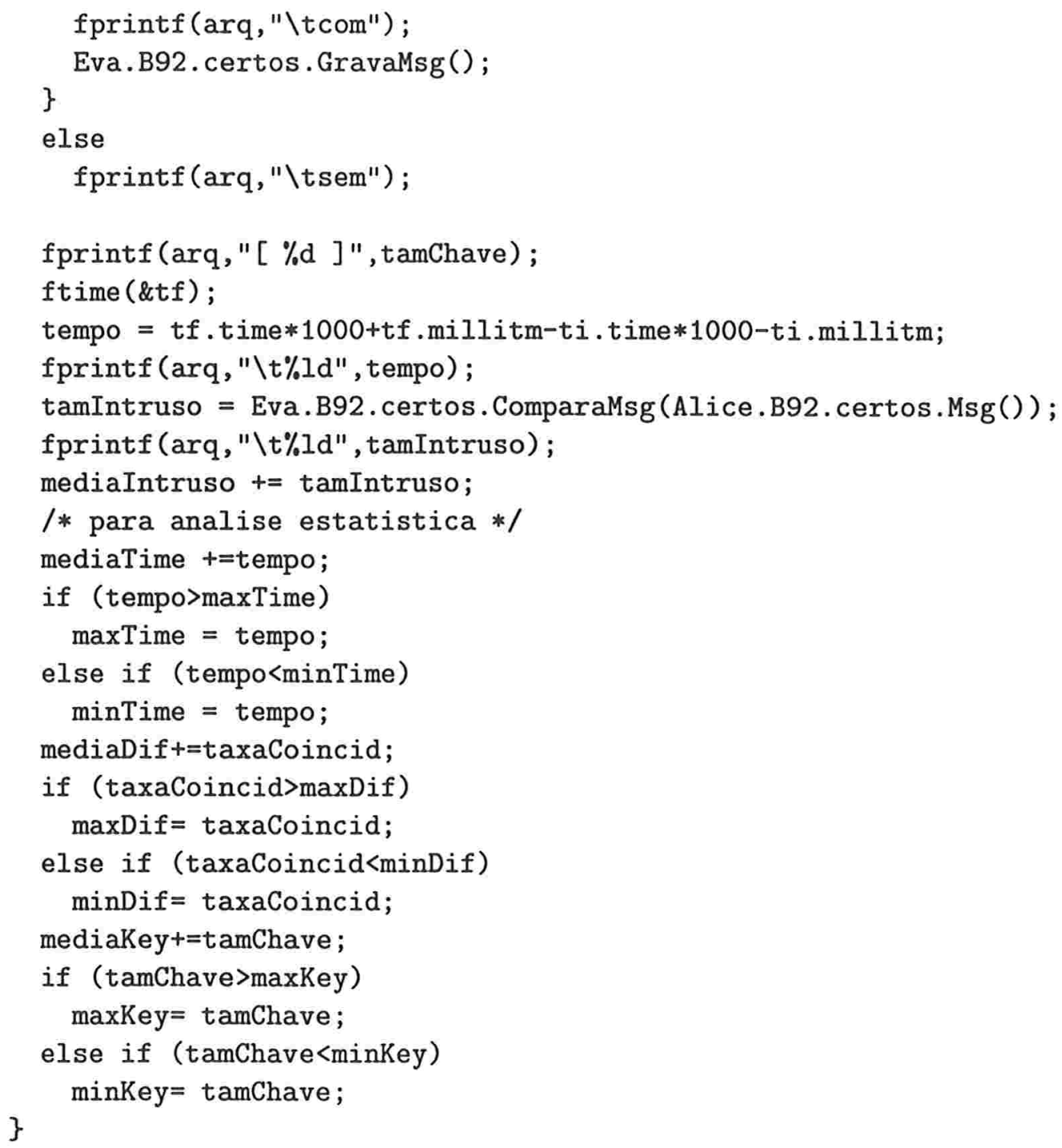




\section{Índice Remissívo}

amplificação da privacidade, 27

ataque

ataque de Breidbart, 29

divisão de feixe, 29

interceptação e reenvio, 28

man-in-the-middle, 28

resultados, 54

base, 13

bit commitment veja bit comprometido 45

bit comprometido, 45

bit twiddling, 27, 50

canal quântico, 13

chave criptográfica, 7

chave criptográfica, 18

ciframento, 7

coin-tossing protocol, 45

cripto-sistema, veja sistema criptográfico

deciframento, 7

desigualdade de Bell, 15

efeito EPR, 14

fóton, 11

função criptográfica, veja sistema criptográfico função de espalhamento, 25, 50

função hash veja função de espalhamento 25

intruso, 7

One Time Pad, 9

polarização, 12

direção de polarização, 12

plano de polarização, 12

princípio da Incerteza de Heisenberg, 14

sistema criptográfico, 7

texto cifrado, 7

texto legível, veja texto claro

texto claro, 7

texto ilegível, veja texto cifrado

zero-knowledge, 45 